\author{
UNIVERSIDADE DE SÃO PAULO \\ ESCOLA DE ENGENHARIA DE SÃO CARLOS \\ DEPARTAMENTO DE HIDRÁULICA E SANEAMENTO \\ CENTRO DE RECURSOS HÍDRICOS E ECOLOGIA APLICADA
}

JULIO ISSAO KUWAJIMA

ANÁliSE DO MODELO SWAT COMO FERRAMENTA DE PREVENÇÃO E DE ESTIMATIVA DE ASSOREAMENTO NO RESERVATÓRIO DO LOBO

(ITIRAPINA/BROTAS/SP)

São Carlos 



\title{
ANÁLISE DO MODELO SWAT COMO FERRAMENTA DE PREVENÇÃO E DE ESTIMATIVA DE ASSOREAMENTO NO RESERVATÓRIO DO LOBO \\ (ITIRAPINA/BROTAS/SP)
}

\begin{abstract}
Dissertação apresentada à Escola de Engenharia de São Carlos, da Universidade de São Paulo, como parte dos requisitos para obtenção do título de mestre em Ciências da Engenharia Ambiental.
\end{abstract}

Área de Concentração: Engenharias I

Orientador: Prof. Dr. Frederico Fábio Mauad

São Carlos 

AUTORIZO A REPRODUÇÃO E DIVULGAÇÃO TOTAL OU PARCIAL DESTE TRABALHO, POR QUALQUER MEIO CONVENCIONAL OU ELETRÔNICO, PARA FINS DE ESTUDO E PESQUISA, DESDE QUE CITADA A FONTE.

Ficha catalográfica preparada pela Seção de Tratamento da Informação do Serviço de Biblioteca - EESC/USP

Kuwajima, Julio Issao
K98a Análise do modelo de estimativa de assoreamento no Reservatório do Lobo (Itiripa/Brotas-SP / Julio Issao Kuwajima ; orientador Frederico Fábio Mauad. -- São Carlos, 2012.

Dissertação (Mestrado-Programa de Pós-Graduação em Ciências da Engenharia Ambiental) -- Escola de Engenharia de São Carlos da Universidade de São Paulo, 2012.

1. Gerenciamento de recursos hídricos. 2. SWAT. 3. Assoreamento. 4. SIG. 5. Reservatórios. 6. Calibração. I. Título. 



\section{FOLHA DE JULGAMENTO}

Candidato: Engenheiro JULIO ISSAO KUWAJIMA

Título da dissertação: "Análise do modelo SWAT como ferramentas de prevenção e de estimativa de assoreamento no reservatório do Lobo (Itirapina/Brotas/SP)".

Data da defesa: $24 / 01 / 2012$

\section{Comissão Julgadora:}

Prof. Dr. Frederico Fábio Mauad (Orientador)

(Escola de Engenharia de São Carlos/EESC)

Prof. Dr. João Luiz Boccia Brandão

(Escola de Engenharia de São Carlos/EESC)

Prof. Dr. Fernando das Graças Braga da Silva

(Universidade Federal de Itajubá)

\section{Resultado:}
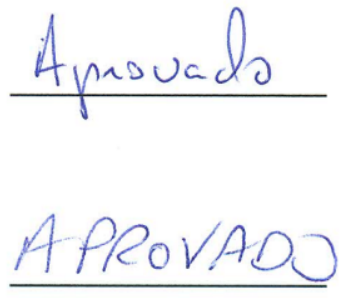

A provado

Coordenador do Programa de Pós-Graduação em Ciências da Engenharia

Ambiental:

Prof. Dr. Frederico Fabio Mauad

Presidente da Comissão de Pós-Graduação:

Prof. Associado Paulo Cesar Lima Segantine 



\section{DEDICATÓRIA}

À minha família, amigos e a todos que se interessam no meu trabalho. 



\section{AGRADECIMENTOS}

Aos companheiros do Núcleo de Hidrometria, Gustavo, Renato, Diego, André, Juliana, Roberta, Paulo e ao Miro pela convivência e pela amizade destes últimos anos.

A todos os funcionários do CRHEA que garantem condições para nossas pesquisas.

Ao Eng, José Dimas, ao Eng. Marcus Vinícius e Eng. Gustavo Bernardes pelos anos de convivência e amizade, ao time de polo aquático e aos moradores e amigos da República FuraZoio.

Ao Prof. Dr. Frederico Fábio Mauad, pela orientação, pela oportunidade e confiança em minha pesquisa.

Aos Professores. Sílvio Crestana e Lázaro Valentin Zuquette pelos conselhos e ajuda nos estágios iniciais da pesquisa.

À Escola de Engenharia de São Carlos, pela formação recebida e pela oportunidade de realizar minha pesquisa.

Ao $\mathrm{CNPq}$ pela bolsa para viabilização desta pesquisa, através do Edital MCT/CNPq/CTHidro na22/2009. 



\section{EPÍGRAFE}

"Ab esse ad posse

Ab esse ad posse valet consequentia

Ab oportere ad esse valet consequentia

Ab oportere ad posse valet consequentia

A non posse ad non esse valet consequentia

Ab esse ad posse valet, a posse ad esse non valet consequentia."

"Da possibilidade para a realidade;

A partir do fato que algo ser real, então se pode inferir que é possível;

A partir do fato de que algo deve ser, então se pode inferir que é real;

A partir do fato de que algo deve ser, então se pode inferir que é possível;

A partir do fato de algo não ser real, então se pode inferir que é impossível;

A partir da realidade de algo se pode deduzir sua possibilidade, mas a partir da possibilidade de algo não é possível deduzir sua realidade"

Na teoria das consequências (v. modais) utilizam-se uma série de locuções para provar e indicar se uma consequência é ou não válida. As expressões mencionadas são as consequências modais cuja suas locuções se usam mais frequentemente. 



\section{RESUMO}

KUWAJIMA, J.I. Análise do modelo SWAT como ferramentas de prevenção e de estimativa de assoreamento no reservatório do Lobo (Itirapina/Brotas/SP). 2012. Dissertação (Mestrado) - Escola de Engenharia de São Carlos, Universidade de São Paulo, São Carlos, 2012.

Condições pedológicas, pluviosidade, alterações no uso e ocupação do solo, práticas de manejo de culturas e de preservação interferem diretamente na geração de sedimentos e na taxa de erosão. Em uma bacia hidrográfica esta geração de sedimentos excessiva pode resultar em problemas como o assoreamento dos corpos de água e de reservatórios. Nos reservatórios esta deposição de sedimentos pode representar perda de volume de reservação, promovida pelos sedimentos depositados no fundo da barragem. Com o tempo esta perda poderá vir a representar comprometimento da disponibilidade hídrica para irrigação, para o consumo humano, e para geração de energia. As obras de dragagem destes sedimentos são muito caras e resolvem somente os sintomas do problema e não suas causas. Desta forma as quantificações desse assoreamento e de seus deflagradores se mostram necessárias para o planejamento e gestão de recursos hídricos. A presente pesquisa se propõe a avaliar a aplicabilidade do modelo SWAT (Soil Water Assessment Tool) como ferramenta de estimativa de geração de sedimentos para reservatórios avaliando seus resultados, suas potencialidades e fragilidades para as condições locais e sugerir futuras pesquisas e/ou modificações no modelo. O modelo que foi desenvolvido originalmente pelo USDA (United States Departmente of Agriculture) para avaliar erosão e balanço hídrico de bacias hidrográficas, conta com um vasto número de aplicações no mundo, documentação e usuários. A área a ser estuda é bacia do reservatório do Lobo, que possuí uma área aproximada de 227 $\mathrm{km}^{2}$ e localizado no município de Itirapina e de Brotas. Atualmente o reservatório é utilizado tanto para geração energética e como atração turística local. Dois cenários de simulação foram selecionados: Cenário 1 de 1977 até 1985 e Cenário 2 de 1996 até 2006. Para realizar as simulações foram utilizados a versão ArcSWAT 2005 version2.34 para realizar as simulações e o SWAT-CUP 4.3.1 para calibração.Os dados de entrada do modelo são: dados de chuvas e vazão diários obtidos da ANA (Agência Nacional das Águas), cartas de levantametno pedológico e cartas de uso e ocupação obtidas a partir de imagens CBERS e LANDSAT. Após calibração utilizando SUFI2 obteve-se o aporte de sedimentos na barragem para os dois cenários. Os resultados do primeiro cenário apresentaram influência negativa de dados inconsistentes de dados de vazão utilizados e limitações observadas na discretização do modelo nas representações do mosaico de uso e ocupação muito fragmentado para este cenário. O segundo cenário, no entanto obteve resultados satisfatórios comprovando a capacidade do modelo como ferramenta de avaliação de geração e aporte de sedimento em reservatórios.

Palavras-chave: Gerenciamento de Recursos Hídricos, SWAT, Assoreamento, SIG, Reservatórios, Calibração. 



\begin{abstract}
KUWAJIMA, J.I. Análise do modelo SWAT como ferramentas de prevenção e de estimativa de assoreamento no reservatório do Lobo (Itirapina/Brotas/SP). 2012. Dissertação (Mestrado) - Escola de Engenharia de São Carlos, Universidade de São Paulo, São Carlos, 2012.
\end{abstract}

The sediment yield and erosion rates are directly affected by pedologic conditions, precipitation, land and use changes, management and soil preservation practices. Excessive sediment yield in a watershed could result in difficulties caused by siltation processes in rivers and reservoirs. Sediment deposition at the bottom of reservoirs and dams may result in volume loss. In time such loss could become impairment of water availability for irrigation, human consumption and power generation. Sediment dredging is an expensive solution that will address only the symptoms and not the causes of the issue. Therefore assessing the amount of sediment and their causes is required for Water Resources Management and Planning. The present research aims to evaluate the applicability of the SWAT (Soil and Water Assessment Tool) as sediment generation and contribution estimation tool for reservoirs evaluating the results, assessing the model strengths and weakness for the local contitions and make sugestions for future research and/or model modifications.. Originally developed by the USDA (United States Department of agriculture) to assess erosion and water balance of watersheds, this model has a large number of users, available documentation and registered applications across the world. The study area, with an approximate area of $227 \mathrm{~km}^{2}$ is the Lobo reservoir watershed, located at the municipalities of Itirapina and Brotas. The reservoir is currently used for hydropower generation and as a tourist attraction. Two simulation scenarios were chosen: Scenario 1from 1977 to 1985 and Scenario 2 from 1996 until 2006. To perform the simulations the ArcSWAT 2005 version 2.34 was selected and the SWAT-CUP 4.3.1 for the calibration. The data input was: daily precipitation and discharge flow datasets from ANA (Agência Nacional das Águas), pedological survey chats and land use charts obtained from CBERS and LANDSAT imagery. After calibration using SUFI2, sediment yield and contribution at the dam was obtained for both scenarios. The first scenario results showed negative effects caused by inconsistent input data flow and limitations regarding model discretization on the model representation of highly fragmented land use. The second scenario, however achieved satisfactory results demonstrating the model ability as sediment yield and contribution in reservoir evaluation tool.

Keywords: Water Resources Management, SWAT, Siltation, GIS, Reservoir, Model Calibration 



\section{ÍNDICE DE FIGURAS}

Figura 1 - Esquema de formação de depósitos de sedimentos nos reservatórios com indicação dos principais problemas decorrentes (Carvalho, 1994).

Figura 2 - Seções tranversais comparativas de levantamentos de reservatório (Carvalho, 1994). 45

Figura 3 - Esquema do desenvolvimento histórico do SWAT ( GASSMAN et al.2007).......52

Figura 4 - O reservatório do Lobo (International Lake Environment Committee, 2010)........58

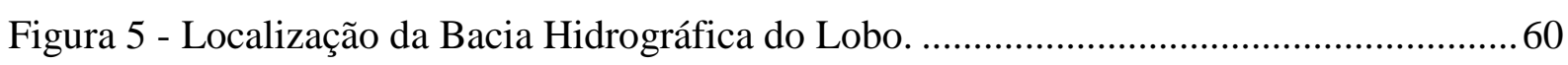

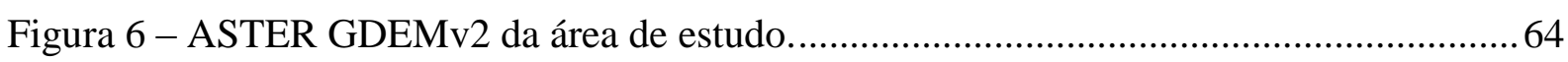

Figura 7 - Resultado da classificação de uso e ocupação para a região.................................. 66

Figura 8 - Levantamento Pedológico Semi-Detalhado para região de estudo........................ 67

Figura 9 - Estações Climatológicas e Pontos de Monitoramento (cenário de 1977 - 1984).... 74

Figura 10 - Estações de Monitoramento e Pontos de Monitoramento (Cenário 1996-2006). 75

Figura 11 - Carta de Uso e Ocupação (1984). .................................................................. 92

Figura 12 - Carta de Uso e Ocupação (2010). .................................................................... 94

Figura 13 - Digitalização de Classes de Solo para a Bacia de Estudo...................................97

Figura 14 - Ciclo Hidrológico considerado pelo modelo SWAT (NEITSCH et al., 2001)...107

Figura 15 - Processos ecológico considerado pelo modelo SWAT (NEITSCH et al., 2001).

Figura 16 - Etapas do algoritmo SUFI-2 (Abbaspour, 2008).......................................... 119

Figura 17 - Classes de Declividade da Região de Estudo................................................. 122

Figura 18 - Classificação Pedológica da Região de Estudo.................................................. 124

Figura 19 - Classes de Uso e Ocupação de Solo utilizadas pelo SWAT (1984). .................. 126 


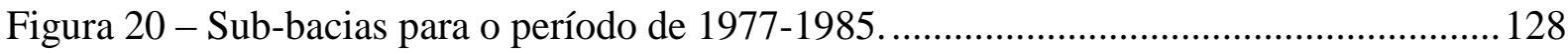

Figura 21 - Unidades de Resposta Hidrológica (1984)...................................................... 129

Figura 22 - Classes de Uso e Ocupação de Solo utilizada pelo SWAT (2010)...................... 139

Figura 23 - Sub-bacias para o período de 1996-2006......................................................... 141

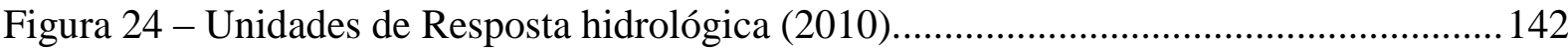




\section{ÍNDICE DE GRÁFICOS}

Gráfico 1 - Curva bruta cota x vazão para o Córrego do Geraldo. ------------------------------- 78

Gráfico 2 - Curva consistida CotaX Vazão para o Córrego Geraldo. ---------------------------- 78

Gráfico 3 - Curva cota x vazão para o Córrego das Perdizes. ------------------------------------ 80

Gráfico 4 - Curva cota x vazão para a estação de monitoramento Jacaré-Açú 1 no Ribeirão do

Lobo.

Gráfico 5- Curva bruta Cota x Vazão para a estação de monitoramento Jacaré-Açú 2 no Ribeirão do Lobo. 82

Gráfico 6 - Curva consistida Cota xVazão para a estação de monitoramento Jacaré-Açú 2, localizada no Ribeirão d Lobo. 83

Gráfico 7 - Curva cota x vazão para a estação de monitoramento Siriema no Ribeirão do Lobo. 84

Gráfico 8 - Curva cota x vazão para o Rio Itaqueri. 85

Gráfico 9 - Médias de Temperatura mínima, máxima e radiação solar mensal média para o período de 1977 até 2011.

Gráfico 10 - Precipiração mensal média para o período de 1977 até 2011. 91

Gráfico 11 - Calibração da vazão para Jacaré-Açú 2(1977-1985). 132

Gráfico 12 - Calibração da vazão para Jacaré-Açú 1(1977-1985). 133

Gráfico 13 - Calibração da vazão para Córrego das Perdizes(1977-1985). 134

Gráfico 14 - Calibração da vazão para Córrego do Geraldo (1977-1985). 135

Gráfico 15 - Calibração da vazão para Siriema (1977-1985). 136

Gráfico 16 - Calibração da vazão para Rio Itaqueri (1977-1985).

Gráfico 17 - Calibração da vazão para Jacaré-Açú 2(1996-2006). 145 
Gráfico 18 - Calibração da vazão para Jacaré-Açú 1(1996-2006). 


\section{ÍNDICE DE TABELAS}

Tabela 1 - Padronização para determinação da quantidade de estações de monitoramento a serem instaladas nos empreendimentos (ANEEL/ANA, 2010).

Tabela 2 - Frequiência desejável para levantamentos topo-batimétricos de reservatórios (adaptado de CARVALHO et al, 2000). 46

Tabela 3 - Comparação da pluviosidade entre um local de clima temperado (1) e outro subtropical (2) - Médias entre 1917 e 1985. (Paterinani , 1990). 57

Tabela 4 - Comparação entre clima temperado e tropical para a cultura do milho. (Modificado de Pateriani, 1990). 57

Tabela 5 - Características do reservatório do Lobo (TUNDISI, 1986). 60

Tabela 6 - Características da Barragem. 60

Tabela 7 - Características do ASTER GDEM.

Tabela 8 - Especificação das imagens de satélite LANDSAT 5 e 7 e CBERS. 65

Tabela 9 - Listagem da quantidade de estações de monitoramento para o estado de São Paulo e para a bacia do rio Tietê.

Tabela 10 - Estações com dados de chuva. 70

Tabela 11 - Estações com dados de cotas e vazão 71

Tabela 12 - Estações de Monitoramento Elegidas por Cenário. 73

Tabela 13 - Parâmetros estatísticos climáticos da estação climatológica do CRHEA para o perído de 1977 até 2011. .89

Tabela 14 - Distribuição das classes de Uso e Ocupação do Solo para 1984. 93

Tabela 15 - Distribuição das classes de Uso e Ocupação do Solo para 2010. 95

Tabela 16 - Conversão aproximada de classificações pedológicas. 96 
Tabela 17 - Classes identificadas da digitalização do Levantamento Pedodológico SemiDetalhado do Estado de São Paulo de 1984 para a bacia. 98

Tabela 18 - Grupamento de Solos segundo sua qualidades, características e resistência à erosão (Lombardi Neto et al. 1989 apud Sartori, 2005a ).

Tabela 19 - Sumário de estatísticas comparando diferenetes procedimentos de calibração de incertezas (Abbaspour, 2008 - modificado). 114

Tabela 20 - Classes de Declividade da Bacia. 123

Tabela 21 - Classes de Solo para o modelo SWAT. 125

Tabela 22 - Classes de Uso e Ocupação do Solo (1984). 127

Tabela 23 - Valores dos parâmetros finais da calibração (1977-1985). 130

Tabela 24 - Análise de Sensibilidade para os parâmetros (1977-1985) 131

Tabela 25 - Sumário da performance da calibração (1977-1985). 131

Tabela 26 - Classes de Uso e Ocupação do Solo (1984).... 140

Tabela 27 - Valores dos parâmetros finais da calibração (1996-2006). 143

Tabela 28 - Análise de Sensibilidade para os parâmetros (1996-2006). 144

Tabela 29 - Sumário da performance da calibração (1996-2006). 145 


\section{SUMÁRIO}

RESUMO XV

ABSTRACT XVII

ÍNDICE DE FIGURAS ............................................................................................................................XIX

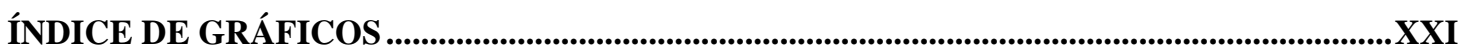

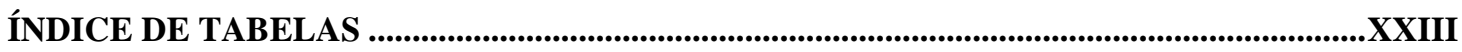

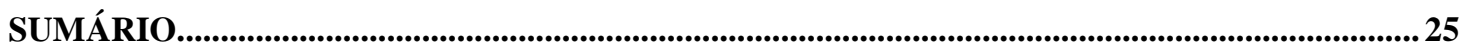

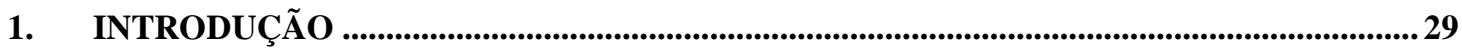

2. OBJETIVOS

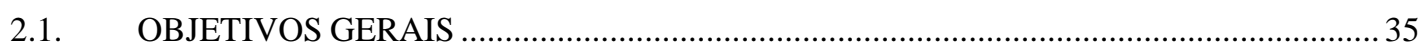

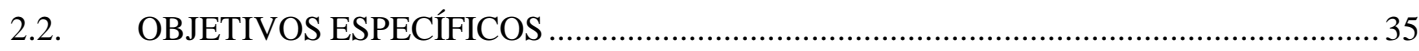

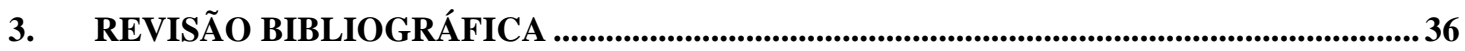

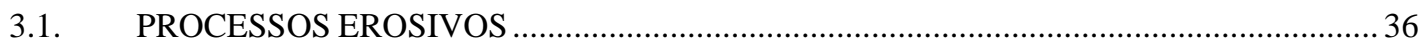

3.2. EFEITOS DO USO E OCUPAÇÃO DO SOLO NA GERAÇÃO DE SEDIMENTOS .......... 37

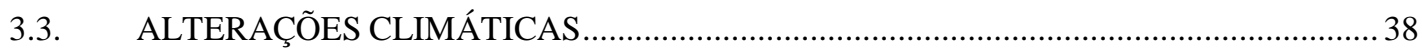

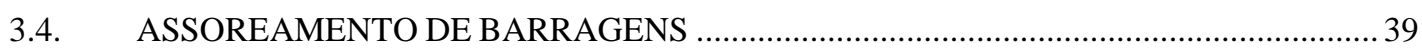

3.5. RESOLUÇÃO CONJUNTA ANEEL/ANA No 3 DE 10 DE AGOSTO DE 2010 ….............. 42

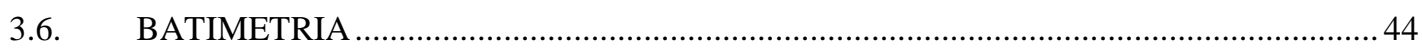

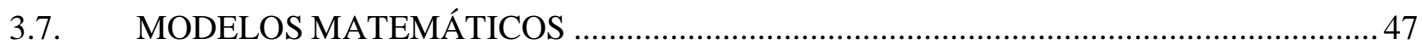

3.8. MODELOS MATEMÁTICOS DE ESTIMATIVA DE SEDIMENTAÇÃO ……………...... 48

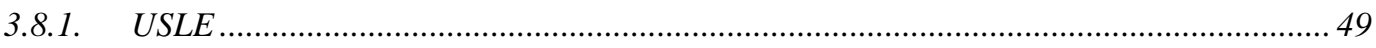

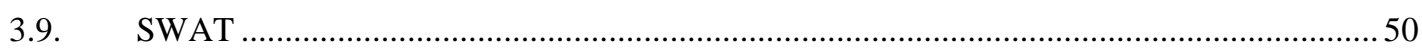

3.9.1. DESENVOLVIMENTO HISTÓRICO DO SWAT ……………….............................. 50

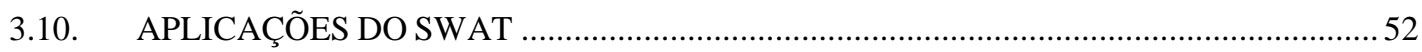

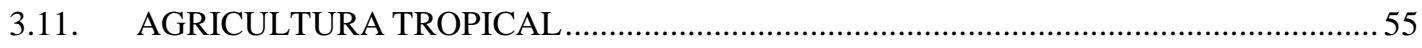




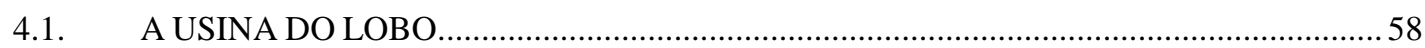

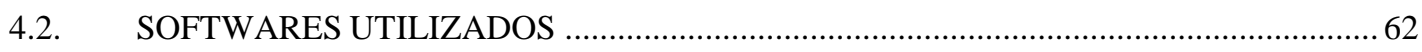

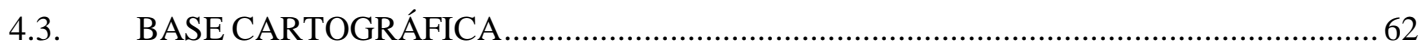

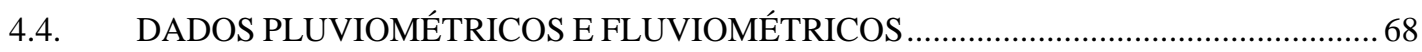

4.5. CENÁRIOS DE SIMULAÇÃO .................................................................................... 72

4.6. ELABORAÇÃO DE DADOS DE ENTRADA DO MODELO...........................................76

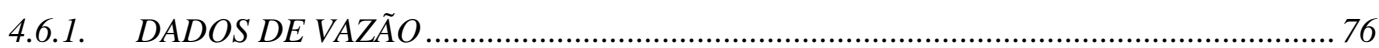

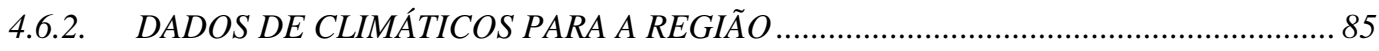

4.7. CARTA DE USO E OCUPAÇÃO ….......................................................................... 91

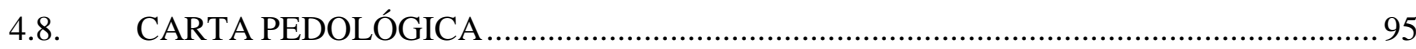

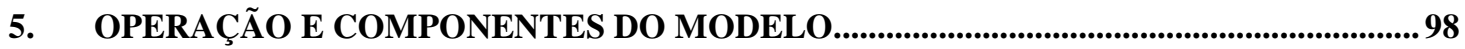

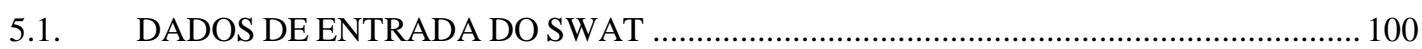

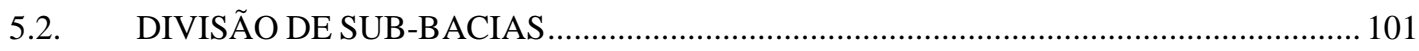

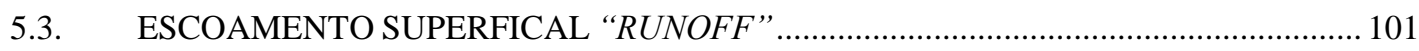

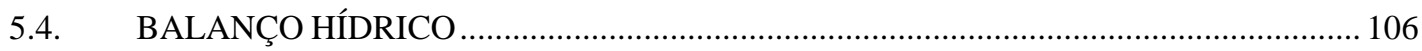

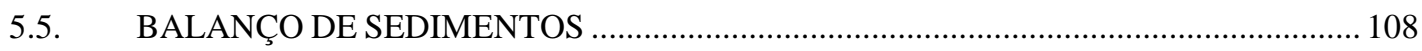

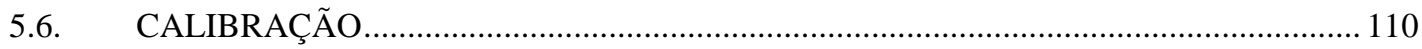

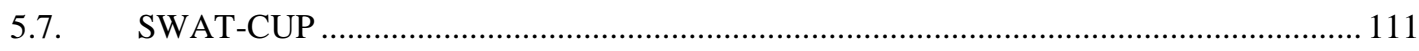

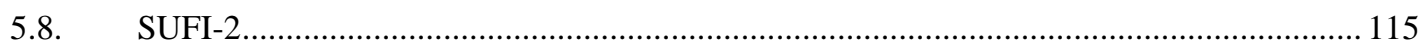

5.8.1. COEFICIENTES DE CORRELAÇÃO DE PEARSON …............................................ 119

5.8.2. COEFICIENTE DE EFICIÊNCIA DE NASH-SUTCLIFFE ..................................... 120

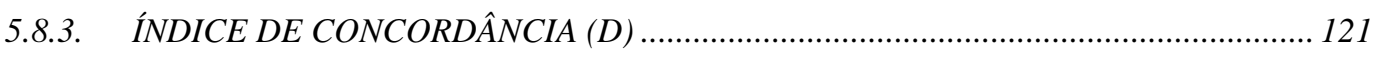

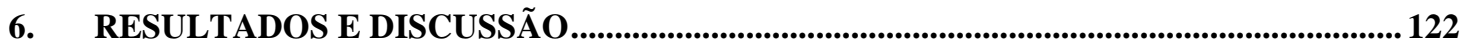

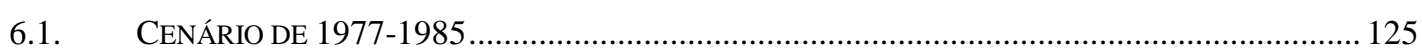

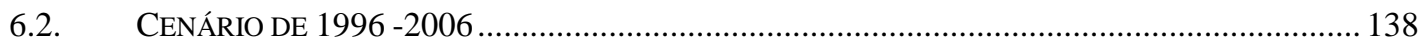

7. CONCLUSÕES E RECOMENDAÇÕES...................................................................................... 148 
8. REFERÊNCIAS BIBLIOGRÁFICAS. 



\section{INTRODUÇÃO}

Os reservatórios são estruturas criadas pelo homem que barram rios e cursos de água armazenando-a tanto para abastecimento quanto para geração de energia entre outros usos, portanto o volume de água de um reservatório é um aspecto vital para o bom funcionamento do mesmo. Durante a época de chuvas é armazenado o excedente de água a fim de ser utilizado para abastecer as demandas e garantindo este abastecimento mesmo na época de seca ou estiagem. O volume disponível nos reservatórios varia de reservatório para reservatório, mas está diretamente relacionado com a topografia do terreno o qual é construído.

A capacidade de armazenamento dos reservatórios ou capacidade de reservação é o volume disponível para armazenamento de água para abastecimento ou para geração de energia do reservatório. Desta forma, todo o gerenciamento de um reservatório é feito a partir do dado de volume útil, que é representado por uma curva que relaciona a cota ou nível da água (profundidade relacionada e um marco de altitude conhecida em relação ao nível do mar) e o volume a ela associado. Permintindo que através de uma simples leitura de régua, obter o volume do reservatório no exato momento, fornecendo subsídio para se determinar vazões que são utilizadas em seus diversos usos, a abertura de vertedores, vazão turbinada, outorga para irrigação, etc.

A deposição de sedimentos no fundo do tributário gera alteração do relevo do fundo do reservatório, geralmente tendo como conseqüência a perda de capacidade de armazenamento devido ao assoreamento. Em outras palavras, a condição original do levantamento topográfico prévio ao enchimento do reservatório é alterada, passando não mais condizer com a atualidade. Sendo necessário monitoramento constante do nível de 
assoreamento dos reservatórios para se conhecer a capacidade de reservação real dos mesmos e para atualizar a curva-chave do reservatório.

Quanto maior a idade do reservatório menor será a fidelidade do dado anterior ao enchimento com a condição real, devido a maior quantidade de sedimentos acumulados no reservatório e por isso uma menor capacidade de armazenamento de água, o que pode vir a gerar problemas de gestão.

A erosão e sedimentação podem dificultar o fornecimento de água e perda de patrimônio , Segundo Mahmood ${ }^{1}$, (1987 apud CARVALHO, 2000) em um estudo para do Banco Mundial demonstrou que a vida útil média dos reservatórios existentes em todos os países no Mundo havia decrescido de 100 para 22 anos, sendo o custo em 1987 de 6 bilhões de dólares anuais para a remoção dos volumes assoreados. O mesmo autor demonstrou também que a perda média anual de volume dos reservatórios devido ao depósito de sedimentos era de $1 \%$, sendo variável de país para outro, bem como de região para outra.

Mais de $25 \%$ da descarga global de sedimentos suspensos é considerada ser retida pelos reservatórios (VÖRÖSMARTY et al. 1997). Este acúmulo de sedimentos infligiu muitos danos desde o fim do século 20: nos EUA, reservatórios passaram por reformas ou mesmo precisaram ser desativados e demolidos, nos rios Eufrates (Iraque), Mekong (Tailândia), Syr Darya (Uzbequistão) observa-se conflitos de uso da água reservada entre países à jusante e à montante, bem como sedimentação.

Os custos para recuperação ou desativação das existentes infraestruturas são provavelmente enormes (WORLD WATER ASSESSMENT PROGRAMME, 2009). A reparação, reformar as estruturas de antigas barragens para reforça-las, implicará em

${ }^{1}$ MAHMOOD, K. (1987). Reservoir sedimentation - impact, extent and mitigation. World Bank Tech. Paper No. 71. Washington, DC. 
expressivos gastos. Em casos extremos, pode haver a necessidade de desativação da barragem, quando esta não mais desempenhar seu papel, como nos casos em que se encontra em péssimo estado de conservação e oferecer perigo, onde o assoriamento é muito alto ou em locais onde o fluxo do rio precisa ser mantido para a pesca ou para outros ecossistemas. A recuperação e a desativação também devem ser baseadas de acordo com os custos, se os custos de manutenção exceder os benefícios financeiros e econômicos futuros. (WORLD COMMISSION OF DAMS, 2000).

Em vista dos riscos e custos de uma eventual desativação de barragens a resolução conjunta ANEEL/ANA de Agosto de 2010 prevê que haja condições para criação e manutenção de uma rede de monitoramento do assoreamento dos reservatórios, para maior controle e fiscalização da conservação e segurança de barragens.

Apesar do problema de assoreamento do reservatório ser inevitável, causar grandes despesas ou até mesmo consequências irreversíveis às obras hidráulicas, pode-se minimizar parte desses problemas causados pela deposição de sedimentos, tendo assim, um controle dos sedimentos afluentes ao reservatório por meio destas medidas (CARVALHO et al, 2000).

Tendo em vista o risco da escassez de recursos hídricos, seja de forma quantitativa ou qualitativa, decorrente das atividades humanas, principalmente, devido aos lançamentos de resíduos e aos usos múltiplos, é preciso que haja um planejamento e gerenciamento de forma integrada, visando à otimização do mesmo. Quando se pretende estudar e planejar o uso da água de uma região é preciso adotar unidades ou áreas de estudo. Neste caso, a melhor unidade de estudo é a bacia hidrográfica. A bacia hidrográfica pode ser definida de forma simples como o conjunto de terras drenadas por um rio principal e seus afluentes, onde normalmente a água escoa dos pontos mais altos para os mais baixos. Os pontos mais altos são chamados de divisores de água de uma bacia hidrográfica. Portanto, todos os resíduos das 
atividades humanas como esgoto, agrotóxicos e lixo que forem lançados na região de uma bacia hidrográfica, poderão atingir, na época das chuvas, o rio principal.

De acordo com MacCauley, D.S. e Hufschmidt, M.M. (1995) a utilização da bacia hidrográfica como unidade de planejamento, possibilita considerar a junção de todos os fatores (econômicos, políticos, sociais e culturais) relacionados à área da bacia. $\mathrm{O}$ primeiro fator que deve ser levado em consideração em um planejamento é a realização de uma completa caracterização da bacia a ser estudada. Este conjunto de informações possibilita conhecer o sistema, o que dará suporte à tomada de decisões de gerenciamento dos recursos hídricos, dentre outros.

A avaliação do assoreamento é feita através de campanhas batimétricas, que são estudos para determinar a topografia do fundo do reservatório para determinação do volume do reservatório e atualizar as curvas de operação do mesmo.

Os modelos de erosão do solo como a USLE (Equação Universal de Perda de Solos ou “Universal Soil Loss equation”), RUSLE (versão revisada da equação universal de solos), o WEPP (“Water Erosion Prediction Project”) e o SWAT ("Soil and Water Assessment Tool”) são ferramentas matemáticas usadas para representar os processos erosivos dos solos. Associados a um Sistema de Informação Geográfica (SIG) podem ser usados para modelar as taxas de perda de solo, assoreamento dos corpos de água, estruturas de controle de erosão, avaliação de práticas de manejo e estudo e planejamento ambiental. Estas equações podem usadas para avaliar e estudar as condições atuais e futuras de conservação de solo, e assim estimar as vulnerabilidades da bacia em sofrer erosão hídrica e gerar o assoreamento dos reservatórios por transporte de sedimentos.

Os modelos citados uma vez calibrados, validados e verificados, podem fornecer dados de estimativa da taxa de assoreamento na base temporal de dias, fornecendo assim 
informações importantes para as políticas de gerenciamento de um reservatório que os dados nos intervalos de anos dos levantamentos batimétricos não fornecem, pode-se citar como exemplo, o efeito na taxa de assoreamento ocasionado por alterações do uso e ocupação do solo, ou mesmo a prevenção de impactos através da análise dos impactos para cenários futuros para distintos usos e ocupação dos solos.

O conjunto de dados batimétricos com modelos hidrológicos matemáticos pode ser usado para a gestão destes recursos hídricos. A ferramenta e modelação pode fornecer dados para preencher esta lacuna temporal aonde não existem dados batimétricos, como uma ferramenta para tomada de decisões.(Kuwajima et al.,2011a).

O Programa Produtor de Água desenvolvido pela ANA (Agência Nacional da água) tem como foco a redução da erosão e do assoreamento de mananciais no meio rural. É um programa de adesão voluntária de comitês de bacia, no qual é prevista remuneração aos produtores que adotarem medidas de preservação em seu (Emmerich e Marcondes, 1975)terreno. Estas ferramentas podem ser utilizadas como orientadores de decisão para ações e medidas dos participantes deste programa.

Desde então o Núcleo de Hidrometria pertencente ao Centro de Recursos Hídricos e Ecologia Aplicada (CRHEA) da Escola de Engenharia de São Carlos (EESC), Universidade de São Paulo (USP), têm firmado parcerias com concessionárias do setor energético como a AES Tietê e a Companhia Energética de São Paulo (CESP), realizando de pesquisas em gerenciamento de recursos hídricos aplicando modelos de Sistema de Suporte a Decisão (SSD) aplicados à geração hidrelétrica em reservatórios de múltiplos usos, capacitação de pessoal em técnicas hidrométricas e estudos batimétricos, cálculo de assoreamento e previsão de vida útil de reservatórios. 
Este presente estudo teve como objetivo ajustar as equações de estimativa de perda de solo, verificar a aplicabilidade e aptidão para criação de cenários futuros, como ferramenta de tomada de decisão para a gestão de recursos hídricos. Tem como uma das metas da presente pesquisa analisar o desempenho do modelo quanto suas potencialidades como uma ferramenta para tomada de decisões e como ferramenta para avaliar assoreamentos de reservatórios. Outros frutos desta pesquisa foram valores e parâmetros para a calibração do modelo para a região de estudo, o mapeamento das áreas mais críticas do entorno do reservatório em relação à produção de sedimentos. 


\section{OBJETIVOS}

Os modelos matemáticos de estimativa de perda de solo por erosão hídrica devem ser ajustados para cada situação e realidade para que se obtenham resultados compatíveis com a realidade em questão. $\mathrm{O}$ modelo $\mathrm{SWAT}$ apresenta a potencialidade de servir como importante ferramenta no planejamento e no estudo do assoreamento de reservatórios.

Assim a seguinte pesquisa se propõe à:

\subsection{OBJETIVOS GERAIS}

Aplicar e avaliar o modelo SWAT, como ferramenta de suporte para análise da estimativa de assoreamento de barragens; e como ferramenta de suporte a decisão para o gerenciamento de recursos hídricos.

\subsection{OBJETIVOS ESPECÍFICOS}

- Calibrar o modelo SWAT, para as condições locais;

- Estimar a produção de sedimentos na área de estudo

- Estimar o aporte de sedimentos no reservatório do Lobo (Itirapina/SP);

- Gerar mapas e cartas; 


\section{REVISÃO BIBLIOGRÁFICA}

\subsection{PROCESSOS EROSIVOS}

Erosão hídrica é o resultado do desgaste abrasivo ou da desagregação por embate, feito pela água sobre um substrato mineral com o qual tem contato. A ação mecânica ou impactante produz partículas sólidas de diversos tamanhos e formas. O processo erosivo é precedido de intemperismos, ação de agentes desagregadores físicos, químicos e biológicos ativos, potencializados pelas condições em que se encontra o corpo em erosão, por exemplo, a posição topográfica e o tipo de cobertura vegetal que o reveste. A erosão torna-se acelerada principalmente nas vertentes mais íngremes, onde a vegetação é rala ou inexistente, com solos arenosos e quando são aplicadas técnicas agrícolas inadequadas às condições dos terrenos (EMMERICH e MARCONDES,1975).

Conforme o uso do solo e s precipitações, ocorrem erosão e transporte de sedimentos para corpos de água. Nas barragens, há a alteração do relevo do fundo do reservatório, geralmente tendo como conseqüência a perda de capacidade de armazenamento devido ao assoreamento. Desta maneira, sedimentos se depositam no fundo da barragem, alterando esta capacidade de reservação. Em outras palavras, a condição original do levantamento topográfico prévio ao enchimento do reservatório é alterada, passando não mais condizer com a atualidade.

De acordo com Vögtle e Bähr (1999), a erosão e sedimentação causadas pela água correspondem ao desprendimento de partículas de solo devido ao impacto da queda d'água ou pelo seu fluxo seguido de seu posterior acúmulo. Todos os cursos d'água naturais apresentam a propriedade de carrear sedimentos e o volume deste material depende da região drenada pelo curso d'água. O material transportado, partículas de rochas, solos e de matéria orgânica, caracterizam o tipo dos sedimentos do curso d' água (BRANCO et. al, 1977). 


\subsection{EFEITOS DO USO E OCUPAÇÃO DO SOLO NA GERAÇÃO DE SEDIMENTOS}

Os processos físicos que ocorrem em uma bacia hidrográfica, como erosões, inundações e assoreamentos dos corpos hídricos, podem ser deflagrados ou mesmo acentuados devido aos padrões de uso e ocupação do solo. Estes processos geram consequiências diretas ou indiretas na qualidade da água, como alterações físicas, químicas e biológicas no meio aquático, bem como alterações metabólicas dos microorganismos.

Alterações nos usos e ocupações do solo, modificações hidrológicas, somadas às influências localizadas como ocupações humanas nas encostas, geram significativos impactos podendo citar como os mais importantes, aumento na produção de sedimentos nas encostas, aumento de aporte de sedimentos no rio, perda da qualidade da água do rio e perda de biodiversidade.

Segundo Jiogxin (2003) em um estudo no Rio Huang He (Rio Amarelo) os impactos notados foram aumento das erosões bem como aumento do aporte de sedimento que chega à costa. As discargas de sólidos suspensos no mesmo rio aumentaram cerca de 2 a 10 vezes nos últimos 2000 anos. Em contraste, o represamento e canalização reduziram muito o aporte de sedimento para a região costeira em outros rios pela retenção deste nas barragens (SYVISTKI et al, 2005).

A ocupação humana pode resultar em desmatamento e urbanização, tendo como uma de suas consequências alterações no escoamento superficial, infiltração e exposição do solo pela retirada da cobertura vegetal, que atua tanto como proteção natural do impacto direto de precipitações como barreira quebrando a energia das águas do escoamento. Além disto, as 
raízes auxiliam a infiltração de água no solo através do aumento dos poros por ação das mesmas e pela retenção da umidade do solo.

A vegetação é, portanto uma peça-chave para o suprimento hídrico, qualitativo e quantitativo tanto em países desenvolvidos, quanto em países em desenvolvimento. Segundo Liniger \& Weingartner, 1998, a importância da vegetação nas bacias hidrográficas poderá aumentar substancialmente, uma vez que os recursos hídricos se tornem escassos, particularmente em países em desenvolvimento.

Segundo relatório da ONU, (WORLD WATER ASSESSMENT PROGRAMME, 2009), os locais em que houve implementação de programas de conservação de solos, apresentaram redução de erosão durante o século 20. Nos EUA, medidas promovidas pela lei de segurança alimentar de 1985, conseguiram reduzir a erosão total anual de uma cultura em aproximadamente $40 \%$, de 3,4 Gt/ano para 2,0 Gt/ano (URI N.D e LEWIS, J.A. 1999). Na China medidas de controle em empregadas na década de 70 na região da Bacia do Médio Rio Amarelo reduziram em aporte de sedimentos anuais em 0,3 bilhões de toneladas (HU et al, 2008).

\subsection{ALTERAÇÕES CLIMÁTICAS}

Ciclos hidrológicos mais vigorosos implicam em condições hídricas mais extremas, o que pode afetar as relações entre hidrologia e geomorfologia. As alterações nos regimes de chuva podem alterar a vegetação e por sua vez contribuir para a erosão. Processos de desertificação são causados devido à erosão e degradação do solo e mudanças na vegetação. A erosão hídrica vem aumentando em muitas regiões do mundo, a maior parte como conseqüência de ações antropogênicas como modificação e ocupação da terra. Leemans \& Kleidon, 2002, avaliando os processos de desertificação afirmaram que as precipitações 
pluviométricas mais intensas ocasionaram um aumento nos sólidos suspensos (turbidez) em lagos e reservatórios devido à erosão fluvial do solo.

No entanto, devido à falta de informações e dados, não existem evidências conclusivas que evidenciem que alterações climáticas passadas estejam relacionadas a um aumento expressivo nas erosões e no transporte de sedimentos. (IPCC, 2007).

De acordo com Bates, B.C et al (2008)

"Todos os estudos sobre erosão dos solos mostram que é esperado um aumento nas intensidades das precipitações que poderão levar a maiores taxas de erosão (IPCC,2007). Em adição, a mudança de precipitação no inverno com a diminuição de neve e um aumento de chuva, devido ao aumento das temperaturas, gera um aumento dos processos erosivos. Isto pode resultar, por exemplo, em impactos negativos na qualidade da água em áreas rurais. $\mathrm{O}$ derretimento do pergelissolo (permafrost) expõe partes do solo e induz estados de erosão de solo que antes eram de não erosão Outros impactos indiretos das mudanças climáticas na erosão de solos, estão relacionadas ao solo e as mudanças de vegetação associadas à ações de adaptação Os poucos estudos sobre os impactos da mudança climática no transporte de sedimentos, sugerem um aumento deste transporte devido ao aumento da erosão, particularmente em regiões com processos de fluxo de água (“runoff”) aumentados. “

\subsection{ASSOREAMENTO DE BARRAGENS}

A construção de uma barragem e a formação de seu reservatório implica em modificações nas condições naturais do curso d'água a partir da redução na velocidade da corrente e, conseqüentemente, na capacidade de transporte de sedimentos pelo rio, favorecendo sua deposição nos reservatórios que, aos poucos, vão perdendo sua capacidade 
de armazenar água. Portanto, seja o reservatório para fins de geração de energia, de irrigação, de abastecimento ou de outros usos, o conhecimento da vida útil desse empreendimento dependerá diretamente do fluxo de sedimentos no curso d'água (LIMA et. al, 2003).

A deposição de sedimentos em reservatórios é um processo complexo que apresenta inúmeros fatores de influência, como o tamanho e a forma do reservatório; a razão entre a capacidade do reservatório e o tamanho da bacia; a razão entre a capacidade do reservatório e o deflúvio afluente; a topografia da bacia, uso da terra e cobertura vegetal; bem como a declividade e densidade da rede de canais; e características físicas e químicas do sedimento afluente (DENDY, 1968).

Os sedimentos transportados pelo sistema fluvial são primeiramente depositados devido à redução de velocidade da água nos corpos de água, gerando diversos impactos ambientais tanto em rios, lagos e reservatórios. Os principais fatores que afetam a produção de sedimentos na área de drenagem apontados por ICOLD (1989) são a precipitação, tipo de solo e formação geológica; Cobertura do solo, uso do solo, a topografia, natureza da rede de drenagem (densidade, declividade, forma, tamanho e conformação dos canais), o escoamento superficial e as características dos sedimentos (granulométricas, mineralógicas etc.).

À medida que os sedimentos se acumulam no lago, a capacidade de armazenamento de água do mesmo vai diminuindo. Enquanto uma contínua deposição ocorre, há uma distribuição de sedimentos nos reservatórios cuja forma é influenciada pela operação e também pela ocorrência de grandes enchentes responsáveis por carreamento de muito sedimento. Quando a vida útil do aproveitamento é afetada pelos depósitos, então são necessárias mudanças na operação do reservatório ou outras medidas que procurem remediar o problema (ICOLD, 1989). 
Outros efeitos podem ser citados como, por exemplo, aqueles a montante da área de remanso que ficam sujeitos a enchentes mais constantes e também aqueles a jusante da barragem cuja calha de rio sofre erosão devido à falta de sedimentos no escoamento e devido à atenuação das enchentes e regularização do curso d'água.

Segundo Carvalho (1994), o assoreamento gradual do reservatório, pode vir a impedir a operação do aproveitamento. No caso de usinas hidrelétricas, isso ocorre quando o sedimento depositado alcança a cota da tomada d'água. Essa retenção de sedimentos no reservatório é de certa forma benéfica, pois promove a limpeza da água para seus diversos usos, embora a sedimentação contínua possa resultar em assoreamento indesejável (Figura 1).

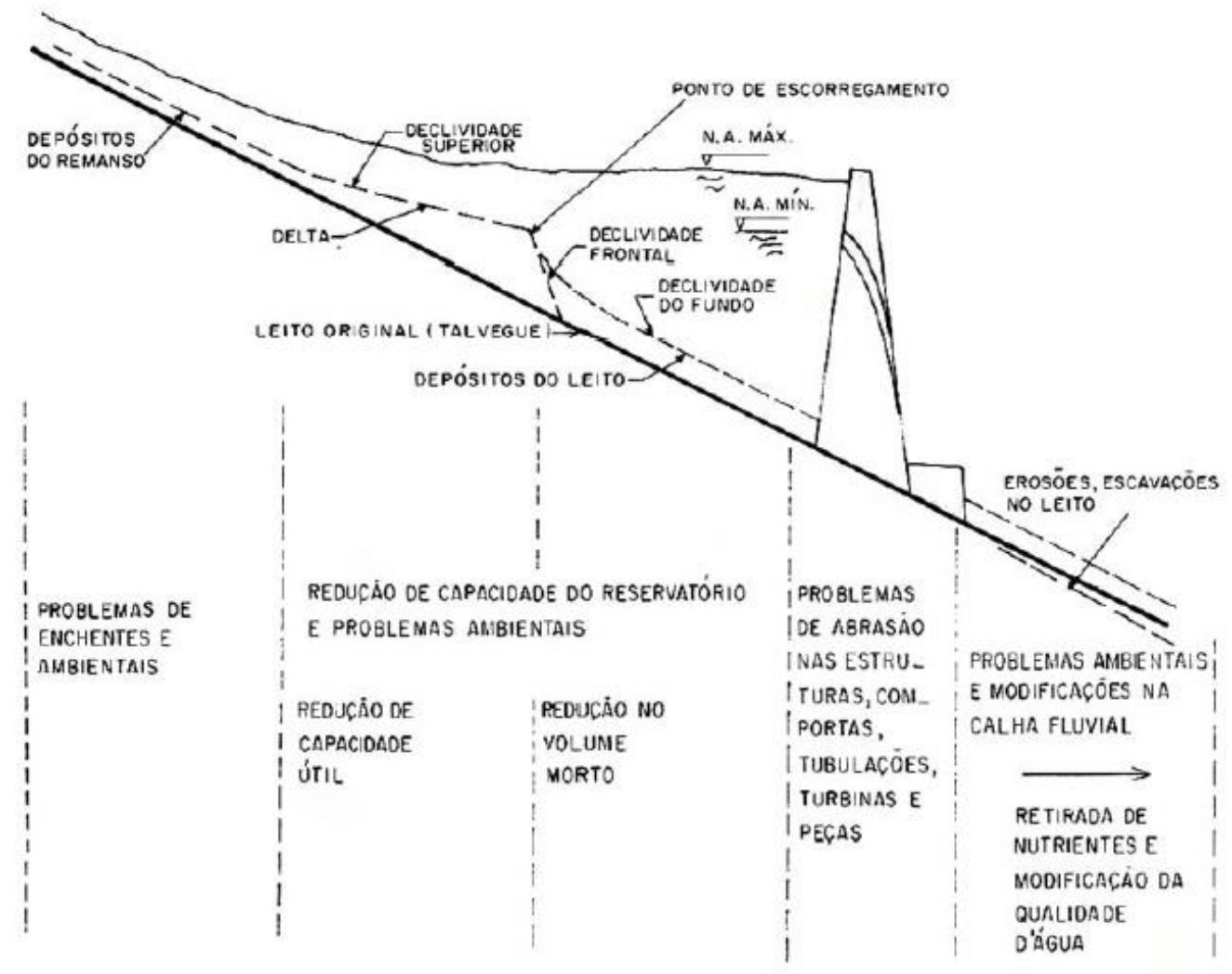

Figura 1 - Esquema de formação de depósitos de sedimentos nos reservatórios com indicação dos principais problemas decorrentes (Carvalho, 1994). 
Como conseqüência do assoreamento dos rios, ocorre redução do volume de água armazenado; o afogamento de locais de desovas, alimentação e abrigo de peixes; o aumento da turbidez da água, prejudicando os aproveitamentos hídricos e reduzindo as atividades de fotossíntese; alteração, destruição e degradação de ecossistemas aquáticos; a degradação da qualidade da água para consumo e conseqüente aumento dos custos de tratamento; a obstrução de canais de irrigação, navegação e trechos de cursos d'água; a formação de bancos de areia dificultando e alterando rotas de navegação; a dificuldade ou impedimento da entrada de água em estruturas hidráulicas de sistemas de captação (Ibdem).

\subsection{RESOLUÇÃO CONJUNTA ANEEL/ANA Nº 3 DE 10 DE AGOSTO DE 2010}

A energia hidrelétrica ocupa uma grande fatia da matriz energética brasileira, atualmente $71,02 \%$ da matriz provém desta modalidade de geração elétrica, sendo que desta porcentagem 67,75\% são geradas por Usinas Hidrelétricas de Energia (UHE), 3,10\% de Pequenas Centrais Hidrelétricas (PCH) e 0,17\% de Centrais Geradoras Hidrelétricas (CGH) (ANEEL, 2011a).

É importante ressaltar também que o país atravessa um momento de franco crescimento econômico e que a expansão da geração energética se faz necessária. Projeções de crescimento populacional (MME \& EPE, 2010) e econômicos preveem aumento do consumo de energia no país de 455,2 TWh em 2010 para 561,8 TWh em 2014 e 712,0 TWh em 2019 um aumento de 67 \% para o período de 2010-2019. Op.cit. Para o mesmo período está previsto o aumento do parque de geração hidrelétrica instalado de 80,7 GW em 2009 para 116,7 GW em 2019, aumento de 45\%. Um aumento ainda mais significativo será observado para as chamadas fontes de energia alternativas que englobam as PCHs, Biomassa e eólica para o mesmo perído o aumento será de 7,6 GW em 2009 para 21,5 GW para 2019 um 
aumento significativo de 183\%. Segundo outra fonte (ANEEL, 2011b), estão previstos o acréscimo de 7.919,2 MW de potência instalada para o ano de 2011, representando aproximadamente 29\% a mais do que o acréscimo registrado em 2010 (ANEEL, 2011b).

Durante crise do setor elétrico da década de 90 e com a extinção do DNAEE (Departamento Nacional De Águas e Energia Elétrica), e criação da ANEEL (Agência Nacional de Energia Elétrica) em 1996 e da ANA (Agência Nacional das Águas) em 2000, além da reestruturação da CPRM (Companhia de Pesquisa de Recursos Minerais em 1995 observou-se uma redução do quadro de funcionários diminuição drástica da oferta de cursos de capacitação em técnicas hidrométricas, e evidenciada retração das atividades de monitoramento hidrossedimentológico dos empreendimentos hidrelétricos (ESTIGONI et al 2011).

Neste contexto para assegurá-la, a garantia de disponibilidade de energia, além dos investimentos nos novos empreendimentos e para recuperar a infraestrutura de monitoramento hidrossedimentológioco nacional, é publicada Resolução Conjunta n 003 ANEEL - ANA em 20 de Outubro de 2010, visando à melhoria do processo de gestão de empreendimentos hidrelétricos, que dispõe sobre a realização de monitoramento hidrossedimentológico em empreendimentos hidrelétricos.

A Resolução Conjunta $n^{\circ} 003$ prevê que as concessionárias de energia sejam responsáveis pela realização do monitoramento (fluviometria, pluviometria, sedimentometria e qualidade de água), criando um enorme investimento privado no levantamento de dados hidrológicos e ao contrário da resolução anterior, a resolução atual prevê punição por meio de multa no caso do não cumprimento da mesma.

Em relação ao número de estações de monitoramento que deverão estar instaladas para a localização, a resolução utiliza o critério da área de drenagem conforme a Tabela 1 abaixo. 
Tabela 1 - Padronização para determinação da quantidade de estações de monitoramento a serem instaladas nos empreendimentos (ANEEL/ANA, 2010).

\begin{tabular}{|c|c|c|c|c|c|}
\hline \multirow{2}{*}{$\begin{array}{c}\text { Tipo de } \\
\text { Monitoramento }\end{array}$} & \multicolumn{5}{|c|}{ Área de Drenagem Incremental } \\
\cline { 2 - 6 } & $<\mathbf{5 0 0} \mathbf{k m}^{\mathbf{2}}$ & $\begin{array}{c}\mathbf{5 0 1} \mathbf{~ \mathbf { 5 . 0 0 0 }} \\
\mathbf{k m}^{\mathbf{2}}\end{array}$ & $\begin{array}{c}\mathbf{5 . 0 0 1} \mathbf{~ \mathbf { 5 0 . 0 0 0 }} \\
\mathbf{k m}^{\mathbf{2}}\end{array}$ & $\begin{array}{c}\mathbf{5 0 . 0 0 1} \mathbf{a} \\
\mathbf{5 0 0 . 0 0 0} \mathbf{k m}^{\mathbf{2}}\end{array}$ & $\begin{array}{c}>\mathbf{5 0 0 . 0 0 0} \\
\mathbf{k m}^{\mathbf{2}}\end{array}$ \\
\hline Pluviométrico & 1 & 3 & 4 & 6 & 7 \\
\hline Linimétrico & 1 & 1 & 1 & 1 & 1 \\
\hline Fluviométrico & 1 & 3 & 4 & 6 & 7 \\
\hline Sedimentométrico & 1 & 2 & 2 & 3 & 3 \\
\hline
\end{tabular}

Outro item importante da resolução é a etapa relacionada à frequência da atualização das curvas Cota x Área x Volume, que deverá ser feita através de levantamentos batimétricos a cada 10 anos. Não são definidos métodos de realização destes estudos.

\subsection{BATIMETRIA}

Atualmente a técnica utilizada para se determinar o assoreamento de reservatórios, é a de estudos batimétricos, que consistem em levantamentos do relevo do fundo do reservatório, que fornecem o volume de água atual das barragens. Os estudos batimétricos são estudos topográficos subaquáticos que possuem diversas finalidades, como fornecimento de dados para: construção de obras civis, como pontes, canais, etc., manutenção de hidrovias e portos, para garantir o calado da navegação; dragagens; e gestão de reservatórios. Os métodos de levantamento de linhas topobatimétricas e de levantamento de contorno do reservatório, são os mais comuns (CARVALHO, 1994).

A taxa de assoreamento é obtida através de séries históricas destes estudos, por meio da comparação dos resultados levantados comparando o volume de uma campanha 
batimétrica feita no passado com o volume levantado pela última campanha. Estes estudos são constituídos das seguintes etapas: planejamento de seções batimétricas, o levantamento de campo, o processamento das informações obtidas, a utilização de softwares para a geração de mapas digitais, geração de isolinhas altimétricas (curvas de nível), bem como a geração de curvas cota-área e cota-volume.

As campanhas de estudos batimétricas tendem a ser onerosas e demandam muito tempo, uma vez que se faz necessário de longas companhas de levantamentos de dados, sendo necessário traçar diversas linha e transectos e uma posterior etapa de processamento e tratamento de dados, de forma obter um MDT (Modelo Digital do Terreno) adequado. É necessário também haver dados como um levantamento batimétrico prévio ou a topografia do terreno anterior ao enchimento da barragem para obter a perda de volume por assoreamento.

Na Figura 2, pode-se observar um exemplo de como um transecto obtido através da batimetria pode revelar o grau de assoreamento, após os processos de sedimentação que ocorrem no fundo do reservatório houve um aumento de cota do mesmo em relação a uma condição inicial aonde não havia deposição de sedimentos.

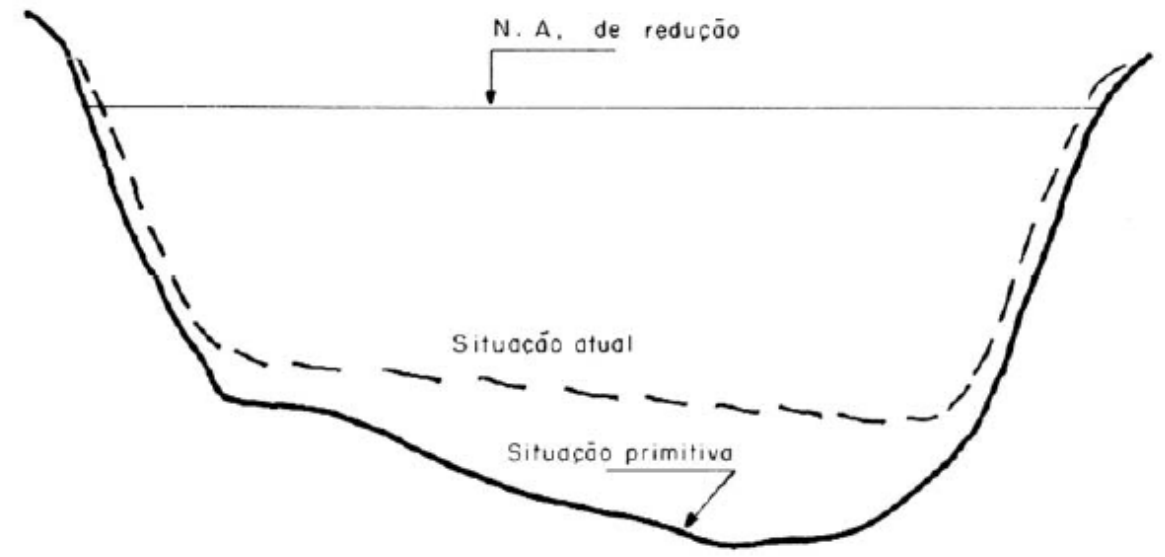

Figura 2 - Seções tranversais comparativas de levantamentos de reservatório (Carvalho, 1994). 
Estes estudos fornecem medidas reais do assoreamento, no entanto os dados não podem ser obtidos numa escala de tempo contínuo, uma vez que a série de dados está limitada ao intervalo de campanhas de levantamento realizadas, esta freqüência depende de vários fatores sendo os principais a sua capacidade total e a quantidade possível de depósito de sedimento devido à carga sólida dos rios. Em pequenos reservatórios e aqueles cuja carga sólida afluente é grande devem ser levantados com maior frequência (Tabela 2). Por outro lado, reservatórios cuja carga sólida afluente fica reduzida terão a freqüência de levantamento diminuída. Como, por exemplo, no caso em que a área de drenagem foi reduzida pela construção de uma barragem a montante (CARVALHO et al, 2000), ou ainda, quando a bacia contribuinte reduziu o valor do deflúvio sólido devido a sua proteção.

Tabela 2 - Freqüência desejável para levantamentos topo-batimétricos de reservatórios (adaptado de CARVALHO et al, 2000).

\begin{tabular}{|c|c|c|}
\hline PORTE DO RESERVATÓRIO & $\begin{array}{c}\text { CALSSIFICAÇÃO EM } \\
\text { VOLUME }\left(\mathbf{1 0}^{\mathbf{6}} \mathbf{m}^{\mathbf{3}}\right)\end{array}$ & $\begin{array}{c}\text { FREQÜÊNCIA DE } \\
\text { LEVANTAMENTO }\end{array}$ \\
\hline Pequeno & $<10$ & 2 anos \\
\hline Médio & Entre 10 e 100 & 5 anos \\
\hline Grande & $>100$ & 10 anos \\
\hline
\end{tabular}

No entanto é importante ressaltar que para determinar a frequência destes estudos devem também ser consideradas outras variáveis como a taxa de assoreamento do reservatório, a idade da obra, condições da área de entorno do reservatório (erosões, uso e ocupação e pedologia).

Segundo (ESTIGONI et al, 2009), até o presente momento ainda não existe uma metodologia padrão para a realização destes estudos e as diferentes metodologias fornecem resultados muito diferentes entre si, devido entre outros aspectos, à incompatibilidade da distribuição da freqüência de dados entre eles. São necessários mais estudos para propor uma 
metodologia padrão, bem como procedimentos e técnicas para que se possa comparar e utilizar em conjunto dois levantamentos que utilizaram metodologias distintas. Esta mesma carência é observada na literatura internacional, a qual não converge para um método padrão consolidado para a realização de estudos batimétricos.

\subsection{MODELOS MATEMÁTICOS}

Os modelos matemáticos, usados em problemas relacionados aos recursos hídricos, são discretizações e simplificações numéricas dos complexos processos que ocorrem na natureza, a fim de auxiliar pesquisadores e administradores a terem uma melhor compreensão dos processos envolvidos e de maneira a auxiliar na gestão e tomada de decisões em relação a estes processos.

Estes modelos são úteis uma vez que monitorar todos os processos que ocorrem em cada terreno e curso de uma bacia é inviável e muito caro, estes modelos permitem entender e reproduzir eventos que ocorreram no passado de forma a permitir que possamos planejar eventos semelhantes no futuro. Estes modelos permitem simular e avaliar o impacto das mudanças que ocorram na bacia, rio ou reservatório podem vir a influenciar a disponibilidade e a qualidade da água, e dessa forma promover a proteção e o uso racional dos recursos hídricos, bem como auxiliar a melhoria e a prevenção de problemas relacionados a estes recursos.

Os modelos hidrológicos podem ser tanto usados para prever, quanto para investigar os fenômenos físicos de uma bacia hidrográfica: Modelos de previsão são usados para obter uma resposta específica para um problema específico, enquanto que os de investigação servem para aprofundar o conhecimento dos processos hidrológicos (GRAYSON et al, 1992). 


\subsection{MODELOS MATEMÁTICOS DE ESTIMATIVA DE SEDIMENTAÇÃO}

A estimativa da erosão hídrica desempenha um importante papel no planejamento, avaliação de uso e ocupação do solo e para o manejo, não somente nos EUA, mas também na maioria das regiões do mundo. A principal ferramenta tem sido a equação universal de perda de solo (EUPS ou USLE), que foi desenvolvida por Wischmeier e Smith (1961).

O desenvolvimento de equações matemáticas para estimar a erosão do solo e os efeitos da conservação escolhida, tipo de culturas, práticas de manejo em perdas de solo começou em por volta dos anos 1940, com Zingg, A.W. (1940) e Simth, D.D. (1941). Através da análise de mais de uma extensa base de dados a USLE (equação universal de perda de solos), foi lançada em 1961 (WISCHMEIER e SMITH, 1961), sendo revisada posteriormente e atualizada em 1965 e 1978 (WISCHMEIER e SMITH, 1965, 1978).

A RUSLE, a versão revisada da USLE foi desenvolvida para ser uma versão computadorizada da USLE (RENARD et al, 1997). A mesma estrutura da fórmula usada na USLE é usada na RUSLE, agregando diversas melhorias, como um sub-fator para avaliar e ajustar valores para o tipo de cobertura do solo, novas equações para calcular a declividade e comprimento das vertentes, bem como outros recursos que a USLE não possui.

Conforme o conhecimento sobre os processos evoluíam, as limitações da USLE se tornaram mais aparentes, como a dificuldade de aplicá-la às novas culturas desenvolvidas e novas técnicas de manejo, bem como a inaptidão da fórmula para atuar em condições para as quais não foi desenvolvida. Mesmo com suas limitações a USLE tem sido bem sucedida nas tarefas de predição e estimativa da erosão hídrica e como ferramenta de escolha de medidas de conservação de solo e técnicas de manejo.

Baseadas nestas limitações o Departamento Norte Americano de Agricultura encomendou uma pesquisa para melhoria e substituição da USLE. Como resultado do esforço 
de quatro agências (Agriculture Research Service, Soil Conservation Service, Bereau of Land Management e U.S. Department of the Interior), surgiu o WEPP (Water erosion Prediciton Project)

O modelo do WEPP (Water Erosion Prediction Project) é um processo orientado para a simulação computadorizada contínua, que pode ser aplicada para perfis de taludes e encostas ou bacias hidrográficas (FLANAGAN e NEARING, 1995).

\subsubsection{USLE}

Segundo Santos et al (2001), o USLE é o modelo de predição de erosão hídrica mais aplicado, devido à sua simplicidade, parâmetros envolvidos e da facilidade de ser implementado. Afirmam ainda que a USLE possuí caráter bastante empírico, o que significa que os resultados estão bastante relacionados às condições de calibragem do ponto quantitativo.

A equação universal de perda de solos, estima a perda média anual de solos usando chuvas, solo, topografia e práticas de manejo, ela é representada pela seguinte equação:

$$
A=R \cdot K \cdot L \cdot S \cdot C \cdot P
$$

\footnotetext{
Aonde:

$A=$ Perda de Solo anual por unidade de área (t/ha/ano);

$R=$ Fator chuva, erosividade $($ MJ.mm/ha.hora.ano $)$

K= Fator erodibilidade do solo (t.ha.hora/ha.MJ.mm);

$L=$ Fator comprimento do declive $(m)$;

$S=$ Fator grau do declive (\%);

$C=$ Fator uso e manuseio;

$P=$ Fator prática conservacionista .
} 


\subsection{SWAT}

SWAT é acrônimo para 'Soil and Water Assessment Tool, modelo em escala de uma bacia de um rio, ou bacia hidrográfica, desenvolvido pelo Dr. Jeff Arnold para o USDA-ARS (United States Department of Agriculture-Agricultural Research Service). O SWAT foi desenvolvido para predizer o impacto das práticas de manejo de solo na água, a geração de sedimento e aporte de agrotóxicos em grandes e complexas bacias hidrográficas que apresentem grande variedade de solos, usos e ocupações do solo e técnicas de manejo através de longos períodos de tempo (NEITSCH et al, 2005).

O SWAT é a continuação de quase 30 anos de esforços de modelação conduzidos pela USDA-ARS. Este modelo tem ganhado aceitação internacional como uma robusta e interdisciplinar ferramenta de modelação de bacias hidrográficas, evidenciado pelas conferências anuais internacionais sobre SWAT, e publicações relacionadas ao modelo apresentadas em outros encontros científicos e revistas científicas e vasta comunidade de usuários.

\subsubsection{DESENVOLVIMENTO HISTÓRICO DO SWAT}

Segundo Gassman et al.(2007), as origens do modelo atual do SWAT é resultado direto de revisões e alterações do SWRRB (Simulator for Water Resources in Rural Basins). Este software foi desenvolvido pela USDA nos anos 80, para a gestão de impactos na água e movimento de sedimentos de bacias rurais não monitoradas nos EUA. O modelo SWRRB é resultado da fusão de modelos anteriores desenvolvidos pela USDA-ARS como o CREAMS (Chemicals, Runoff and Erosion from Agriculture Management Systems), o GLEAMS 
(Groundwater Loading Effects on agricultural Management Systems) e o EPIC (Environmental Impact Policy Climate).

O SWRRB começou a ser desenvolvido no início da década de 1980, com a modificação da rotina de chuva do CREAMS. Entre as melhorias incorporadas ao modelo, que podem ser citadas : o aumento da superfície de "runoff" e de outros cálculos, de apenas um campo, para até 10 sub-bacias, para a previsão da produção de água em uma bacia; o aperfeiçoamento do método do cálculo de pico de "runoff"; cálculo de perdas de carga; e a adição de novas rotinas com: fluxo de retorno de água subterrânea, armazenamento de reservatórios, o modelo para crescimento de culturas do EPIC, um simulador de clima e transporte de sedimentos. Outras modificações foram feitas ao SWRRB no final dos anos 80, com a incorporação do componente do GLEAMS para destino de pesticidas e um método opcional da USDA-SCS (USDA Soil Conservation Service) para estimar taxas de picos de "runoff". Este arsenal de ferramentas aumentou a aptidão deste modelo para lidar com uma vasta gama de problemas relacionados à gestão da qualidade de água em bacias hidrográficas. (Gassman op cit.)

O modelo ROTO (Routing Outputs to Outlet), foi desenvolvido para resolver outra deficiência do SWRRB. O modelo só podia tratar bacias divisíveis em até 10 sub-bacias, com extensão limitada até $100 \mathrm{~km}^{2}$. Este novo modelo conectava os dados gerados por várias simulações do SWRRB unificando-os em um único resultado. Porém, esta nova rotina mostrou-se ser muito pesada, exigindo muito armazenamento computacional, uma vez que eram necessários muitos dados de entrada e saída do SWRRB para combiná-los posteriormente em um único arquivo final. Era necessário rodar o SWRRB várias vezes independentemente para depois alimentar o ROTO com estes resultados para assim gerar o resultado final (Gassman op cit). 
O modelo SWAT foi então concebido solucionando esta dificuldade, ambos os modelos SWWRB e ROTO foram mesclados em um único modelo. Desde sua criação no começo da década de 1990, o SWAT foi constantemente revisado, atualizado e expandido, desta forma aumentaram as potencialidades do modelo. $\mathrm{O}$ esquema do desenvolvimento do modelo pode ser visualizado na Figura 3.

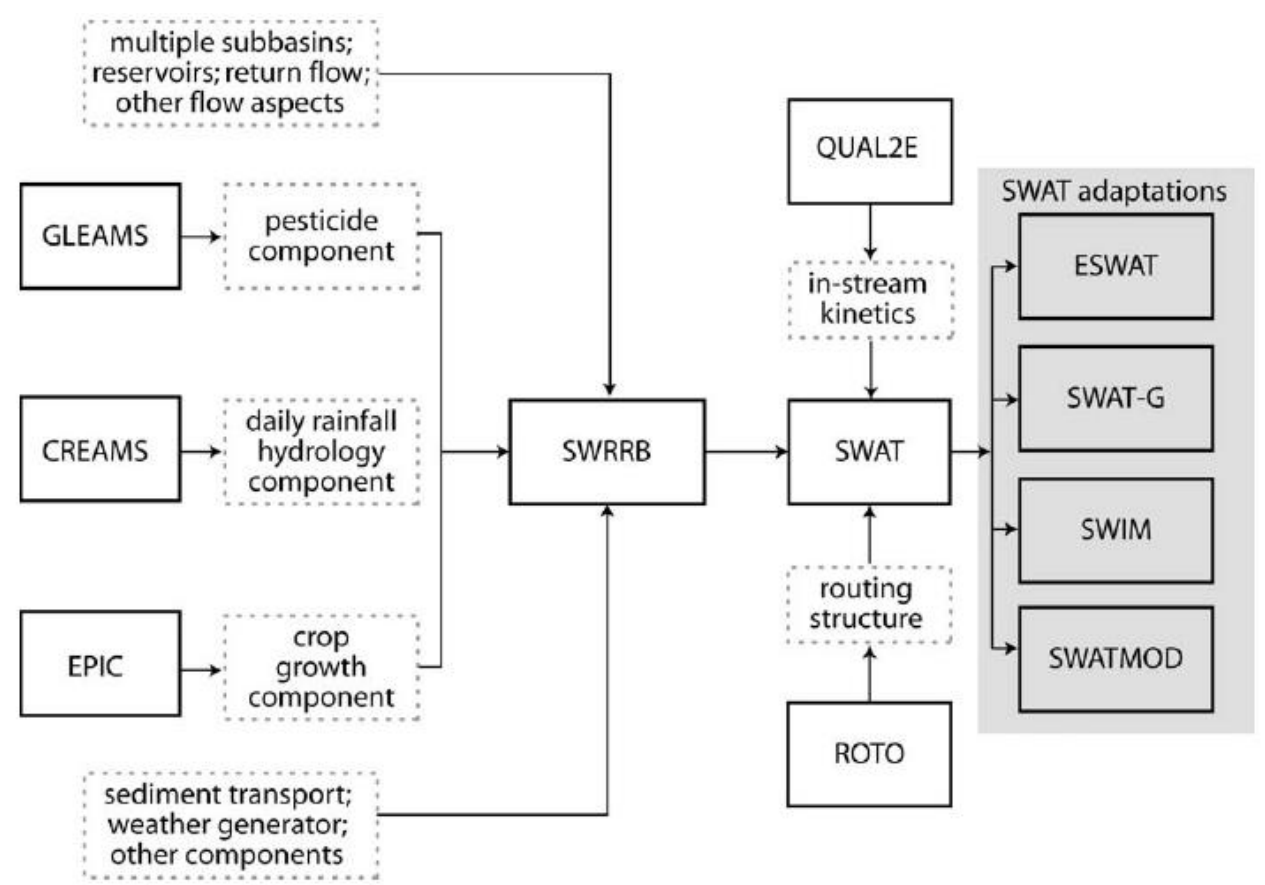

Figura 3 - Esquema do desenvolvimento histórico do SWAT ( GASSMAN et al.2007).

\subsection{APLICAÇÕES DO SWAT}

Com mais de 700 artigos relacionados, o modelo prova ser uma ferramenta muito versátil para estudar diversos problemas relacionados à hidrologia, qualidade de água em diferentes escalas de bacias (Gassman, 2011).

Ele tem sido usado extensivamente na Europa, incluindo projetos patrocinados por várias Agências da Comissão Europeia. Vários modelos incluindo o SWAT foram usados 
para quantificar os impactos da mudança climática para cinco diferentes bacias hidrográficas europeias, e um conjunto de nove modelos incluindo o SWAT, foi testado em 17 bacias hidrográficas europeias diferentes (GASSMAN et al, 2007). Diversos países desenvolveram versões modificadas do SWAT como SWAT-Korea e SWAT-Germany.

No entanto, Hiepe (2008) destaca que o número de aplicações do modelo para condições tropicais são poucas, sendo que a maior parte das aplicações registradas para o modelo são para condições temperadas. Apesar de haverem trabalhos aplicados para este tipo de condição muitos estudos devem ser considerados como preliminares e com frequência apresentam sérias limitações nos resultados devido à escassez de dados disponíveis.

O primeiro trabalho que se tem notícia no Brasil foi realizado por Oliveira em um estudo hidrossedimentológico na região costeira do Rio Joanes (1999) desde então se observa um aumento progressivo de trabalhos publicados que utilizaram o modelo. De 1999 até 2010 foram registrados 74 trabalhos publicados, 60 deles como artigos e 14 em teses e dissertações, sendo que $51 \%$ destes trabalhos são sobre os estados de São Paulo (19\%), Santa Catarina (16\%) e Paraná (16\%). (Garbossa, 2011).

\section{Potencialidades do SWAT}

O desenvolvimento primário do modelo enfatiza principalmente impactos do clima e práticas de manejo, carga para a qualidade de água e sua destinação, flexibilidade na discretização de bacias e simulação de tempo contínua. E graças aos avanços na tecnologia de processamento e de armazenamento de dados simulações são possíveis para extensas áreas.

Nos últimos anos, observa-se um aumento no leque de aplicações em que o modelo pode ser empregado, mostrando a robustez e flexibilidade da ferramenta. Outro fator 
importante é a ampla documentação disponível, bem como uma grande comunidade de usuários e de técnicas para calibração, que tornam o modelo bastante acessível.

Outro aspecto que torna a interface muito atrativa é sua versão para MAPWindow, que é uma plataforma SIG open source, dispensando a necessidade de adquirir licenças de softwares para poder rodar o modelo.

Embora o modelo possua algoritmos para calcular diferentes constituintes dinâmicos de uma bacia hidrográfica, o modelo só conseguirá descrever estes processos se forem usados dados de entrada de qualidade. Os dados de entrada, que descrevem a estrutura física da bacia, são geralmente associados ao modelo através de uma interface SIG.

\section{Limitações do SWAT}

A principal limitação para a modelação hidrológica de grandes áreas é o detalhamento espacial necessário para simular de maneira correta os processos ambientais. Um exemplo disso é a precipitação em uma bacia hidrográfica, que não ocorre de maneira uniforme, por isso há dificuldade em representar a variabilidade espacial destes dados. Outra limitação do modelo é referente à precisão das Unidades de Resposta Hidrológica, ou HRU (Hydrologic Response Units), ao simular variações de terrenos que incluem práticas de conservação, como por exemplo, em uma HRU em que apresente práticas de preservação da vegetação ripária.

Os arquivos de dados podem ser difíceis de manipular, podendo apresentar vários registros faltando. Outro problema comum à modelação que também é presente no SWAT é o quanto à necessidade de grande número de entrada de dados para poder obter resultados satisfatórios, no caso do SWAT ao menos 5 anos de observações de dados hidrológicos é necessária para simulação, recomendo-se também que haja pelo menos 1 ano de dados para 
“aquecer" o modelo, ou seja o primeiro ano de resultados simulados deve ser descartado ou analisado à parte uma vez que este serviu para inicializar os valores dos parâmetros de simulação. Esta necessidade de grande entrada de dados pode inviabilizar a aplicação do mesmo em regiões em que há pouco registro e monitoramento hidrossedimentológico

\subsection{AGRICULTURA TROPICAL}

Ao se aplicar o modelo, que foi desenvolvido para as condições dos EUA, os modeladores encontram algumas dificuldades na tentativa de encontrar um parâmetro equivalente ou aproximar dados embutidos no banco de dados do SWAT, visto que as técnicas e práticas agrícolas observadas no Brasil são distintas das observadas nos EUA ou Europa.

De acordo com Kuwajima et al. (2011b), as técnicas empregadas nas plantações e lavouras brasileiras são as mesmas que podem ser encontradas nos países de clima temperado, com a diferença que estas sofreram alguma adaptação ou alteração para serem empregadas para nosso tipo de solo, manejo de cultura, condições climáticas ou mesmo comportamento das espécies vegetais.

Um exemplo disto é o arado, enquanto que na Europa a técnica de aragem intensiva, aonde o solo é intensamente trabalhado com auxílio de discos e aivecas, é utilizada para melhorar as condições para o crescimento da raiz, a mesma técnica em países tropicais pode prejudicar as culturas, uma vez que através desta prática o solo fica descoberto e exposto ao calor e às intensas precipitações pluviométricas, assim acelerando a degradação e a erosão da camada superficial fértil do solo. (Kuwajima, op cit).

Outra característica das práticas agrícolas brasileiras seria a agricultura familiar que pode ser muito desafiadora de ser modelada, principalmente por ser caracterizada por uma 
baixa produtividade e eficiência de emprego de insumos como água e fertilizantes e utilização de técnicas tradicionais como queimadas.

Segundo Kato et al (1999) o emprego desta técnica pode representar grande perdas de nutrientes do solo por dispersão na atmosfera, lixiviação e percolação. Outras variáveis que são alteradas por esta prática é o teor de umidade do solo, além da volatilação da matéria orgânica do solo.

\section{Culturas Tropicais}

As mesmas espécies encontradas em países tropicais e em temperados apresentam um comportamento muito distinto para as duas condições de clima. O que pode ser atribuído principalmente ao fotoperíodo. Enquanto na região temperada os dias de verão apresentam em torno de 15 a 16 horas de sol, para as regiões tropicais a duração do dia no verão é mais curta com 13 horas em média (Paterniani, 2001).

Nestas condições uma maior atividade fotossintética e maior fixação de $\mathrm{CO}_{2}$ são esperadas de ocorrerem na região tropical em comparação aos trópicos. Além disto noites mais frias e curtas influenciam no período de respiração e emissão de $\mathrm{CO}_{2}$.

Num estudo compartivo sobre o comportamento de diferentes espécies de milho, em Ames, Iowa, EUA e em Piracicaba, SP, Paterniani (1990) observou comportamento muito distinto para as duas regiões.( Tabela 3 e Tabela 4). 
Tabela 3 - Comparação da pluviosidade entre um local de clima temperado (1) e outro subtropical (2) - Médias entre 1917 e 1985. (Paterinani , 1990).

\begin{tabular}{|c|c|c|c|c|c|}
\hline \multicolumn{3}{|c|}{ Ames, IOWA, EUA } & \multicolumn{3}{c|}{ Piracicaba, SP, Brasil } \\
\hline Período & Médias (mm) & Desvio Padrão & Período & Médias (mm) & Desvio Padrão \\
\hline $\begin{array}{c}\text { Pré-Plantio } \\
\text { (Set/Jun) }\end{array}$ & 618,5 & 117,96 & & & \\
\hline Julho & 92.6 & 35.51 & Dez & 218,9 & 75,88 \\
\hline Agosto & 97,6 & 40.74 & Jan & 216,1 & 94,1 \\
\hline
\end{tabular}

Tabela 4 - Comparação entre clima temperado e tropical para a cultura do milho. (Modificado de Pateriani, 1990).

\begin{tabular}{|c|c|c|}
\hline Características & Temperado & Tropical \\
\hline \multicolumn{3}{|c|}{ Condições de crescimento } \\
\hline Variação climática anual & Relativamente estável & Variável, não previsível \\
\hline Variação pluviométrica anual & Relativamente uniforme & Variável, não previsível \\
\hline Chuvas entre locais & Relativamente unifome & Variável, não previsível \\
\hline Fotoperíodo & Dias longos & Dias curtos \\
\hline Temperatura noturna & Frescas & Mais quentes \\
\hline Condições de solo & Geralmente favoráveis & Freqüentemente adversas \\
\hline Período de semeadura & Restrito (poucos dias) & Amplo (vários meses) \\
\hline Período Vegetativo & Bem definido & Variável amplo \\
\hline Dificuldades de germinação & Solos frios e fungos & Insetos de solo \\
\hline Infestação de ervas daninhas & Mediana & Alta \\
\hline Insetos de grãos armazenados & Baixa infestação & Alta infestação \\
\hline \multicolumn{3}{|c|}{ Tipos de Milho } \\
\hline Ciclo vegetativo & $\begin{array}{l}\text { Uniforme, adaptado à estação } \\
\text { de crescimento e socio- } \\
\text { econômicas. }\end{array}$ & $\begin{array}{c}\text { Variável para adaptaões a } \\
\text { condições climáticas }\end{array}$ \\
\hline Altura da planta & Mediana a baixa & Geralmente alta \\
\hline
\end{tabular}




\section{MATERIAIS E MÉTODOS}

\subsection{A USINA DO LOBO}

O reservatório foi construído entre 1933 e 1935 para geração de energia elétrica pelo engenheiro Eloy Chaves, a represa foi propriedade da Central Elétrica de Rio Claro desde sua inauguração até 1966, quando passou a ser da CESP (Companhia Energética de São Paulo) a partir de 1997 passou a ser propriedade Elektro e é atualmente gerenciada pela Aratu Geração S/A. Inicialmente a potência instalada era de $2.500 \mathrm{kVA}$ passando por uma reforma e atualmente conta com uma potência instalada de 2,21 MW. Na Figura 4 imagens da barragem.
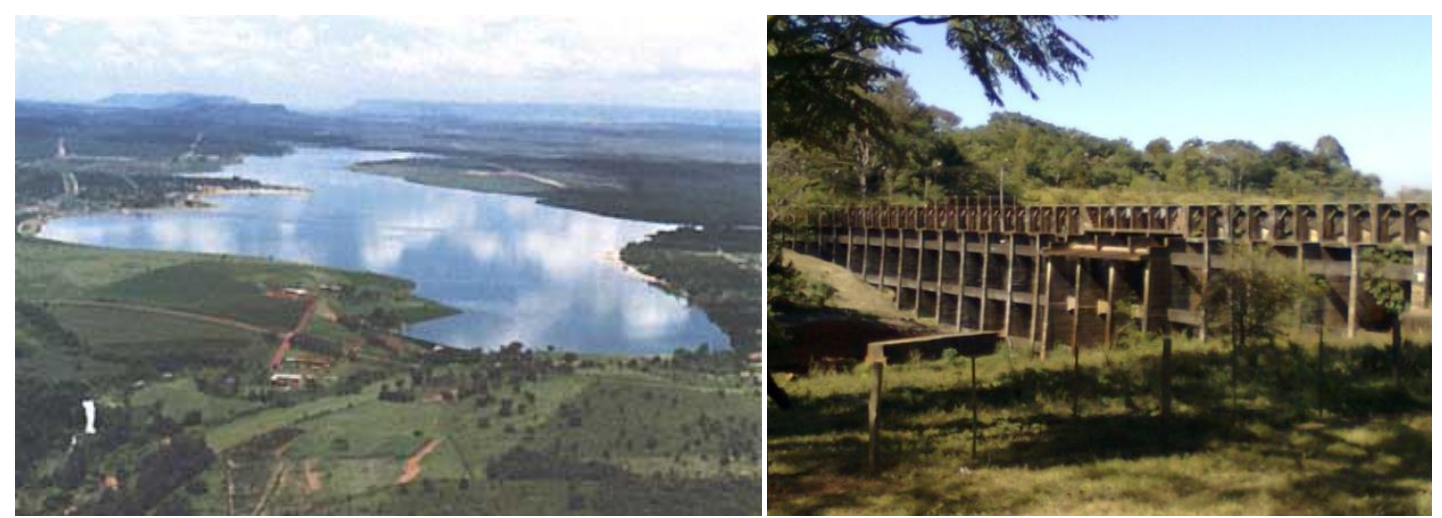

Figura 4 - O reservatório do Lobo (International Lake Environment Committee, 2010).

A Usina do Lobo, conhecida popularmente como "Usina do Broa", está localizada divisa de três distritos municipais : Itirapina, Brotas e São Carlos no estado de São Paulo na região sudeste do Brasil (Figura 5). Os principais tributários da represa são os Rios Itaqueri, Rio Geraldo, Ribeirão do Lobo, Córrego do Feijão e Córrego das Perdizes. 


\section{Localização da Bacia Hidrográfica do Lobo}
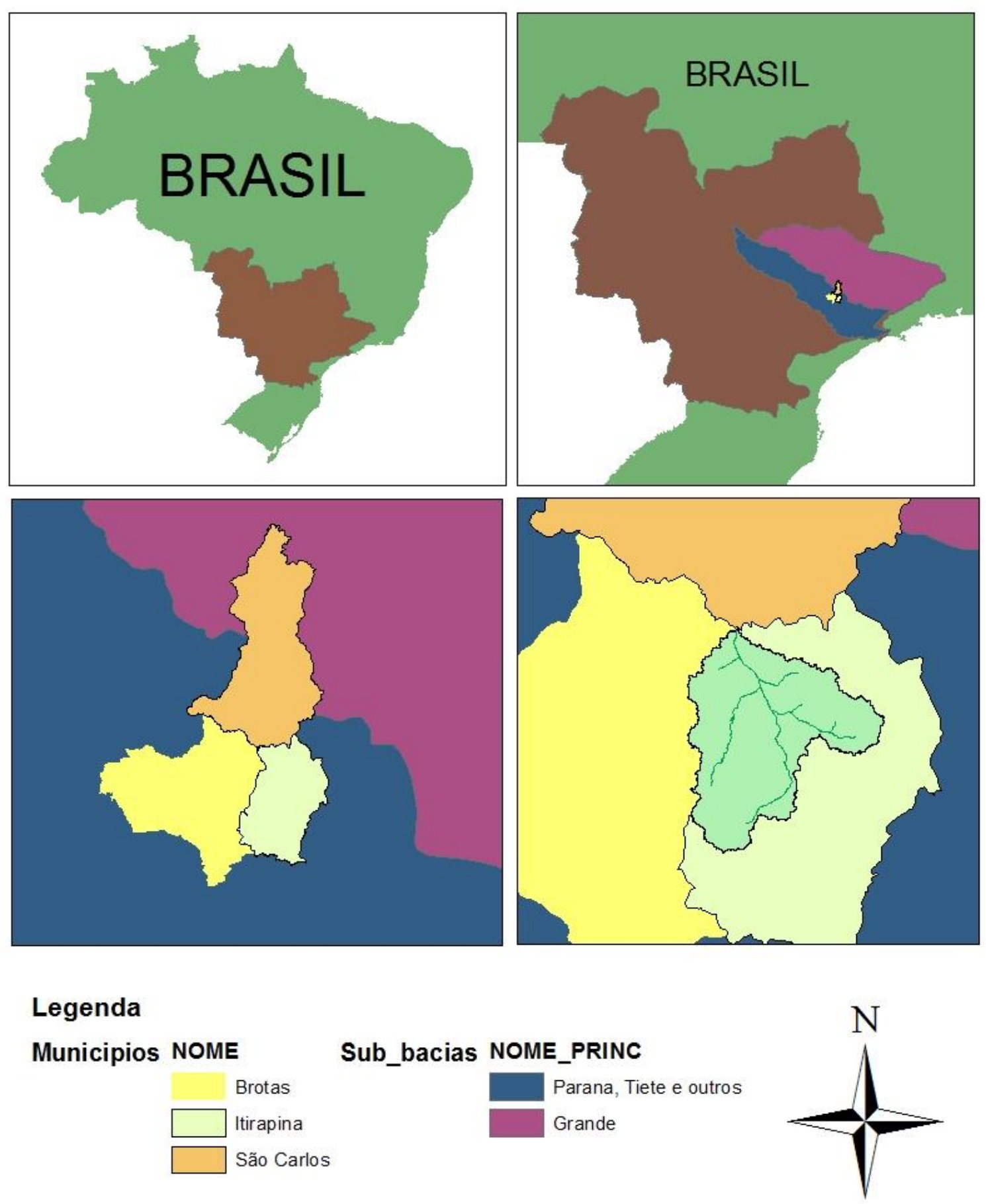
Figura 5 - Localização da Bacia Hidrográfica do Lobo.

A usina é constituída de tomada d’água, conduto forçado de chapa de ferro com uma distância total de 709,10 m até a casa de força, da casa de força a água turbinada se encontra novamente com a água do rio. As características do reservatório estão apresentadas na Tabela 5 abaixo

Tabela 5 - Características do reservatório do Lobo (TUNDISI, 1986).

\begin{tabular}{|c|c|}
\hline Comprimento & $8,0 \mathrm{~km}$ \\
\hline Largura Máxima & $2,0 \mathrm{~km}$ \\
\hline Largura Média & $0,9 \mathrm{~km}$ \\
\hline Profundidade máxima & $12,0 \mathrm{~m}$ \\
\hline Profundidade média & $3,0 \mathrm{~m}$ \\
\hline Área de superfície & $6,8 \mathrm{~km}^{2}$ \\
\hline Perímetro & $21,0 \mathrm{~km}$ \\
\hline Volume & $22,0 \times 10^{6} \mathrm{~m}^{3}$ \\
\hline
\end{tabular}

O reservatório conta com um comprimento de $7,5 \mathrm{~km}$, localizado em uma bacia bastante plana sua profundidade média e de $3 \mathrm{~m}$ sendo sua profundidade máxima de $12 \mathrm{~m}$ nas proximidades da barragem, o nível de água varia em torno de $1,5 \mathrm{~m}$. As caracterísiticas da barragem do reservatório estão apresentadas na Tabela 6.

Tabela 6 - Características da Barragem.

\begin{tabular}{|l|l|}
\hline Altura máxima & $706 \mathrm{~m}$ \\
\hline Cota na Crista da Barragem & $691 \mathrm{~m}$ \\
\hline Cota na soleira da barragem & $691,7 \mathrm{~m}$ \\
\hline N.A. Máximo Maximorum & 704,5 \\
\hline N.A. Máximo Útil & $704 \mathrm{~m}$ \\
\hline N.A. Mínimo Útil & $699 \mathrm{~m}$ \\
\hline
\end{tabular}


Os usos múltiplos da água na bacia hidrográfica são diversificados: abastecimento público; transporte e navegação nos reservatórios; pesca e aqüicultura; irrigação; turismo e recreação nos rios e reservatórios; usos industriais; curtumes e mineração. O conjunto desses usos gera resíduos que contribuem para o aumento das vulnerabilidades da bacia hidrográfica

Segundo Tundisi et al.(2003) a bacia sofre impactos de atividade antrópica e de demanda de água, tais quais: descarga de esgoto não tratado, desmatamento, mineração de areia, turismo e pesca esportiva.

A bacia do reservatório do Lobo-Broa é alvo de estudos por aproximadamente 40 anos. Os primeiros estudos liminológicos no reservatório se iniciaram em 1971, desde então diversos outros estudos sobre climatologia, biologia, hidrologia e química têm sido feitas no local. Os principais centros de pesquisa que desenvolveram pesquisas no local são a Universidade de São Paulo com o Centro de Recursos Hídricos e Ecologia Aplicada (CRHEA) e a Universidade Federal de São Carlos. O CHREA está engajado atualmente em diversos projetos de pesquisa.

\section{Condições Climáticas da região}

O Clima da região segundo a classificação de Köppen é do tipo Cwa, Tropical mesotérmico, contendo verões chuvosos e invernos secos, sofrendo influência de frentes frias chegando do sul principalmente durante o inverno e o outono. A pluviosidade anual media é de $1.300 \mathrm{~mm}$ e sua estação seca dura de abril até setembro (Tundisi, 1986). 


\subsection{SOFTWARES UTILIZADOS}

Para elaboração dos dados de entrada, simulação de cenários e calibração foram utilizados os seguintes softwares:

- $\quad$ ArcSWAT 2005 version2.34 para ArcGIS 9.1

- $\quad$ Arc SWAT Editor 2.1.5

- $\quad$ SWAT CUP 4.3.1

- Microsoft Windows XP, ou Windows 2000, sistemas operacionais com o patch mais recente kernel.

- ArcGIS-ArcView 9.1 com service pack 2 (Build 766)

- ArcGIS Spatial Analyst 9.1 extension

- ArcGIS Developer Kit (encontado em C:IProgram Files\ArcGIS\DeveloperKitl)

- ArcGIS DotNet support (encontrado em C:|Program Files\ArcGIS \DotNet $\backslash)$

- $\quad$ Microsoft .Net Framework 1.1

- Adobe Acrobat Reader version 7 ou versões posteriores

\subsection{BASE CARTOGRÁFICA}

Para a elaboração dos mapas e cartas necessários e rodar a interface gráfica do modelo foram utilizados o MDT (Modelo Digital de Elevação do Terreno), Carta de uso e ocupação do solo, Carta de Solos da região de estudo:

I. MDT 
Foram utilizadas imagens ASTERDEM (advanced Spaceborne Thermal Emission and Reflection Radiometer) da Nasa de resolução espacial de 30 m, disponíveis para download gratuíto nos sites da NASA,USGS e da ERSDAC (Japão). As características do ASTER GDEM estão apresentadas na Tabela 7. A Figura 6 mostra a imagem utilizada no modelo SWAT.

a. ASTER GDEM (Aster Global digital Elevation Model) versão 2

Tabela 7 - Características do ASTER GDEM.

\begin{tabular}{|c|c|}
\hline Formato & Geo TIFF (16 bits) \\
\hline Coordenada Geográfica & Latitude e Logitude Geográfica \\
\hline Resolução & $30 \mathrm{~m}$ \\
\hline Precisão do DEM & $7 \sim 14 \mathrm{~m}$ \\
\hline
\end{tabular}




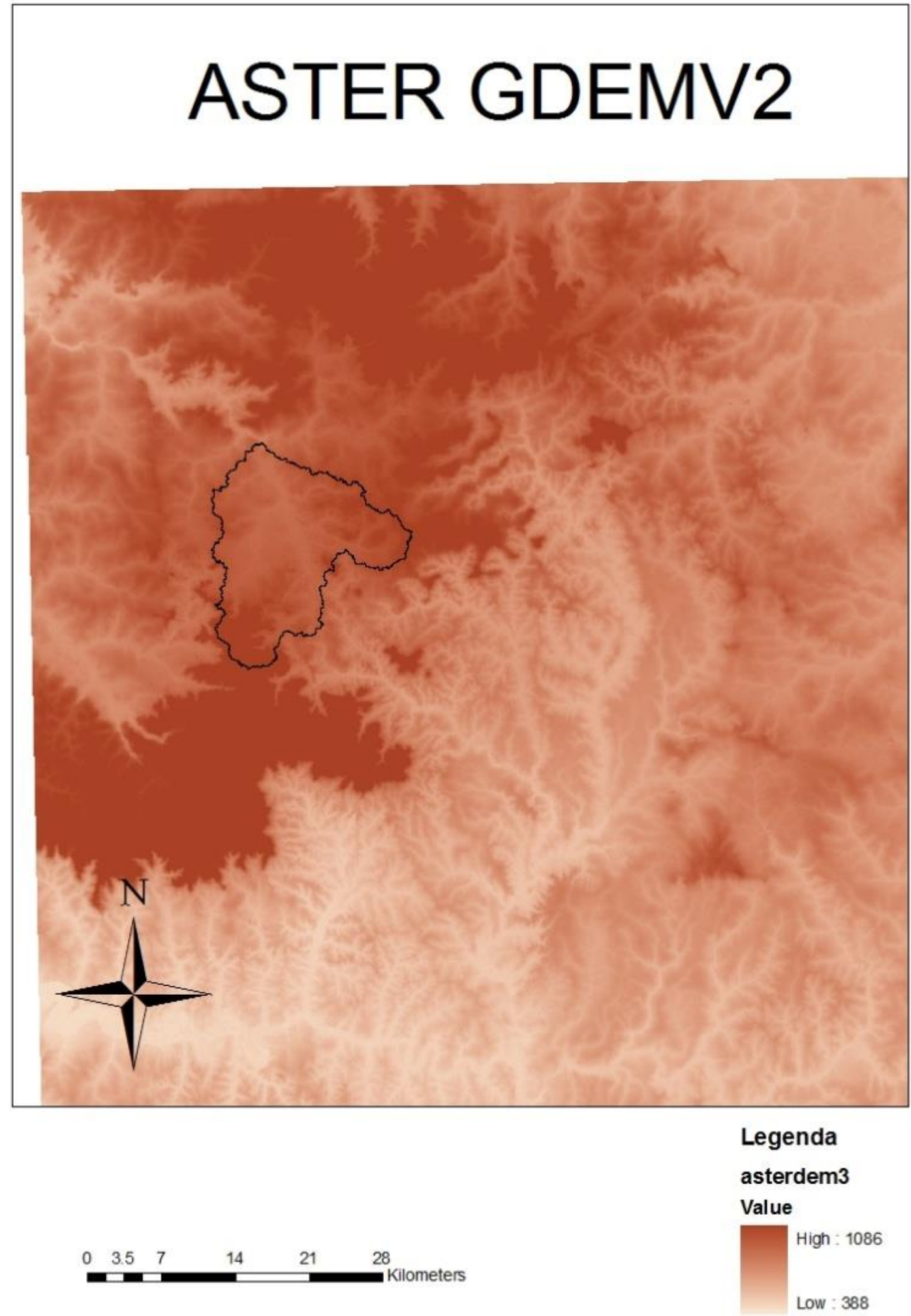

Figura 6 - ASTER GDEMv2 da área de estudo. 
II. Carta de Uso e Ocupação do solo:

A carta de uso e ocupação do solo foi feita através da classificação não supervisionada de imagens de satélite LANDSAT e CBERS, que estão disponíveis para download gratuito no site do INPE seguida de revisão dos resultados para categorização das parcelas em classes de uso e ocupação. As especificações das imagens LANDSAT 5 e 7 e CBERS estão apresentadas na Tabela 8 abaixo. Figura 7 mostra os resultados da classificação do uso e ocupação do solo para 1984 e 2010

a. Imagens de satélite LANDSAT e CBERS

Tabela 8 - Especificação das imagens de satélite LANDSAT 5 e 7 e CBERS.

\begin{tabular}{|c|c|c|}
\hline Especificação & LANDSAT 5 e 7 & CBERS \\
\hline Bandas espectrais $(\mu \mathrm{m})$ & $\begin{array}{l}0,45 \text { - 0,52 - Banda } 1 \\
0,52 \text { - 0,60 - Banda } 2 \\
0,63-0,69 \text { - Banda } 3 \\
0,76-0,90 \text { - Banda } 4 \\
1,55 \text { - 1,75 - Banda } 5 \\
10,4-12,5-\text { - Banda } 6 \\
2,08-2,35 \text { - Banda } 7\end{array}$ & $\begin{array}{r}0,50 \text { - 1,10 (pancromática) } \\
1,55 \text { - 1,75 (infravermelho } \\
\text { médio) } \\
2,08-2,35 \text { (infravermelho } \\
\text { médio) } \\
10,40 \text { - 12,50 (infravermelho } \\
\text { termal) }\end{array}$ \\
\hline Resolução espacial & $\begin{array}{c}30 X 30 \mathrm{~m} \\
120 X 120-\text { Banda } 6\end{array}$ & $\begin{array}{c}80 \text { X80m }(160 \text { X 160m } \\
\text { Termal })\end{array}$ \\
\hline
\end{tabular}




\section{Cartas de Uso e Ocupação}

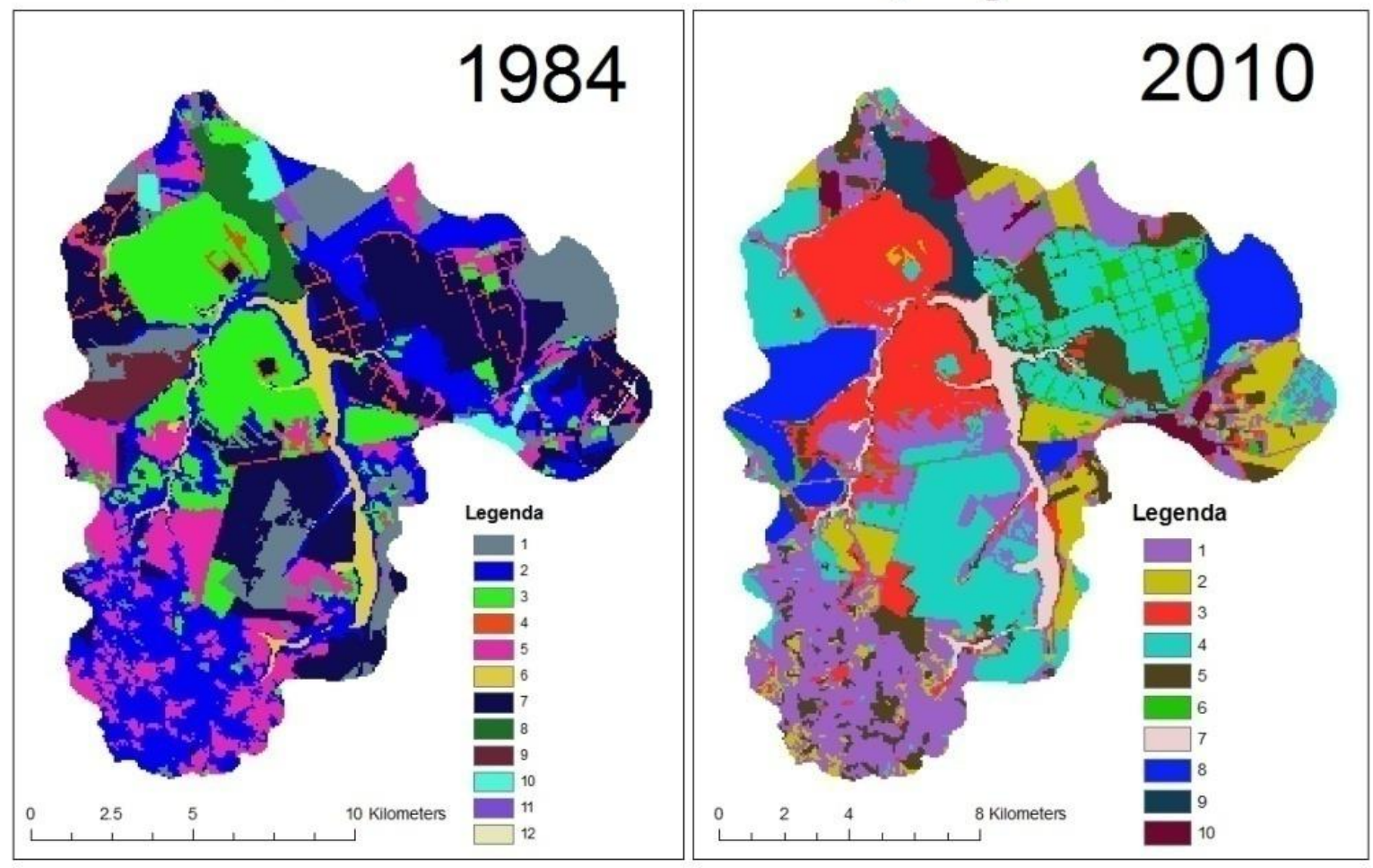

Figura 7 - Resultado da classificação de uso e ocupação para a região.

III. Mapa de Solos da Região de Estudo

A elaboração do arquivo para a carta pedológica consistiu da digitalização um levantamento pedológico existente. A Figura 8, mostra as classes de solos para a região do estudo.

a. Levantamento Pedológico Semi-Detalhado do Estado de São Paulo ( Convênio EMBRAPA- Secretaria de Agricultura do Estado de São Paulo. Coordenadoria da Pesquisa Agropecuária Intituto Agronômico-Divisão de Solos-Seção de Pedoogia, quadrícula de São Carlos (SF.23-Y-A-I) na escla 1:100.000 de 1981 


\section{Levantamento Pedológico Semi-Detalhado do Estado de São Paulo}

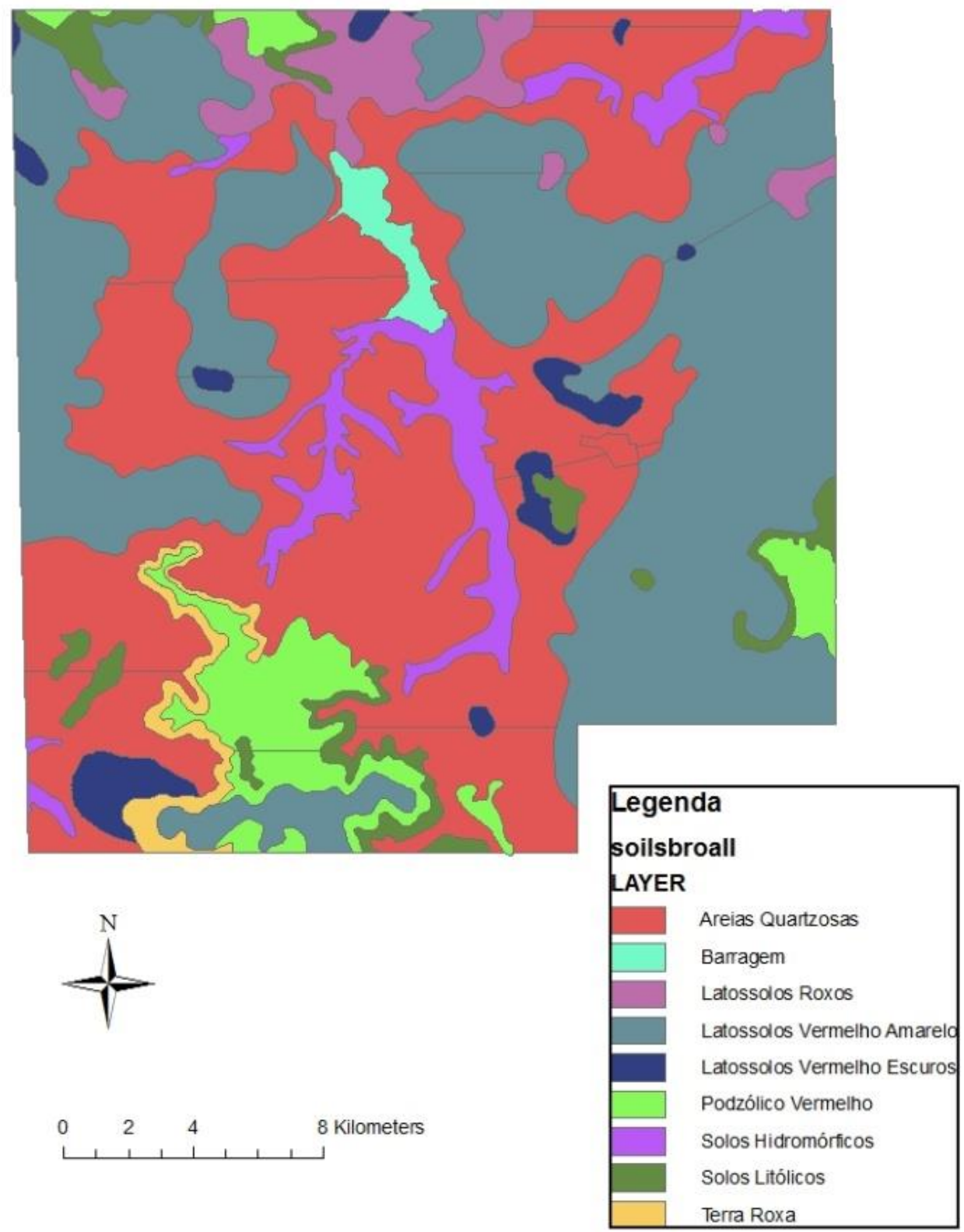

Figura 8 - Levantamento Pedológico Semi-Detalhado para região de estudo. 


\subsection{DADOS PLUVIOMÉTRICOS E FLUVIOMÉTRICOS}

O modelo necessita de ao menos 5 anos de dados para poder gerar resultados satisfatórios, na área de estudo escolhida além do número reduzido de estações de monitoramento, existe outro problema referente com as séries de dados, sendo que muitas apresentam dados inconsistentes ou muito fragmentadas. Conforme explicitado anteriormente observa-se em nível nacional uma dificuldade de encontrar dados para monitoramento de recursos hídricos.

A solução para corrigir estes problemas está em estimar os dados inexistentes através de interpolação utilizando outras estações existentes na área, caso não existam outras estações na região uma solução alternativa é de gerar estes dados utilizando o gerador de dados climáticos, que será mais a fundo explicado na seção 4.6.2, no entanto é importante ressaltar que estes dados são gerados aleatóriamente podendo resultar em incertezas nos resultados.

Na Tabela 9 estão listados as quantidades de estações com dados para o Estado de São Paulo e para a Bacia do Rio Tietê, é possível inferir que existem apenas 3 estações de monitoramento sedimentométrico para a bacia do Rio Tietê inteira e apenas 15 em funcionamento para o estado de São Paulo. 
Tabela 9 - Listagem da quantidade de estações de monitoramento para o estado de São Paulo e para a bacia do rio Tietê.

\begin{tabular}{|c|c|c|c|c|}
\hline \multirow{3}{*}{$\begin{array}{c}\text { Tipo de } \\
\text { estação de } \\
\text { monitoramento }\end{array}$} & \multicolumn{2}{|c|}{ Estado de São Paulo } & \multicolumn{2}{|c|}{$\begin{array}{l}\text { Bacia } 6 \text { (Rio Paraná) e Sub-bacia } \\
\text { nº } 62 \text { (Tietê entre outros) }\end{array}$} \\
\hline & \multicolumn{2}{|c|}{ Quantidade de estações } & \multicolumn{2}{|c|}{ Quantidade de estações } \\
\hline & Totais & Ativas & Totais & Ativas \\
\hline $\begin{array}{l}\text { Dados de } \\
\text { chuvas }\end{array}$ & 1250 & 2194 & 863 & 439 \\
\hline Pluviometria & 35 & 35 & 14 & 14 \\
\hline Dados de cotas & 208 & 371 & 125 & 69 \\
\hline Vazões & 52 & 21 & 53 & 17 \\
\hline $\begin{array}{c}\text { Dados de } \\
\text { Sedimentos }\end{array}$ & 15 & 21 & 3 & 3 \\
\hline $\begin{array}{l}\text { Qualidade de } \\
\text { água }\end{array}$ & 383 & 444 & 199 & 179 \\
\hline
\end{tabular}

Para a bacia hidrográfica de estudo foram levantadas todas as estações de monitoramento existentes, muito embora houvesse um número satisfatório de estação de dados de chuva (Tabela 10) em operação, apenas duas estações de monitoramento de vazão estão em funcionamento. (Tabela 11). 
Tabela 10 - Estações com dados de chuva.

\begin{tabular}{|c|c|c|c|c|c|c|}
\hline Nome & Código & Município & $\operatorname{Cota}(m)$ & Latitude & Longitude & $\begin{array}{c}\text { Série } \\
\text { Histórica }\end{array}$ \\
\hline Analândia & 2247004 & Analândia-SP & 660 & $-22^{\circ} 07^{\prime} 59.88$ & $-47^{\circ} 40^{\prime} 00.12$ & $1937-2004$ \\
\hline $\begin{array}{c}\text { Fazenda Campo } \\
\text { Alegre }\end{array}$ & 2247185 & Brotas -SP & 733 & $-22^{\circ} 08^{\prime} 49.92$ & $-48^{\circ} 00^{\prime} 03.96$ & $1977-2011$ \\
\hline Siriema & 2247183 & Brotas-SP & 728 & $-22^{\circ} 16^{\prime} 00.12$ & $-47^{\circ} 54^{\prime} 00$ & $1977-1990$ \\
\hline $\begin{array}{l}\text { Est. Ferroviária } \\
\text { campo alegre }\end{array}$ & 2247197 & Brotas-SP & 747 & $-22^{\circ} 14^{\prime} 26.88$ & $-47^{\circ} 57^{\prime} 30.96$ & $1978-2011$ \\
\hline Usina Santa Maria & 2247213 & Brotas-SP & - & $-22^{\circ} 10^{\prime} 00.12$ & $-47^{\circ} 55^{\prime} 59.88$ & $1986-1990$ \\
\hline $\begin{array}{c}\text { Faz. Pequena } \\
\text { Holanda }\end{array}$ & 2247198 & Itirapina -SP & 780 & $-22^{\circ} 10^{\prime} 46.92$ & $-47^{\circ} 46^{\prime} 59.16$ & $1978-2011$ \\
\hline $\begin{array}{c}\text { Visconde de rio } \\
\text { Claro }\end{array}$ & 2247006 & Itirapina-SP & 740 & $-22^{\circ} 09^{\prime} 00$ & $-47^{\circ} 48^{\prime} 00$ & $1937-2004$ \\
\hline Itirapina & 2247012 & Itirapina-SP & 790 & $-22^{\circ} 13^{\prime} 59.88$ & $-47^{\circ} 48^{\prime} 00$ & 1936-1999 \\
\hline Graúna & 2247015 & Itirapina-SP & 610 & $-22^{\circ} 18^{\prime} 00$ & $-47^{\circ} 45^{\prime} 00$ & $1937-2004$ \\
\hline Itirapina & 2247180 & Itirapina-SP & 739 & $-22^{\circ} 14^{\prime} 57.12$ & $-47^{\circ} 49^{\prime} 36.12$ & $1977-2011$ \\
\hline Fazenda Jangada & 2247181 & Itirapina-SP & 699 & $-22^{\circ} 19^{\prime} 59.88$ & $-47^{\circ} 49^{\prime} 59.88$ & $1977-1989$ \\
\hline Itaqueri da Serra & 2247184 & Itirapina-SP & 894 & $-22^{\circ} 20^{\prime} 31.92$ & $-47^{\circ} 55^{\prime} 04.08$ & $1977-2011$ \\
\hline CRHEA-BROA & 2247196 & Itirapina-SP & 732 & $-22^{\circ} 10^{\prime} 27.84$ & $-47^{\circ} 53^{\prime} 48.84$ & $1979-2011$ \\
\hline Usina do Lobo & 2247008 & Itirarpina-SP & 690 & $-22^{\circ} 10^{\prime} 00.12$ & $-47^{\circ} 54^{\prime} 00$ & $1937-2000$ \\
\hline $\begin{array}{c}\text { Ponte Fazenda } \\
\text { Paineira }\end{array}$ & 2248004 & S. Carlos - SP & 580 & $-22^{\circ} 04^{\prime} 00.12$ & $-48^{\circ} 04^{\prime} 00.12$ & $1960-2004$ \\
\hline Ribeirão do Feijão & 2247182 & S. Carlos-SP & 676 & $-22^{\circ} 09^{\prime} 11.88$ & $-47^{\circ} 53^{\prime} 12.12$ & $1977-2011$ \\
\hline $\begin{array}{c}\text { Campus de São } \\
\text { Carlos }\end{array}$ & 2247195 & S. Carlos-SP & - & $-22^{\circ} 00^{\prime} 00$ & $-47^{\circ} 52^{\prime} 59.88$ & $1979-2011$ \\
\hline
\end{tabular}


Tabela 11 - Estações com dados de cotas e vazão.

\begin{tabular}{|c|c|c|c|c|c|c|c|c|}
\hline Nome & Código & Município & $\begin{array}{l}\text { Cota } \\
\text { (m) }\end{array}$ & $\begin{array}{l}\text { Corpo } \\
\text { d’Àgua }\end{array}$ & Latitude & Longitude & $\begin{array}{c}\text { Série } \\
\text { Histórica } \\
\text { (Cotas) }\end{array}$ & $\begin{array}{c}\text { Série } \\
\text { Histórica } \\
\text { (Vazões) }\end{array}$ \\
\hline Siriema & 62760050 & Brotas-SP & 730 & $\begin{array}{c}\text { Rib. do } \\
\text { Lobo }\end{array}$ & $-22^{\circ} 16^{\prime} 01.2$ & $-47^{\circ} 54^{\prime} 00$ & $\begin{array}{l}1977- \\
1990\end{array}$ & $\begin{array}{l}1977- \\
1990\end{array}$ \\
\hline Mineração & 62760070 & Brotas-SP & 730 & $\begin{array}{c}\text { Rio } \\
\text { Itaqueri }\end{array}$ & $-22^{\circ} 15^{\prime} 00$ & $-47^{\circ} 52^{\prime} 01.2$ & $\begin{array}{l}1977- \\
1985\end{array}$ & $\begin{array}{l}1977- \\
1985\end{array}$ \\
\hline $\begin{array}{l}\text { Córrego } \\
\text { das } \\
\text { Perdizes }\end{array}$ & 62760110 & Brotas-SP & 700 & $\begin{array}{l}\text { Córr. } \\
\text { das } \\
\text { Perdizes }\end{array}$ & $\begin{array}{c}- \\
22^{\circ} 11^{\prime} 18.99\end{array}$ & $\begin{array}{c}- \\
47^{\circ} 54^{\prime} 21.99\end{array}$ & $\begin{array}{l}1977- \\
1998\end{array}$ & $\begin{array}{l}1977- \\
1995\end{array}$ \\
\hline $\begin{array}{l}\text { Jacaré- } \\
\text { Açu } 2\end{array}$ & 62760150 & Brotas-SP & 655 & $\begin{array}{c}\text { Rib. do } \\
\text { Lobo }\end{array}$ & $\begin{array}{c}- \\
22^{\circ} 09^{\prime} 29.88\end{array}$ & $\begin{array}{c}- \\
47^{\circ} 54^{\prime} 01.08\end{array}$ & $\begin{array}{l}1977- \\
2011\end{array}$ & $\begin{array}{l}\text { 1977- } \\
2007\end{array}$ \\
\hline $\begin{array}{l}\text { Córrego } \\
\text { do } \\
\text { Geraldo }\end{array}$ & 62760090 & $\begin{array}{l}\text { Itirapina- } \\
\text { SP }\end{array}$ & 700 & $\begin{array}{l}\text { Córr. do } \\
\text { Gerlado }\end{array}$ & $\begin{array}{c}- \\
22^{\circ} 12^{\prime} 20.00\end{array}$ & $\begin{array}{c}- \\
47^{\circ} 52^{\prime} 09.99\end{array}$ & $\begin{array}{l}1977- \\
1998\end{array}$ & $\begin{array}{l}1989- \\
1991\end{array}$ \\
\hline $\begin{array}{l}\text { Jacaré- } \\
\text { Açu } 1\end{array}$ & 62760130 & $\begin{array}{c}\text { Itirapina- } \\
\text { SP }\end{array}$ & 690 & $\begin{array}{l}\text { Rib.do } \\
\text { Lobo }\end{array}$ & $\begin{array}{c}- \\
22^{\circ} 09^{\prime} 56.88\end{array}$ & $\begin{array}{c}- \\
47^{\circ} 54^{\prime} 06.12\end{array}$ & $\begin{array}{l}1954- \\
2011\end{array}$ & $\begin{array}{l}1977- \\
2007\end{array}$ \\
\hline $\begin{array}{c}\text { Fazenda } \\
\text { Santa } \\
\text { Francisca } \\
\text { Lobo }\end{array}$ & 62760000 & $\begin{array}{c}\text { São } \\
\text { Carlos=- } \\
\text { SP }\end{array}$ & - & $\begin{array}{l}\text { Rib. do } \\
\text { Feijão }\end{array}$ & $-22^{\circ} 09^{\prime} 00$ & $-47^{\circ} 52^{\prime} 01.2$ & 1988 & \\
\hline $\begin{array}{l}\text { Ribeirão } \\
\text { do Feijão }\end{array}$ & 62760005 & $\begin{array}{c}\text { São } \\
\text { Carlos-SP }\end{array}$ & 678 & $\begin{array}{l}\text { Rib. do } \\
\text { Feijão }\end{array}$ & $-22^{\circ} 09^{\prime} 18$ & $\begin{array}{c}- \\
47^{\circ} 52^{\prime} 53.04\end{array}$ & $\begin{array}{l}1977- \\
2011\end{array}$ & $\begin{array}{l}1977- \\
2007\end{array}$ \\
\hline $\begin{array}{c}\text { Represa } \\
\text { do } \\
\text { BROHA }\end{array}$ & 62760120 & $\begin{array}{c}\text { São } \\
\text { Carlos-SP }\end{array}$ & 713 & $\begin{array}{l}\text { Rib.do } \\
\text { Lobo }\end{array}$ & $\begin{array}{c}- \\
22^{\circ} 10^{\prime} 00.12\end{array}$ & $-47^{\circ} 54^{\prime} 00$ & $\begin{array}{l}1983- \\
1987\end{array}$ & \\
\hline
\end{tabular}

Após a analisar as séries de dados destas estações constatou-se que elas possuíam várias inconsistências e descontinuidades, o que poderia significar problemas para modelar 
principalmente para calibrar o modelo. A partir da série de dados disponíveis determinaram-se as estações com dados de chuvas e de dados de cotas e vazão para realizar dois cenários.

\subsection{CENÁRIOS DE SIMULAÇÃO}

A escolha dos cenários escolhidos foi feita através da avaliação da série de dados mais longa e menos fragmentada de dados disponíveis para precipitação e vazão medida. Como observou-se que para os cenários atuais não havia uma série de dados satisfatórias optou-se por simular dois cenários no passado um entre 18/03/1977 até 31/03/1985 aonde se observouse maior quantidade de estações em funcionamento e a mais recente com dados existente, com estações de monitoramento reduzidas de 1/01/1996 até 01/01/2006. Na Tabela 12 abaixo estão descritos o número, classe e nome das estações selecionadas por simulação. A Figura 9 mostra a localização espacial das estaçoes climatológicas e pluviométricas para o período de 1977 até 1985. E a Figura 10 a localização espacial das estações climatológica e pluviométricas selecionadas para o período de 1996 até 2006. A diferença entre os dois períodos é que foram utilizadas diferentes estações pluviográficas devido a disponibilidade de séries históricas de dados. 
Tabela 12 - Estações de Monitoramento Elegidas por Cenário.

\begin{tabular}{|c|c|c|c|c|}
\hline Cenário & $\begin{array}{l}\mathbf{N}^{0} \text { de Estações } \\
\text { Pluviométricas }\end{array}$ & Estações Pluviomètricas & $\begin{array}{c}\mathrm{N}^{\mathbf{0}} \mathrm{de} \\
\text { Estações de } \\
\text { dados de } \\
\text { cotas e vazão }\end{array}$ & $\begin{array}{c}\text { Estações de dados e } \\
\text { Vazão }\end{array}$ \\
\hline $\begin{array}{l}1977- \\
1985\end{array}$ & 6 & $\begin{array}{l}\text { 1-)Siriem (2247183) } \\
\text { 2-) Est. Ferroviária Campo } \\
\text { Alegre (2247197) } \\
\text { 3-)Faz.Pequena Holanda } \\
\text { (2247198) } \\
\text { 4-)Itaqueri da Serra (2247184) } \\
\text { 5-) Itirapina (2247180) } \\
\text { 6-) CRHEA (2247196) }\end{array}$ & 6 & $\begin{array}{l}\text { 1-)Córr. Perdizes } \\
\text { 2-)Córr. Geraldo } \\
\text { 3-)Rio Itaqueri } \\
\text { 4-)Siriema(Rib. Do } \\
\text { Lobo) } \\
\text { 5-)Jacaré-Açú } 1 \text { (Rib. } \\
\text { Lobo) } \\
\text { 6-)Jacaré Açú } 2 \text { (rib. Do } \\
\text { Lobo) }\end{array}$ \\
\hline $\begin{array}{l}1996- \\
2006\end{array}$ & 5 & $\begin{array}{l}\text { 1-) Est. Ferroviária Campo } \\
\text { Alegre (2247197) } \\
\text { 2-)Faz.Pequena Holanda } \\
\text { (2247198) } \\
\text { 3-)Itaqueri da Serra (2247184) } \\
\text { 4-) Itirapina (2247180) } \\
\text { 5-) CRHEA (2247196) }\end{array}$ & 2 & $\begin{array}{c}\text { 1-)Jacaré-Açú } 1 \text { (rib. } \\
\text { Lobo) } \\
\text { 2-)Jacaré Açú } 2 \text { (rib. Do } \\
\text { Lobo) }\end{array}$ \\
\hline
\end{tabular}




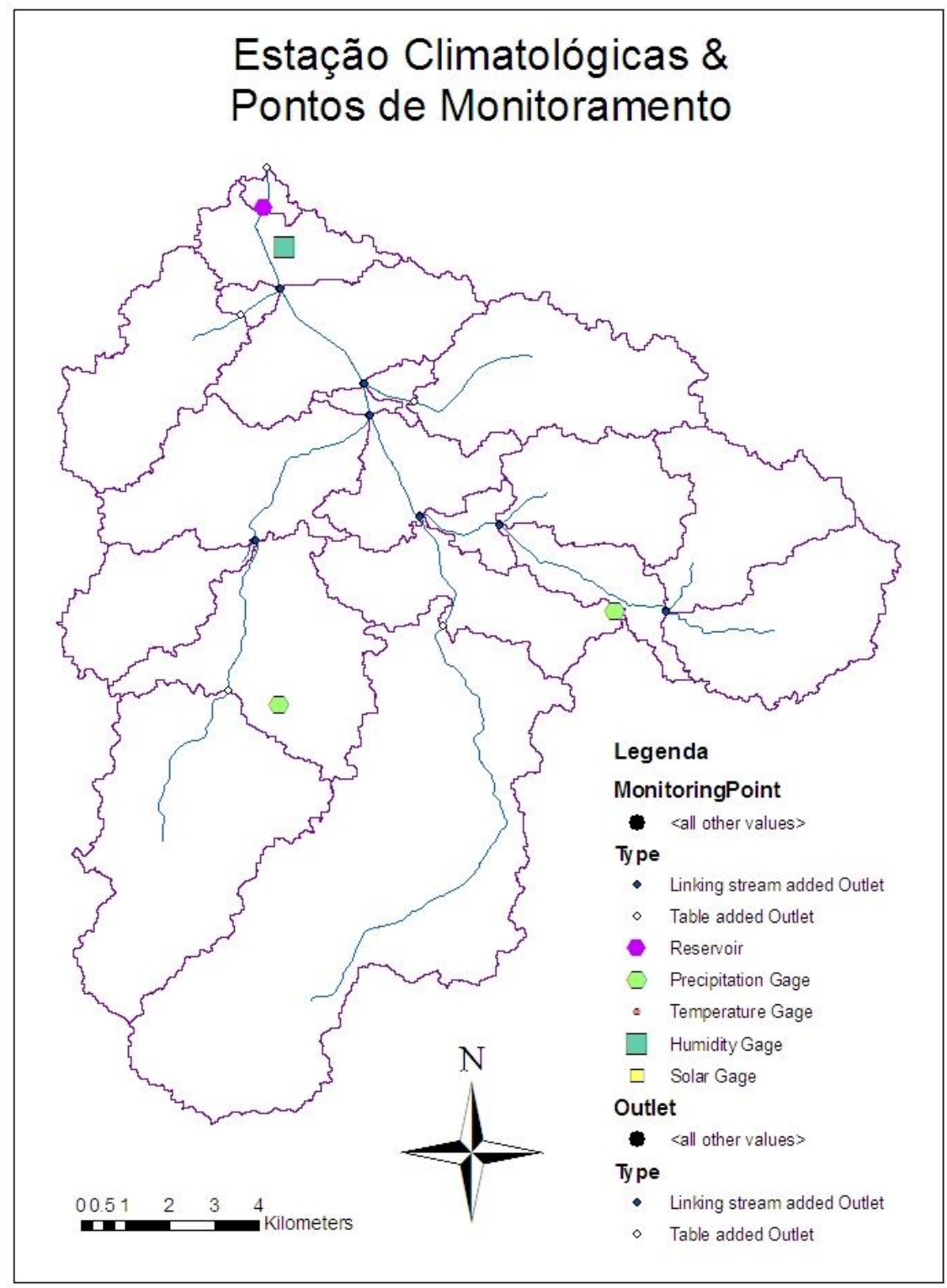

Figura 9 - Estações Climatológicas e Pontos de Monitoramento (cenário de 1977 - 1984). 


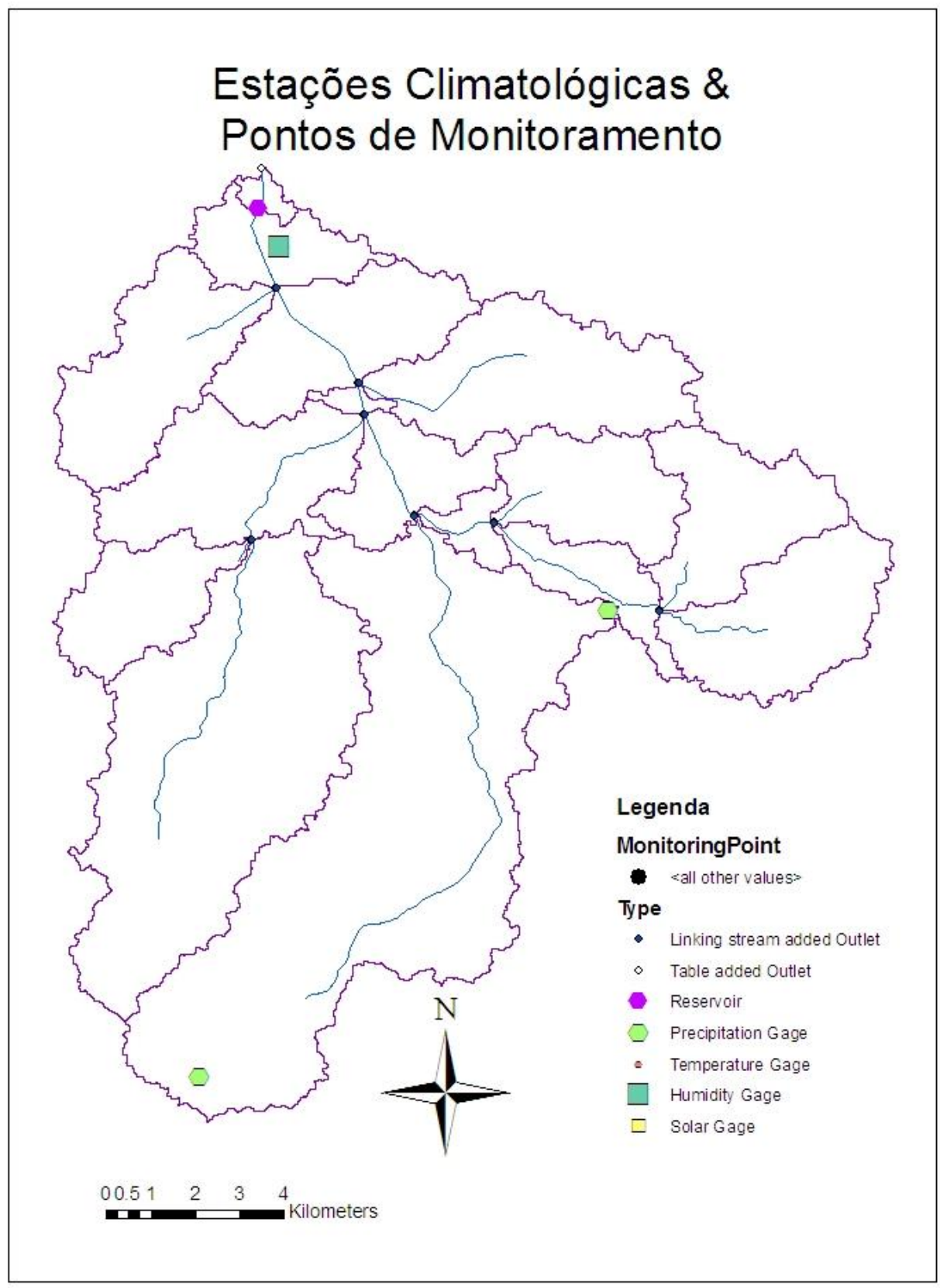

Figura 10 - Estações de Monitoramento e Pontos de Monitoramento (Cenário 1996-2006). 


\subsection{ELABORAÇÃO DE DADOS DE ENTRADA DO MODELO}

Após definidos os períodos de simulação dos cenários, foi necessário tratar os dados de vazão, precipitação, irradiação solar, umidade relativa do ar e temperaturas máxima e mínima para serem inseridos no modelo.

\subsubsection{DADOS DE VAZÃO}

As séries de dados de vazão foram obtidas através do HidroWeb, que é um portal de informações hidrológicas da ANA (Agêncida Nacional de Águas). Neste site é possível baixar todos os dados e séries históricas das estações monitoradas pela ANA em formato Microsoft Access ou em arquivo texto. Para a área de estudo estavam disponíveis dados de 6 estações de monitoramento de vazão, sendo que atualmente somente duas destas estações encontram-se em funcionamento.

Conforme exposto na Tabela 12 da seção 4.4, para o cenário de 1977 a 1985 foi possível obter dados de vazão de 6 estações: 1 localizada no Córrego das Perdizes, 1 no Córrego Geraldo, 1 no Rio Itaqueri e 3 no Ribeirão do Lobo, já para o cenário de 1996 a 2006 existiam dados disponíveis para somente 2 estações, ambas localizadas no Ribeirão do Lobo.

É importante destacar que os perídos de simulação dos cenários foram definidos a partir da maior série de dados completa, ou seja sem lacunas ou intervalos sem dados que foi possível obter. É possível rodar e calibrar o SWAT mesmo com séries de dados quebradas e descontínuas, mas para este caso optou-se por adotar somente os intervalos de dados que estivessem completos, ou aqueles em que fosse possível estimar a vazão a partir dos valors de cota. 
No entanto, alguns dos tributários do reservatório apresentaram resultados insatisfatórios após análise da regressão de dados por dispersão como nos casos do Córrego das Perdizes e do Rio Itaqueri, outros córregos após análise foi possível realizar algum tratametno de dados para obter a curva CotaX Vazão mais realista como no caso dos dados do Córrego do Geraldo e da Estação Jacaré-Açú 2 no Ribeirão do Feijão. Utilizar estes dados pode ser um fator negativo na fase de calibração do modelo, uma vez que são fontes de incertezas.

\section{Córrego do Geraldo}

Esta estação apresenta dados disponíveis de vazão e/ou cota somente para o cenário 1 (1977-1985). Esta foi a única estação que não apresentava dados de vazão para o intervalo de tempo, mas apresentava dados de cota da régua linimétrica para o período inteiro.

Então foi possível estimar a vazão para estas lacunas através de uma regressão linear da dispersão de dados de cota e vazão, obtendo a curva cota x vazão, a qual nos fornece os dados de vazão a partir dos dados de cota. Ao plotar a dispersão de toda a série de dados de 1989 até 1991 obteve-se o Gráfico 1, no qual pode-se observar duas curvas Cota X Vazão, o que significa que há algumas discrepâncias nos dados fornecidos. 


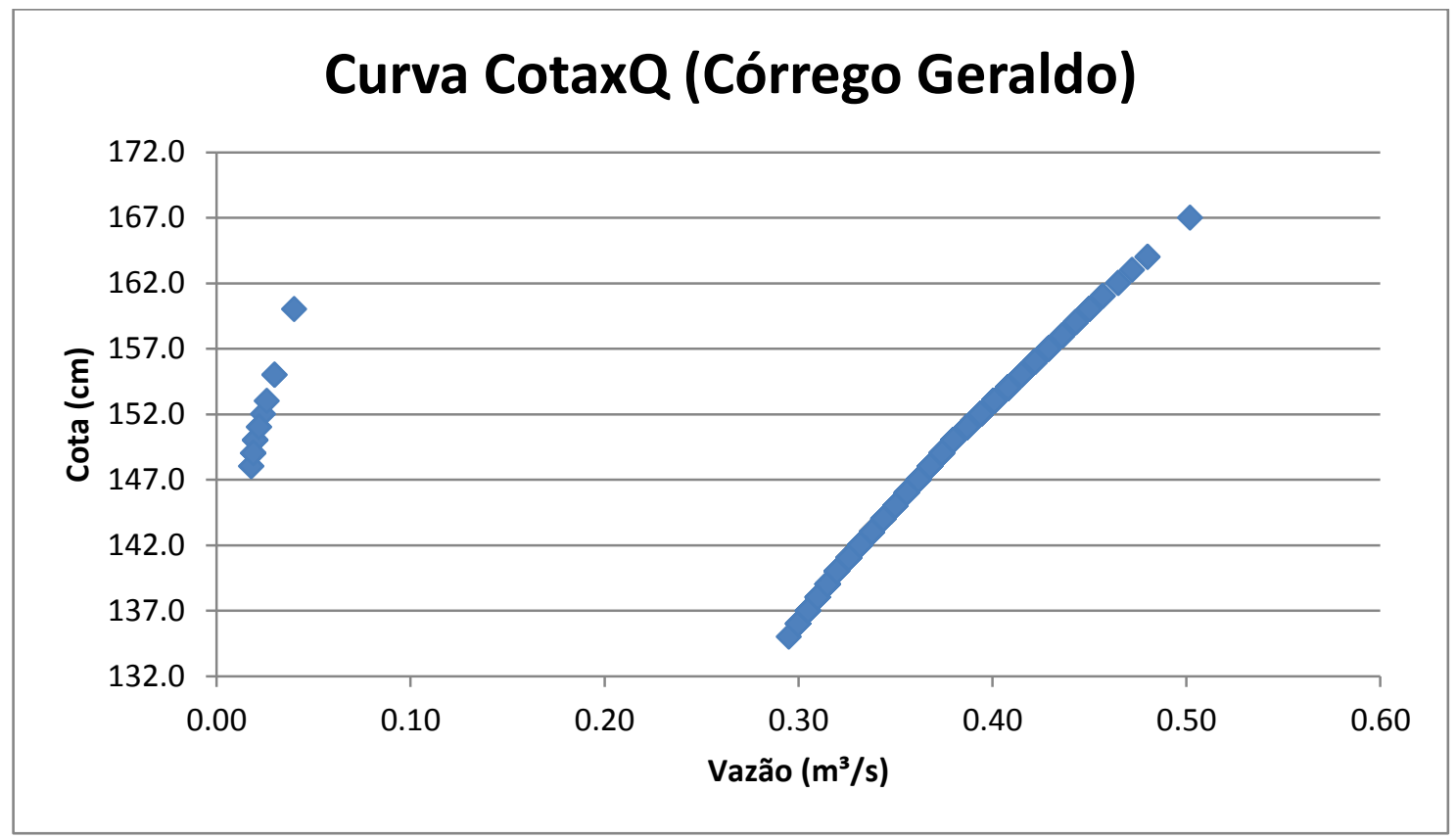

Gráfico 1 - Curva bruta cota x vazão para o Córrego do Geraldo.

Para resolver este problema, os dados da curva menor foram retirados da série histórica obtendo o novo Gráfico 2, com dados mais consistentes e a equação da curva CotaX Vazão.

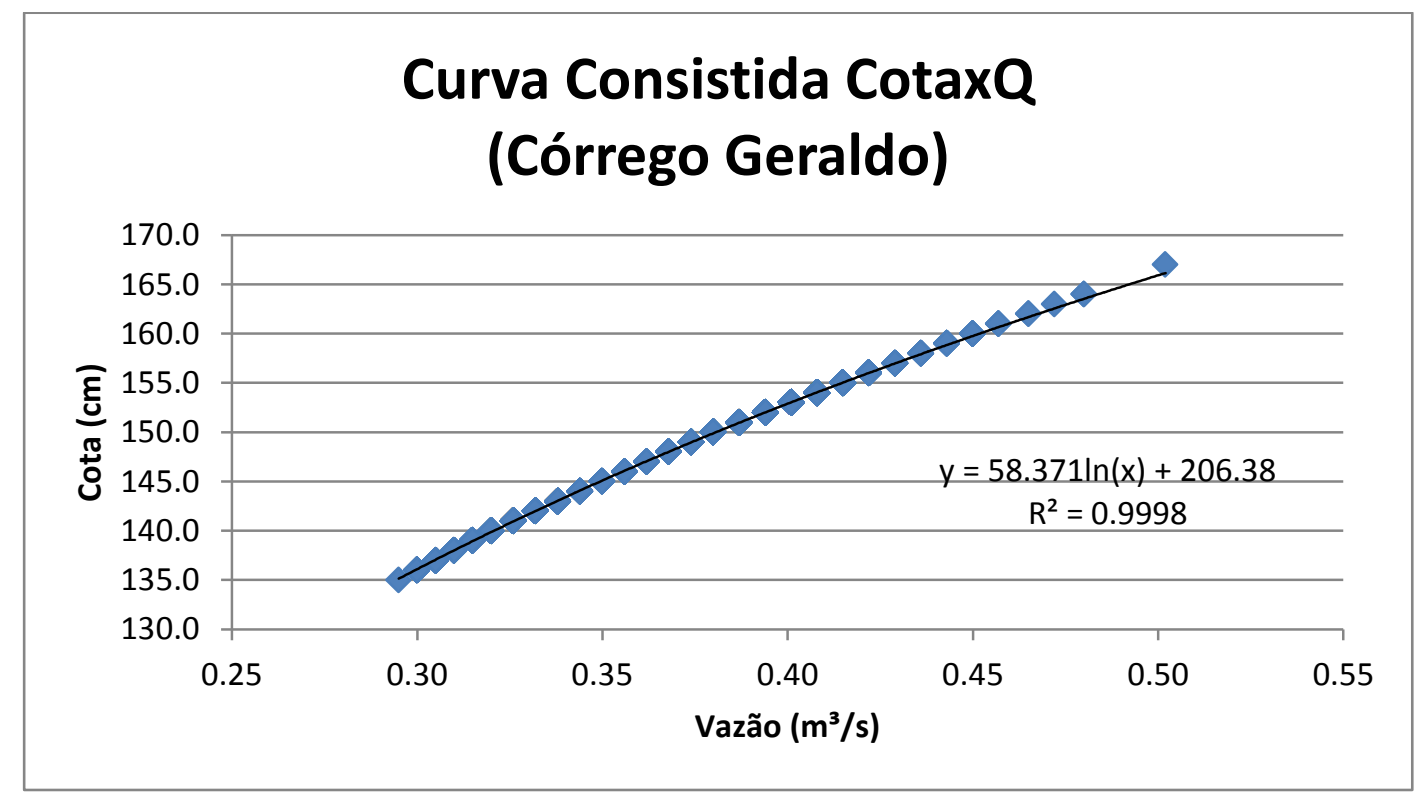

Gráfico 2 - Curva consistida CotaX Vazão para o Córrego Geraldo. 
A equação obtida foi:

$\operatorname{COTA}(\mathrm{cm})=58,371 \times \ln Q\left(\mathrm{~m}^{3} / \mathrm{s}\right)+206,38$

Utilizando a equação 2, estimou-se o valor de vazão a partir dos valores da cota da estação para o período de 1977 até 1985.

\section{Córrego das Perdizes}

Os dados disponíveis para o córrego das perdizes só estão disponíveis para o cenário 1 (1977-1985). Ao plotar um gráfico da dispersão dos dados de cota e vazão, obtemos o Gráfico 3, podemos obeservar que os dados fornecidos por esta estação, estão completamente dispersos, não sendo possível obter uma curva confíavel. Os dados de vazão e/ou de cota mostram-se inconsistentes, neste caso não foi possível fazer qualquer consistência de dados. 


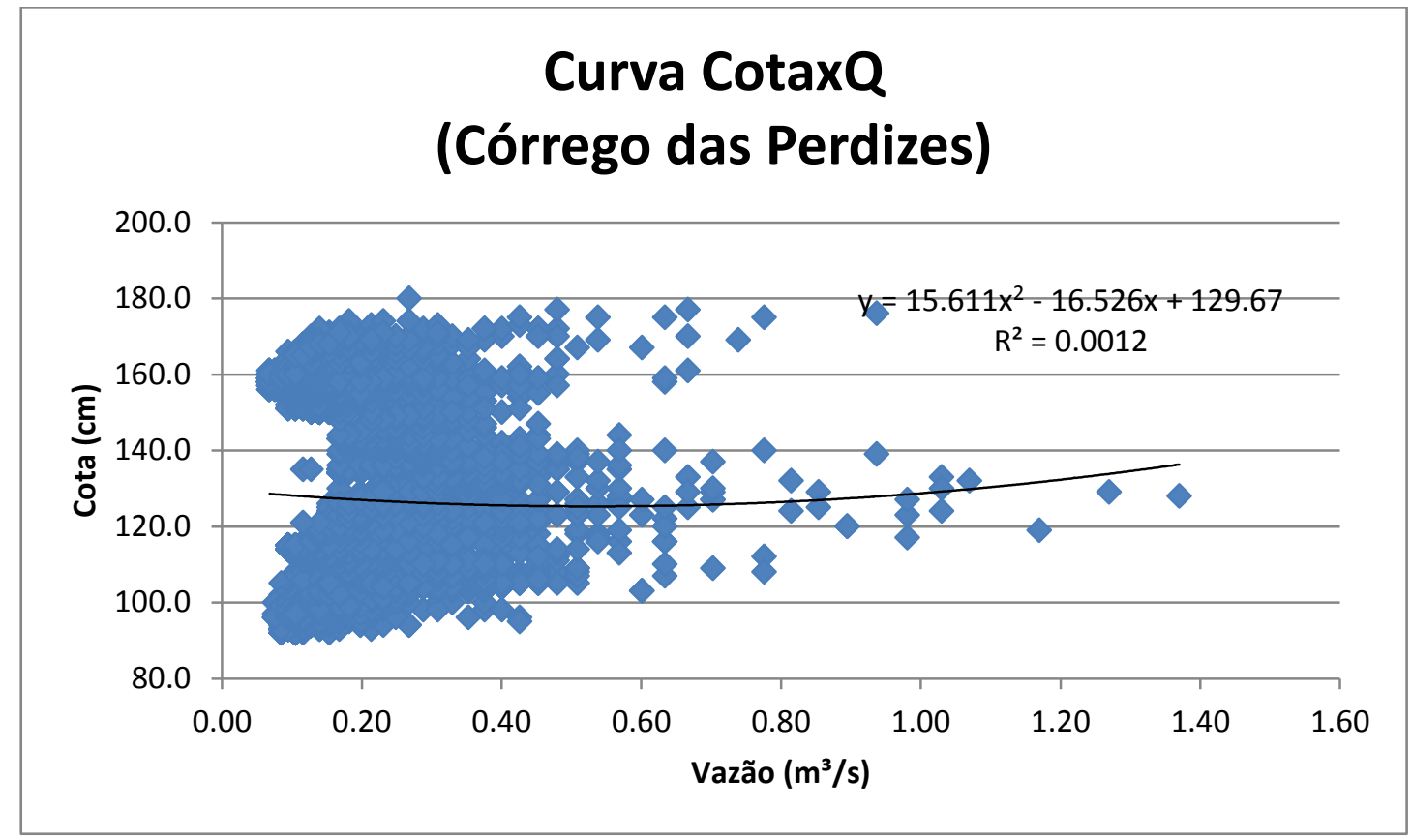

Gráfico 3 - Curva cota x vazão para o Córrego das Perdizes.

\section{Ribeirão do Lobo}

O Ribeirão do Lobo é de longe o tributário mais instrumentado e monitorado da bacia em questão apresentando séries de dados em três pontos diferentes do corpo de água para o Cenário de 1 (1977-1985 e de 2 pontos para o Cenário 2 (1996- 2006).

No Gráfico 4 abaixo estão apresentados a dispersão da série de dados históricos para a estação de monitoramento Jacaré-Açú 1. Os dados deste ponto estão disponíveis para os dois cenários de simulação. 


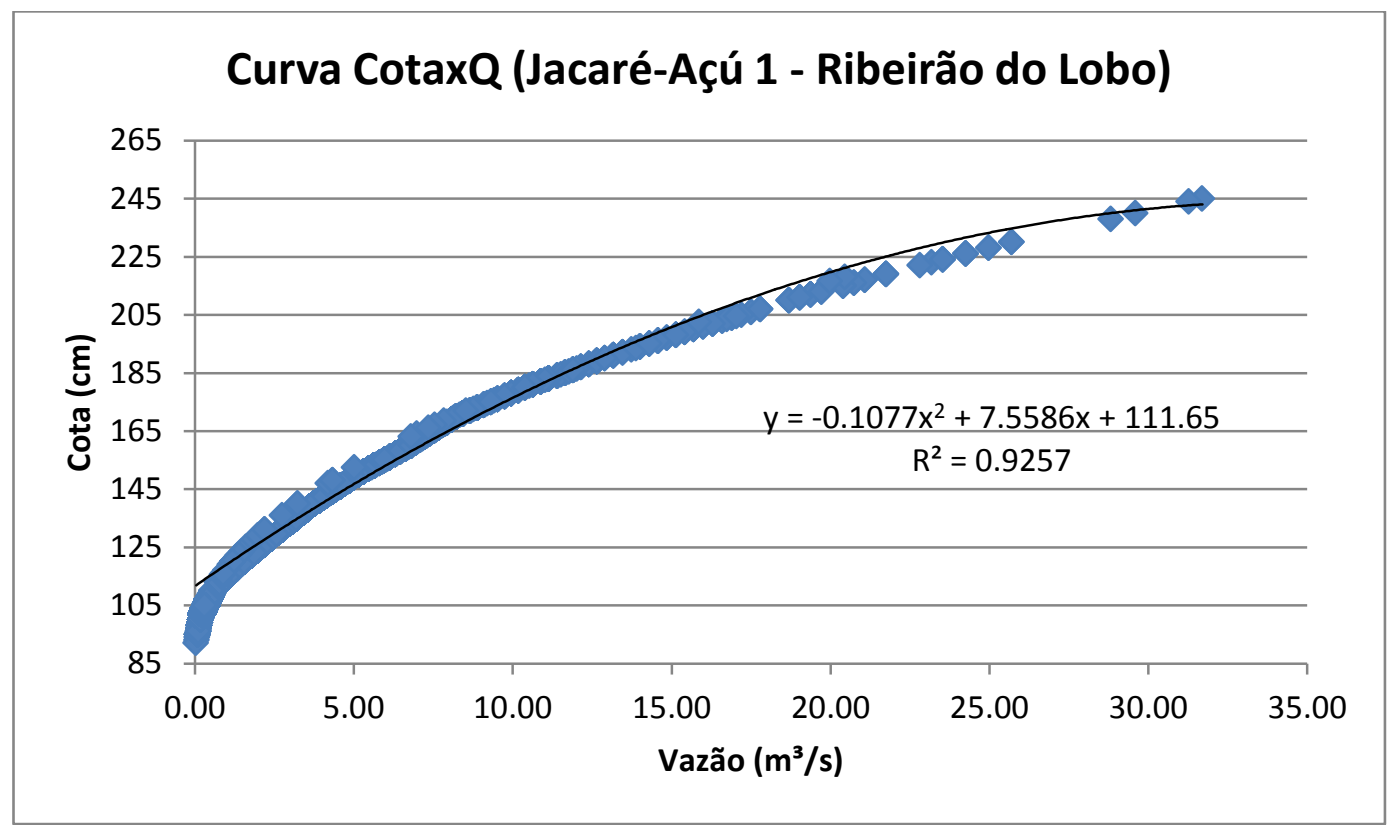

Gráfico 4 - Curva cota x vazão para a estação de monitoramento Jacaré-Açú 1 no Ribeirão do Lobo.

Outro ponto de monitoramento do Ribeirão do Feijão é a Estação Jacaré-Açú 2, está e a Estação Jacaré Açú 1 são as únicas estações que encontram-se em operação na bacia e também as únicas que possuiam série histórica de dados a serem usadas em ambos os cenários de simulação deste estudo. O Gráfico 5 foi obtido da dispersão de todos os dados de vazão e cota disponíveis, nele aparecem duas curvas indicando que há alguns dados discrepantes. 


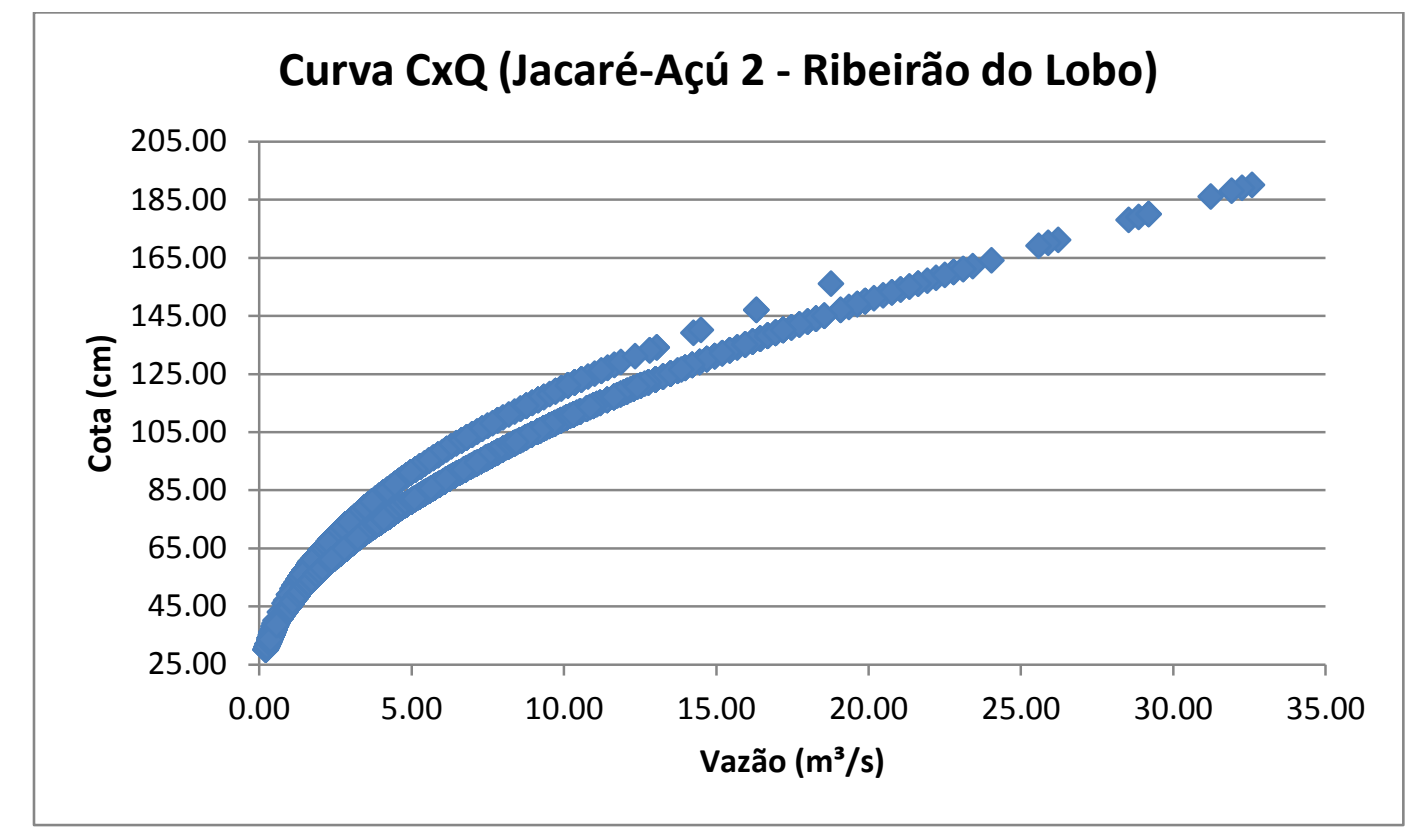

Gráfico 5- Curva bruta Cota x Vazão para a estação de monitoramento Jacaré-Açú 2 no Ribeirão do Lobo.

Após análise dos dados originais, retirou-se os dados inconsistentes que geravam a segunda curva menor, assim obteve-se o Gráfico 6, que mostra a curva consistida dos dados históricos da estação bem como a equação da curva cota vazão. 


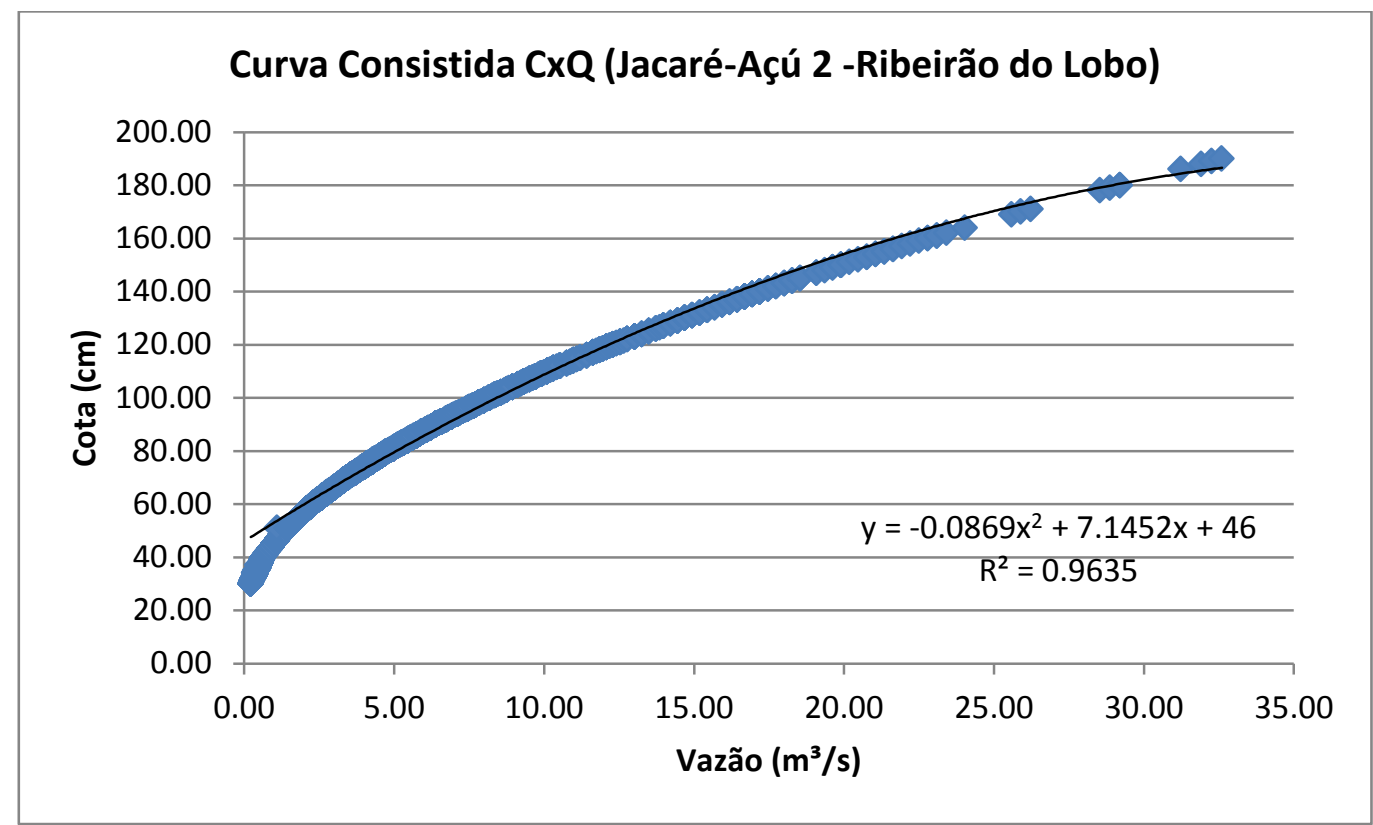

Gráfico 6 - Curva consistida Cota xVazão para a estação de monitoramento Jacaré-Açú 2 , localizada no Ribeirão d Lobo.

O último ponto de monitoramento de vazão do Ribeirão do Lobo é a estação Siriema, novamente obteve-se o Gráfico 7, a partir da dispersão de dados de vazão e cota históricos da estação. A estação que encontra-se desativada só possui uma série de dados para o cenério de simulação 1 (1977-1985). 


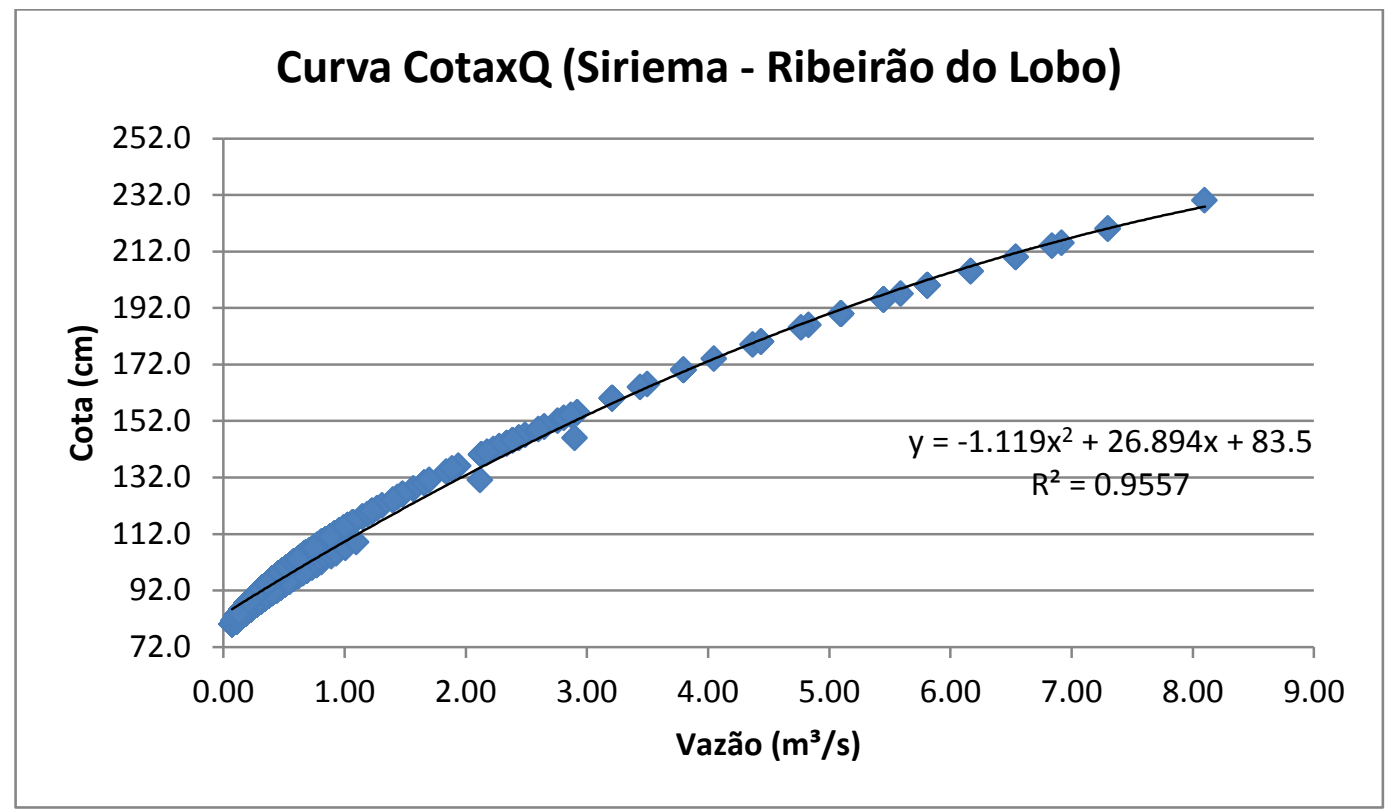

Gráfico 7 - Curva cota x vazão para a estação de monitoramento Siriema no Ribeirão do Lobo.

\section{Rio Itaqueri}

O Rio Itaqueri, que é um importante tributário do reservatório, só possui série histórica de dados de uma estação que encontra-se desativada. A dispersão dos dados gerou o Gráfico 8, assim como os dados da estação do córrego das perdizes, os dados desta estação são muito inconsistentes. A série disponível só possui dados para o cenário de simulação 1 (1977-1985). 


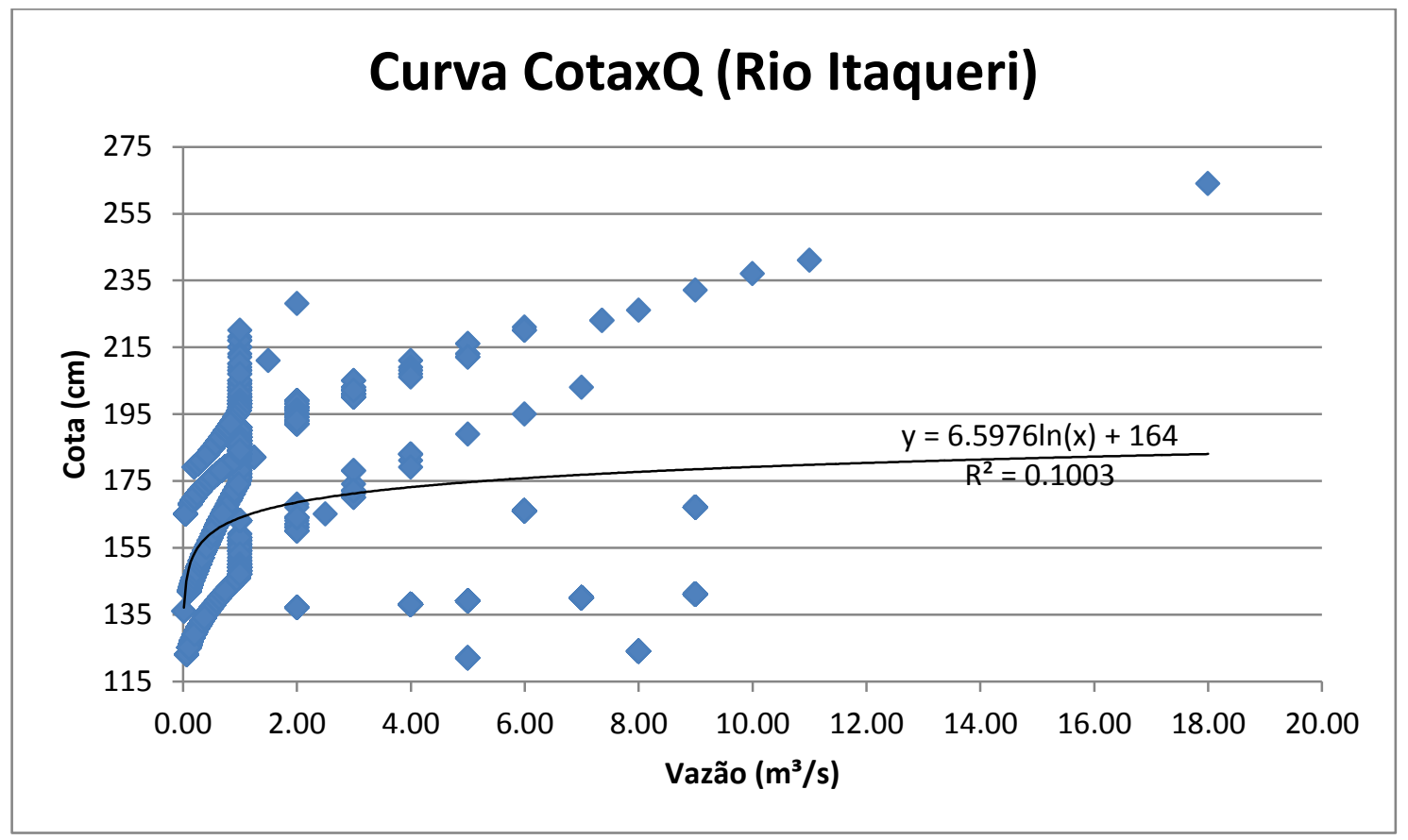

Gráfico 8 - Curva cota x vazão para o Rio Itaqueri.

\subsubsection{DADOS DE CLIMÁTICOS PARA A REGĨ̃O}

Como a série de dados disponíveis se apresentou muito fragmentada e incompleta foi necessário calcular alguns parâmetros de entrada para a construção de um gerador de dados climáticos para completar os dados que estavam faltando para a série de dados de chuva, irradiação solar, temperatura máxima e mínima da bacia. Para isto utilizou-se a série de dados histórica da estação climatológica do CRHEA para o período de 18/03/1977 até 28/02/2011.

Média da temperatura do ar máxima $\left({ }^{\circ} \mathrm{C}\right)$ :

$$
\mu \max , \text { mês }=\frac{\sum_{d=1}^{N} \operatorname{Tmax}, \operatorname{mê} s}{N}
$$


Aonde:

T Max,mês; Ttemperatura máxima para o mês $\left({ }^{\circ} \mathrm{C}\right)$;

N; Ttotal de meses observados;

Média da temperatura do ar mínima $\left({ }^{\circ} \mathrm{C}\right)$

$\mu$ míx, mês $=\frac{\sum_{d=1}^{N} T m i ́ n, m e ̂ s}{N}$

Aonde:

T Mín, mês; Temperatura mínima para o mês $\left({ }^{\circ} \mathrm{C}\right)$;

$N$; Total de meses observados;

Desvio-Padrão para a temperatura do ar máxima diária no mês

$\delta$ max, mes $=\sqrt{\left(\frac{\sum_{d=1}^{N}(\text { Tmax }, \text { mes }-\mu \text { max }, \text { mes })^{2}}{N-1}\right)}$

Aonde:

Tmax, mês; Registro Máximo de Temperatura para o mês;

$\mu$ max, mês; Média da temperatura máxima do Mês ${ }^{\circ} \mathrm{C}$;

$N ; N^{o}$ total de dias observados para um mês específico;

Desvio-Padrão para a temeperatura do ar mínima diária no mês

$\delta$ min, $m e s=\sqrt{\left(\frac{\sum_{d=1}^{N}(\text { Tmin }, \text { mes }-\mu \text { min }, \text { mes })^{2}}{N-1}\right)}$ 
Aonde:

Tmin, mês;Registro mínimo de Temperatura para o mês;

umin, mês; Média da temperatura mínima do Mês ${ }^{\circ} \mathrm{C}$;

$N$; $N^{o}$ total de dias observados para um mês específico;

\section{Precipitação Média para o mês (mm)}

$\overline{\mathrm{P}}=\frac{\sum_{d=1}^{N} \text { Pdia, } \text { mes }}{\text { Anos }}$

Aonde:

$\bar{P}$,Média mensal de precipitação para o mês $(\mathrm{mm})$;

Pdia,mês; preciptação diária para o mês;

N; Total de registro para o mês;

Anos; $N^{o}$ de anos com registros de precipitação diária;

\section{Desvio-Padrão para precipitação diária em um mês (mm/dia)}

$\delta$ mes $=\sqrt{\left(\frac{\sum_{d=1}^{N}(\text { Pdia }, m e s-\bar{P} m e s)^{2}}{N-1}\right)}$

Aonde:

Pdia,mês; Quantidade de precipitação para um dia em um mês (mm);

$\bar{P}$,Média mensal de precipitação para o mês $(\mathrm{mm})$;

N; Total de n] deobservações de precipitação diária; 
Coeficiente de Assimetria para a precipitação diária de um mês

Coef.Ass, $m e s=\frac{N \cdot \sum_{d=1}^{N}(\text { Pdia }, m e s-\bar{P} m e s)^{2}}{(N-1) \cdot(N-2) \cdot(\text { Smes })^{3}}$

Aonde:

$N ; N^{o}$ total de registros de precipitação para o mês;

Pdia,mês; Precipitação registrado para o dia no mês $(\mathrm{mm})$;

$\bar{P}$, Média mensal de precipitação para o mês $(\mathrm{mm})$;

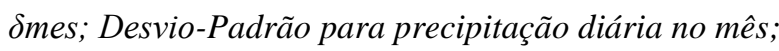

Probabilidade de um dia com preciptação seguido de um dia seco no mês

$P 1=\frac{\operatorname{Dias}_{D, i}^{m}}{\operatorname{Dias}_{\operatorname{secos}, i}}$

Aonde:

$\operatorname{Dias}_{D, i}^{m}$; O n ${ }^{o}$ de vezes que um dia com preciptação é seguido de um dia secano mês i para o período;

Dias $_{\text {Secos }, i} ; N^{o}$ de dias secos no mês i para todo o período;

Probabilidade de um dia molhado seguido de outro dia molhado para o mês

$P 2=\frac{\operatorname{Dias} m / m}{\operatorname{Dias} m}$

Aonde:

Dias $\mathrm{m} / \mathrm{m} ; \mathrm{N}^{o}$ de dias molhados seguidos de molhados para o mês no período; 
Dias $m ; N^{o}$ de dias molhados para o mês;

\section{Média diária de irradiação solar para o mês $\left(\mathrm{MJ} / \mathrm{m}^{2} /\right.$ dia $)$}

$\mu \mathrm{rad}, \mathrm{mês}=\frac{\sum_{d=1}^{N} \operatorname{Rad} \text { dia,mês }}{N}$

Aonde:

Rad dia,mês; Irradiação solar total diária para o dia no mês $\left(\mathrm{MJ} / \mathrm{m}^{2} / \mathrm{dia}\right)$;

$N$; $N^{o}$ total de observações de irradiação solar para o mês;

Do cálculo destes parâmetros para cada mês no intervalo, obteve-se a Tabela 13, cujos valores serviram para criação de um gerador de clima para as condições climáticas da região.

Tabela 13 - Parâmetros estatísticos climáticos da estação climatológica do CRHEA para o perído de 1977 até 2011.

\begin{tabular}{|c|c|c|c|c|c|c|c|c|c|c|c|}
\hline Mês & $\begin{array}{l}\text { Média de } \\
\text { chuva } \\
(\mathrm{mm})\end{array}$ & $\begin{array}{l}\text { Chuva } \\
\text { Desvio }\end{array}$ & Coef. Ass. & P1 & P2 & $\bar{P}$ & $\begin{array}{l}\text { Tmín } \\
\left({ }^{\circ} \mathrm{C}\right) \text { média }\end{array}$ & $\begin{array}{l}\text { T mín } \\
\text { Desvio }\end{array}$ & $\begin{array}{l}\text { T máx } \\
\left({ }^{\circ} \mathrm{C}\right) \\
\text { Média }\end{array}$ & $\begin{array}{l}\text { T máx } \\
\text { Desvio }\end{array}$ & $\begin{array}{l}\text { Radiação } \\
\text { média } \\
\text { (MJ/m²/dia) }\end{array}$ \\
\hline Jan & 287.21 & 122.99 & 0.93 & 0.39 & 0.73 & 20.84 & 17.51 & 3.60 & 28.87 & 4.20 & 17.76 \\
\hline Fev & 218.11 & 93.16 & 0.79 & 0.42 & 0.66 & 19.40 & 17.22 & 3.23 & 29.53 & 3.40 & 18.35 \\
\hline Mar & 156.49 & 79.53 & 1.21 & 0.34 & 0.55 & 14.85 & 16.88 & 3.86 & 29.17 & 3.82 & 17.23 \\
\hline Abr & 211.75 & 142.89 & -1.18 & 0.19 & 0.42 & 8.71 & 14.83 & 5.98 & 27.96 & 3.64 & 15.90 \\
\hline Mai & 68.13 & 49.60 & 1.37 & 0.16 & 0.43 & 7.73 & 11.58 & 5.92 & 25.35 & 4.12 & 12.41 \\
\hline Jun & 38.09 & 41.33 & 1.66 & 0.09 & 0.44 & 4.85 & 9.51 & 6.21 & 24.60 & 3.48 & 11.47 \\
\hline Jul & 29.03 & 34.74 & 2.25 & 0.08 & 0.46 & 4.34 & 9.29 & 6.69 & 24.96 & 6.19 & 12.26 \\
\hline Ago & 39.20 & 45.17 & 1.37 & 0.08 & 0.44 & 4.59 & 1.02 & 4.25 & 26.95 & 5.09 & 14.04 \\
\hline Set & 70.52 & 57.48 & 1.82 & 0.18 & 0.46 & 8.90 & 12.51 & 6.12 & 27.64 & 6.16 & 15.32 \\
\hline Nov & 114.24 & 62.28 & 1.08 & 0.23 & 0.52 & 11.34 & 14.28 & 5.46 & 28.97 & 5.17 & 17.46 \\
\hline Out & 154.12 & 69.15 & 0.56 & 0.32 & 0.54 & 14.40 & 15.57 & 5.35 & 29.35 & 6.94 & 19.53 \\
\hline Dez & 229.47 & 85.50 & 0.51 & 0.42 & 0.68 & 19.97 & 16.72 & 6.15 & 28.67 & 8.68 & 18.69 \\
\hline
\end{tabular}


Os Gráfico 9 abaixo mostrao comportamento climático calculado para o gerador de clima para irradiação solar e temperaturas máxima e mínima. Podemos ver que as temperaturas mais baixas se concentram entre os meses de julho e agosto apresentando acentuada queda nestes meses enquanto que os meses mais quentes são novembro e fevereiro. A radiação solar é maior no mês de novembro e menor em junho.

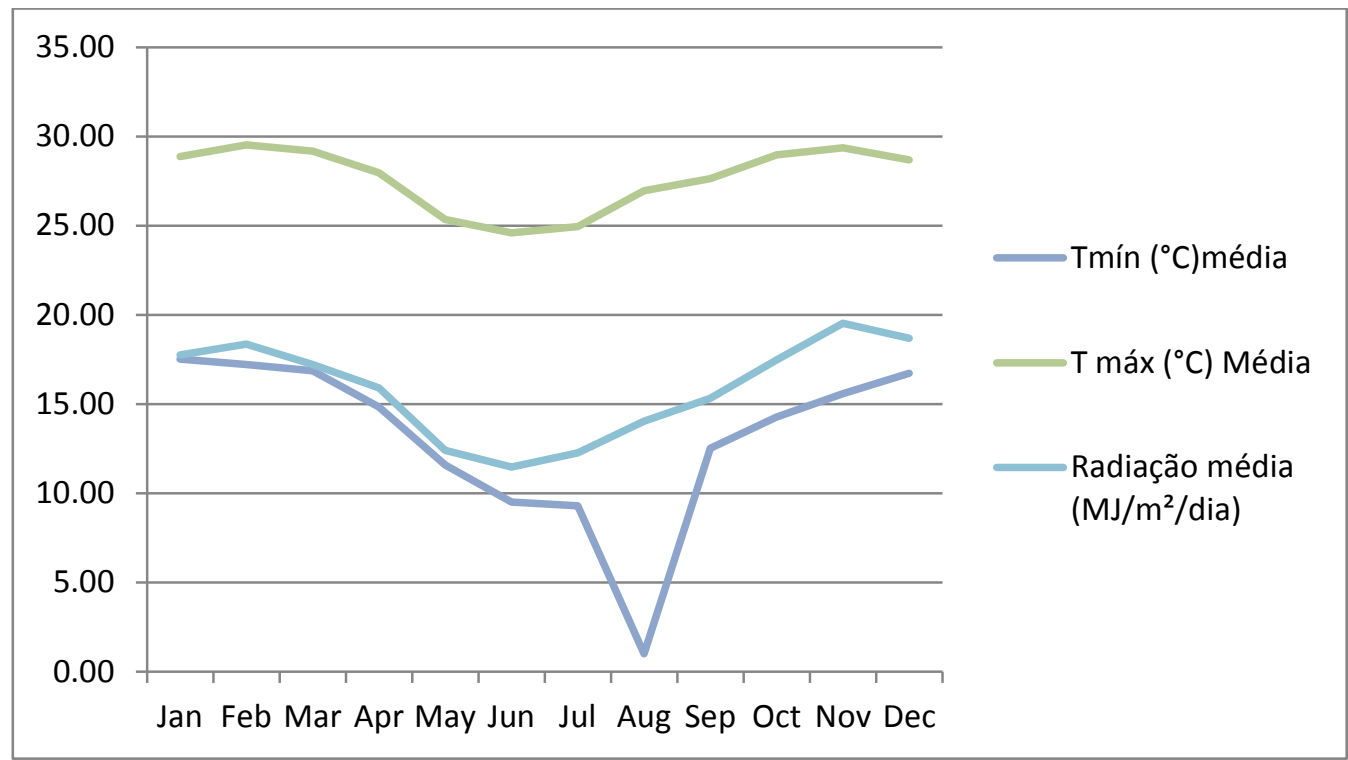

Gráfico 9 - Médias de Temperatura mínima, máxima e radiação solar mensal média para o período de 1977 até 2011.

O Gráfico 10 representa a curva da precipitação média mensal histórica, os meses com maior pluviosidade são janeiro e dezembro e os meses mais secos entre junho e julho. $\mathrm{O}$ gráfico mostra também um curioso comportamento para as chuvas na região entre os meses de março e abril ocorre um rápido aumento da pluviosidade antes de uma queda brusca dos meses mais secos do inverno. 


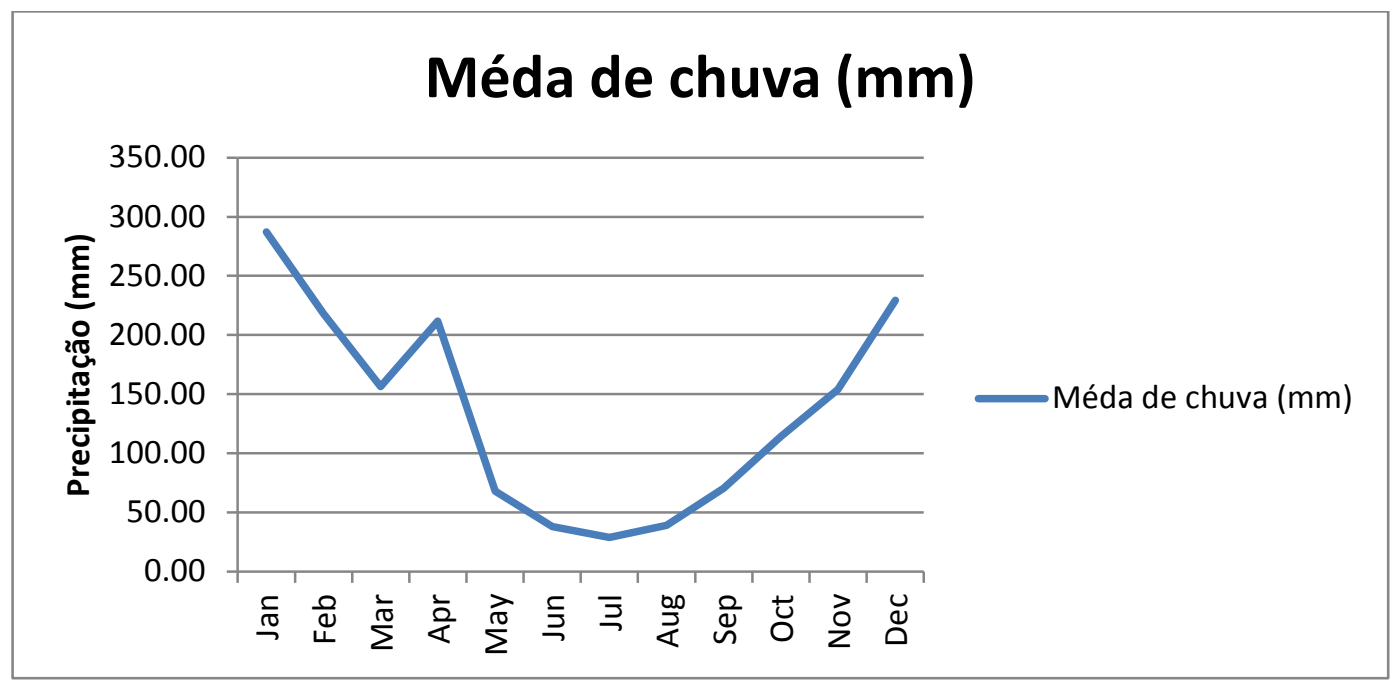

Gráfico 10 - Precipiração mensal média para o período de 1977 até 2011.

\subsection{CARTA DE USO E OCUPAÇÃO}

Foram utilizadas duas imagens de satélite para elaboração das cartas de uso e ocupação da bacia uma datada de 1984 e outra de 2010.

1984

O resultado da classificação não supervisionada seguida de revisão para imagens de satélite para imagens de 1984 podem ser conferidos na Figura 11. 


\section{Carta Uso e Ocupação (1984)}

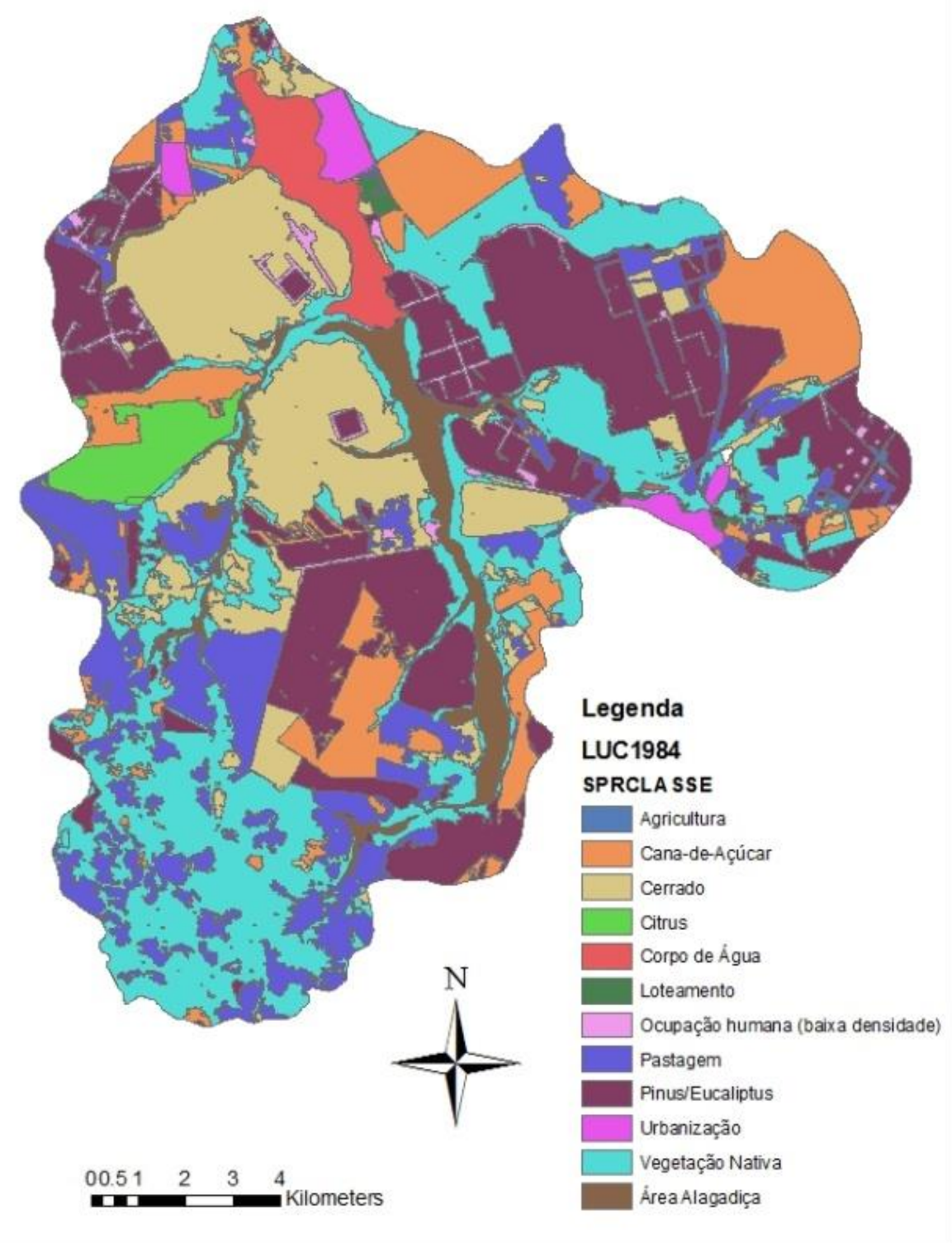

Figura 11 - Carta de Uso e Ocupação (1984). 
A Tabela 14.mostra a área ocupada por cada classe e a porcentagem das mesmas para a imagem de 1984.

Tabela 14 - Distribuição das classes de Uso e Ocupação do Solo para 1984.

\begin{tabular}{|c|c|c|}
\hline Classe & Área $\left(\mathbf{K m}^{2}\right)$ & $\mathbf{( \% )}$ \\
\hline Corpos de Água & 5.767774 & 2.54128 \\
\hline Áreas Alagadas & 7.726952 & 3.4045 \\
\hline Cerrado & 34.988796 & 15.4161 \\
\hline Cana-de-Açúcar & 26.077029 & 11.4896 \\
\hline Agricultura & 0.272022 & 0.11985 \\
\hline Citrus & 4.909526 & 2.16314 \\
\hline Loteamento & 0.58753 & 0.25887 \\
\hline Vegetação Nativa & 55.056568 & 24.258 \\
\hline Pastagem & 31.653808 & 13.9467 \\
\hline Pinus/Eucaliptus & 52.290153 & 23.0391 \\
\hline Ocupação Humana (baixa densidade) & 4.183686 & 1.84333 \\
\hline Urbanização & 3.449075 & 1.51966 \\
\hline
\end{tabular}

2010

O resultado da classificação não supervisionada seguida de revisão para imagens de satélite para imagens de 2010 podem ser conferidos na Figura 12. 


\section{Carta Uso e Ocupação (2010)}

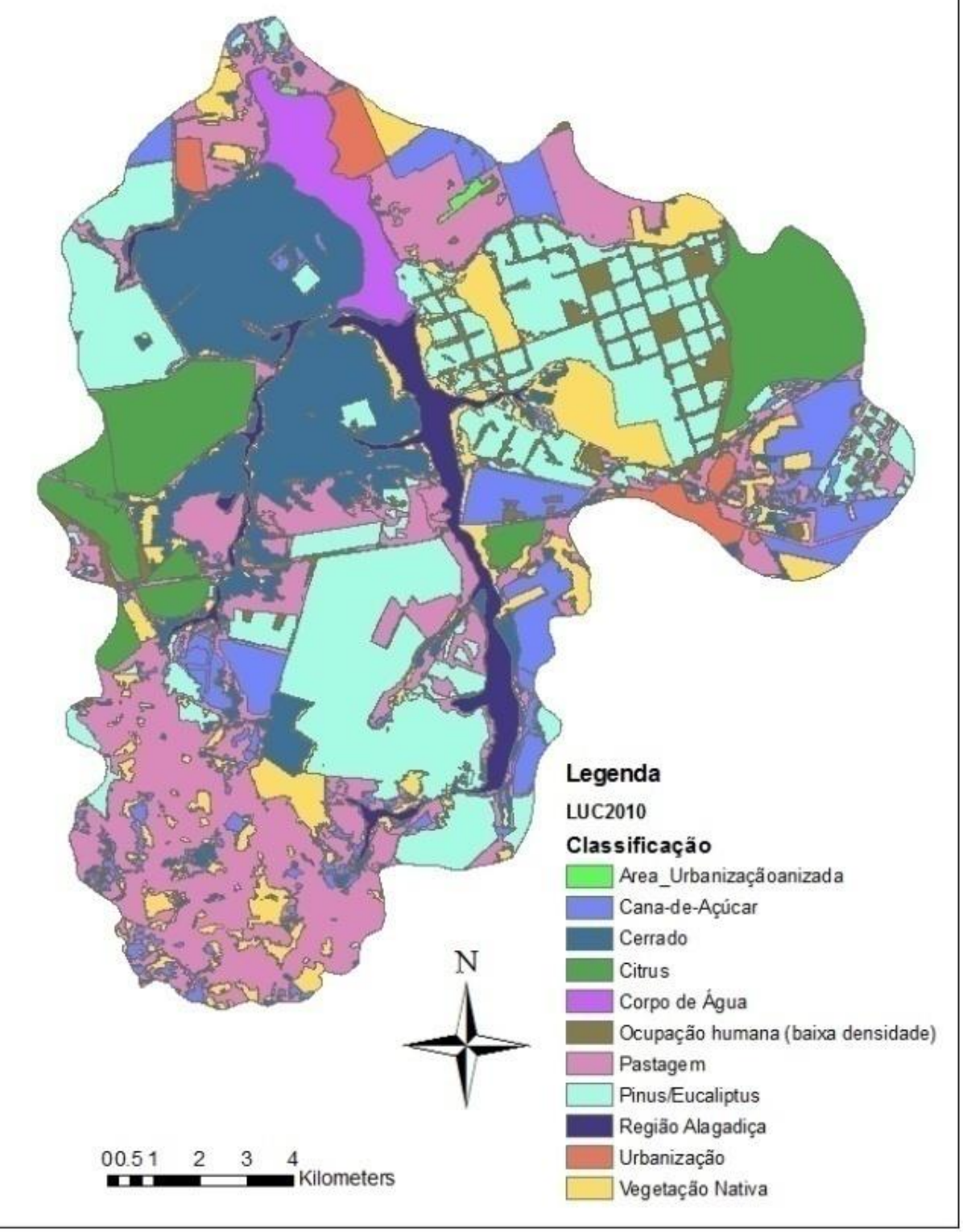

Figura 12 - Carta de Uso e Ocupação (2010). 
A Tabela 15, mostra a área ocupada por cada classe e a porcentagem das mesmas para a imagem de 2010 .

Tabela 15 - Distribuição das classes de Uso e Ocupação do Solo para 2010.

\begin{tabular}{|c|c|c|}
\hline Classe & Área $(\mathbf{k m 2})$ & $\mathbf{( \% )}$ \\
\hline Corpos de Água & 5.767774 & 2.54128 \\
\hline Áreas Alagadas & 7.726952 & 3.4045 \\
\hline Cerrado & 34.988796 & 15.4161 \\
\hline Cana-de-Açúcar & 26.077029 & 11.4896 \\
\hline Agricultura & 0.272022 & 0.11985 \\
\hline Citrus & 4.909526 & 2.16314 \\
\hline Loteamento & 0.58753 & 0.25887 \\
\hline Vegetação Nativa & 55.056568 & 24.258 \\
\hline Pastagem & 31.653808 & 13.9467 \\
\hline Pinus/Eucaliptus & 52.290153 & 23.0391 \\
\hline Ocupação Humana (baixa densidade) & 4.183686 & 1.84333 \\
\hline Urbanização & 3.449075 & 1.51966 \\
\hline
\end{tabular}

\subsection{CARTA PEDOLÓGICA}

De acordo com o mapemamento pedológico realizado em 1981, foram identificados as seguintes classes de solos na região estudada:Areias quartzosas (Aq), Latossoos Roxos (LR), Latossolo Vermelho Escuro (LE), Latossolo Vermelho-Amarelo (PV), Solos Litólicos (PL) Solos Hidromórficos e Terra Roxa Estruturada (TE).

No entanto para uma discretização no modelo é necessário a construção de um banco de dados específicos utilizando mais critérios e parâmetros, iniciando com uma conversão de classes para outras classificações pedológicas mais atualizadas. A conversão foi feita conforme a Tabela 16 
Tabela 16 - Conversão aproximada de classificações pedológicas.

\begin{tabular}{|c|c|c|c|}
\hline $\begin{array}{c}\text { Classificação } \\
\text { Levantaemnto } \\
\text { Pedológico Semi- } \\
\text { Detalhado do Estado } \\
\text { de São Paulo (1981) }\end{array}$ & $\begin{array}{l}\text { Sistema Brasileiro de } \\
\text { Classificação de Solos } \\
\text { (2005) }\end{array}$ & FAO & SOIL TAXONOMY \\
\hline Areias Quartzosas & Neossolos & Arenosols & Quartzipsamments \\
\hline Latossolos Roxos & Latossolos & Ferralsols & Oxisols \\
\hline $\begin{array}{c}\text { Latossolos Vermelho- } \\
\text { Amarelos }\end{array}$ & Latossolos & Ferralsols & Oxisols \\
\hline $\begin{array}{c}\text { Latossolos Vermelho } \\
\text { Escuros }\end{array}$ & Latossolos & Ferralsols & Oxisols \\
\hline $\begin{array}{c}\text { Podzólico Vermelho } \\
\text { Amarelo }\end{array}$ & Espodosssolos & Ferralsols & Oxisols \\
\hline Solos Hidromórficos & Gleissolos & Gleysols & Gleysols \\
\hline Solos Litólicos & Neossolos & Leptosols & $\begin{array}{c}\text { Lithic Othnets/Lithyc } \\
\text { Psamments }\end{array}$ \\
\hline Terra Roxa Estruturada & Nitossolos & $\begin{array}{c}\text { Nitosols, Lixisols, } \\
\text { Alisols }\end{array}$ & $\begin{array}{l}\text { Utisols, Oxisols } \\
\text { (Kandic). Alfisols }\end{array}$ \\
\hline
\end{tabular}

A construção do banco de dados levou em consideração a classificação de grupos hidrológicos para solos brasileiros que será mais detalhadamente discutido no próximo capítulo. Outra limitação identificada foi que a falta de dados acerca das camadas mais profundas dos perfis do solo da região foi necessário adotar uma generalização das mesmas como sendo homogêneas às das camadas mais superficiais. Os resultados da digitalização do Levantamento Pedodológico Semi-Detalhado do Estado de São Paulo de 1984 para a bacia (Figura 13). 


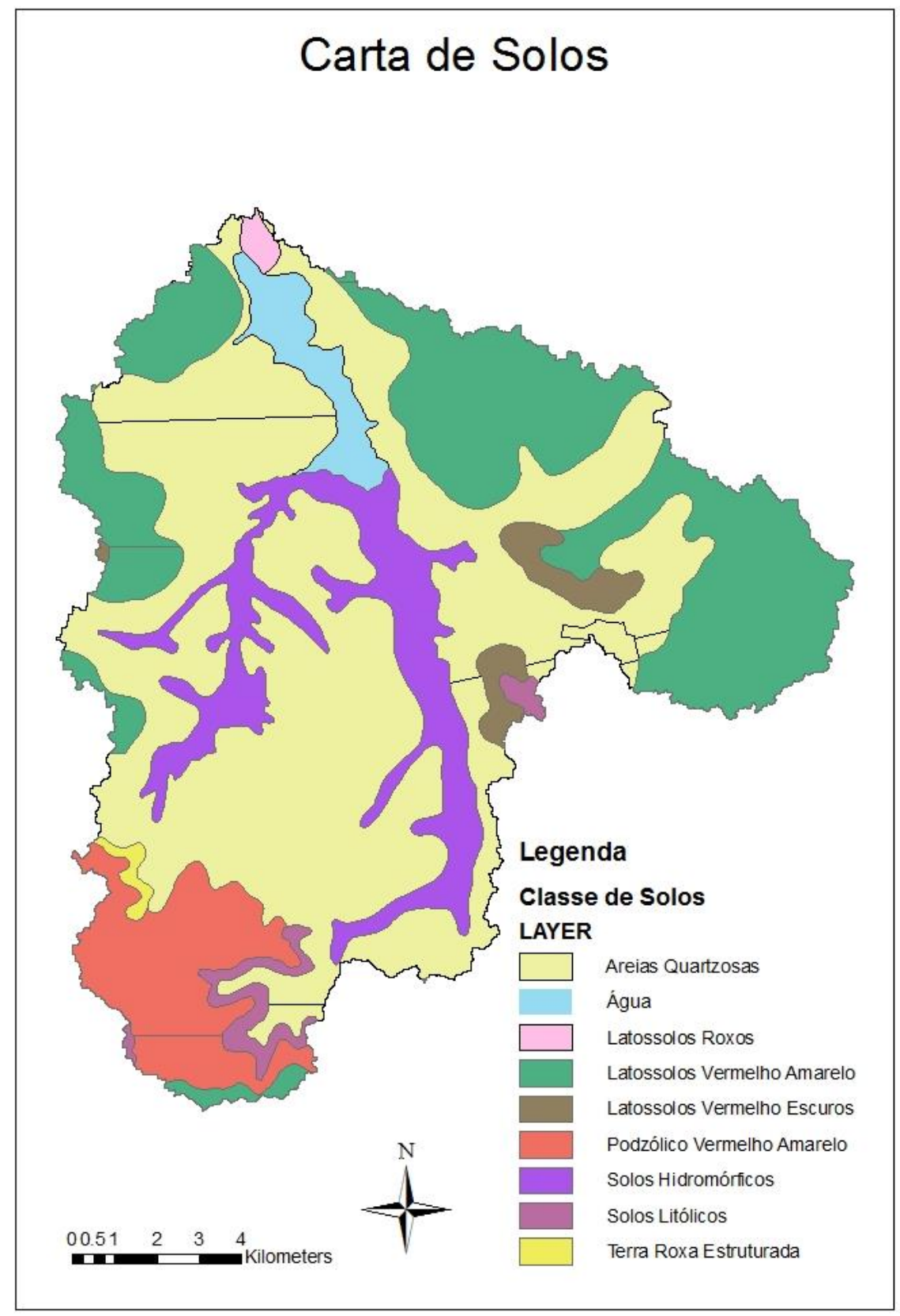

Figura 13 - Digitalização de Classes de Solo para a Bacia de Estudo. 
A seguir a Tabela 17 contendo as classes de solo da bacia bem como sua área e porcentagem de área, resultantes da digitalização do Levantamento Pedodológico SemiDetalhado do Estado de São Paulo de 1984 para a bacia.

Tabela 17 - Classes identificadas da digitalização do Levantamento Pedodológico SemiDetalhado do Estado de São Paulo de 1984 para a bacia.

\begin{tabular}{|c|c|c|}
\hline Classe & Área $\left.\mathbf{( k m}^{\mathbf{2}}\right)$ & $\mathbf{( \% )}$ \\
\hline Areias Quartzosas & 111.260325 & 52.44 \\
\hline Latossolo Vermelho Amarelo & 54.739377 & 25.8 \\
\hline Latossolo Vermelho Escuro & 4.822739 & 2.273 \\
\hline Água & 0.883088 & 0.416 \\
\hline Solos Litólicos & 3.6811 & 1.735 \\
\hline Podzólico Vermelho Amarelo & 17.0327 & 8.027 \\
\hline Solos Hidromórficos & 0.86869 & 0.409 \\
\hline Latossolo Roxo & 18.89352 & 8.904 \\
\hline
\end{tabular}

\section{OPERAÇÃO E COMPONENTES DO MODELO}

O SWAT é um modelo físico, com escala espacial de bacias hidrográficas, de escala temporal contínua e parâmetros distribuídos que utiliza informações espacialmente distribuídas de topografia, uso e ocupação do solo e de clima para modelação hidrológica e que opera em escala de tempo diária (ARNOLD et al., 1998 e FOHRER, 2005). Baseado na topografia, o modelo subdivide a bacia em um número de sub-bacias com intenção de simulação apenas. As sub-bacias delineadas dentro do modelo são simuladas como áreas homogêneas em relação às condições climáticas, as outras subdivisões são feitas dentro de cada sub-bacia para representar áreas homogêneas quanto suas características pedológicas, de uso e ocupação e de topografia. Estas novas áreas subdivididas são as chamadas HRUs (Hydrologi Response Units) ou unidades de resposta hidrológica. 
Os dados de entrada do modelo SWAT estão organizados para terem atributos espaciais. O modelo fornece três níveis espaciais: o de bacia hidrográfica, de sub-bacias e o de unidades de resposta hidrológicas ou HRUs. Para cada nível há um conjunto de parâmetros e dados de entrada para atribuição. O nível espacial maior, o de bacia hidrográfica, remete-se a toda área representada pelo modelo; o nível de sub-bacias remete-se às subdivisões da baciahidrográfica que são hidrologicamente conectadas. As sub-bacias são então subdivididas em HRUs, que são representação de áreas dentro das sub-bacias que apresentem características de solo, uso e ocupação do terreno e de declividades consideradas iguais.

Tanto as sub-bacias quanto as HRUs são definidas pelo usuário, ou seja, o usuário é quem define os parâmetros para tais subdivisões, fornecendo desta forma, algum controle sobre os resultados obtidos pelo modelo SWAT.

Muito embora o modelo utilize-se da escala diária para as simulações, existe a opção de utilizar outras escalas temporais nos resultados das simulações, como dados de saída são diária, mensal e anual. Os dados de saída são apresentados em arquivos no formato de texto e de banco de dados, nas categorias de volume de fluxo, taxa de produção de sedimentos, taxa de nutrientes e taxa de biomassa de plantas.

O modelo apresenta três grandes componentes, sub-bacias, reservatório e canais, cada um destes componentes apresenta diversos subcomponentes. Por exemplo, o componente subbacia consiste de oito subcomponentes: hidrologia, clima, sedimentação, umidade do solo, crescimento de culturas, manejo agrícola e pesticidas. O subcomponente Hidrologia é composto por: "runoff”, fluxo de subsuperfície lateral, percolação, fluxo de água subterrânea, derretimento de gelo, evapotranspiração, perdas de cargas e lagoas.

Para o balanço hídrico em cada HRU da bacia, são considerados quatro volumes de armazenamento: cobertura de neve, camada radicular $(0-2 \mathrm{~m})$, aqüífero raso $(2-20 \mathrm{~m})$ e 
aquíffero fundo (> $20 \mathrm{~m}$ ). A camada radicular pode ser subdividida em diversas camadas. Para o método de curva número SCS, o excesso de água disponível após a contabilização para as perdas iniciais e "runoff", infiltra no solo. Uma técnica para o cálculo da rota da água armazenada é simular o fluxo através de cada camada de solo. O modelo SWAT simula diretamente apenas o fluxo saturado, assumindo que a água está uniformemente distribuída dentro da camada em questão. O fluxo não-saturado entre as camadas é obtido indiretamente através de funções de evaporação do solo e da absorção da água pelas plantas. O fluxo descendente ocorre quando a camada de solo logo abaixo não se encontra saturada e a quantidade de água na camada de solo excede sua capacidade de campo, o fluxo descendente é induzido pela condutividade hidráulica saturada.

O fluxo lateral é simulado através de técnicas cinemáticas baseadas na declividade, comprimento do declive e condutividade saturada. O fluxo ascendente das camadas inferiores para as camadas superiores é regido pelas taxas de capacidade de campo entre as duas camadas. A percolação da parte inferior da zona radicular recarrega o aqüífero raso.

Para a simulação da produção de sedimentos, o SWAT utiliza-se da Equação Universal de Perda de Solos Modificada (WILLIAMS, 1995). Esta equação calcula a quantidade de solos erodida em um HRU que será transmitida em um canal da subbacia na qual está incluída.

\subsection{DADOS DE ENTRADA DO SWAT}

Os dados de entrada do SWAT são: A área de toda bacia hidrográfica, área da sub bacia hidrográfica, a unidade de resposta hidrológica ou (HRU), os reservatórios , descargas nos corpos de água, dados do solo (númerode camadas do perfil pedológico, grupo hidrológico, fração de porosidade, profundidade das camadas, capacidade de carga, 
condutividade hidráulica saturada, fator erobilidade K da EUPS etc..), dados climáticos (dados diários de precipitação, temperatura do ar, umidade relativa do ar e evapotranspiração), dados do número da curva de escoamento superficial $(\mathrm{CN})$ e informações referentes à cobertura do solo.

\subsection{DIVISÃO DE SUB-BACIAS}

O SWAT divide a bacia em sub-bacias e em seguida gera as HRU (Unidades de resposta hidrológica). Esta divisão é feita baseada nos usos e ocupações do solo e nas informações do solo (tipos pedológicos e declividade). O SWAT permite também especificar os critérios de distribuição destas HRU, sendo possível optar por dois tipos de distribuição uma única HRU ou HRUs múltiplas para a sub-bacia.

\subsection{ESCOAMENTO SUPERFICAL “RUNOFF”}

Para o cálculo do escoamento superficial "runoff”, o modelo SWAT possui duas rotinas: utilizando a metodologia de Curva Número ou SCS-CN ("Soil Conservation Service Curve Number") ou através do método de infiltração Green \& Ampt, sendo que a metodologia padrão do modelo é a Curva Número. A maior limitação desta metodologia é que ela não considera eventos de pico de chuva ou a duração dos eventos, ele parte da premissa que a chuva total diária está diluída em suas 24 horas. Já o método Green-Ampt é um modelo baseado na escala temporal, podendo representar impactos da intensidade de chuvas e a duração dos processos de infiltração, que podem representar fenômenos muito importantes se tratando dos latossolos encontrados no estado de São Paulo, caracterizados por seus perfis fundos e relativamente homogêneos. 


\section{Curva Número}

A Curva Número, CN é uma técnica para cálculo de "runoff" desenvolvida pelo Serviço de Conservação de Solos do Departamento de Agricultura dos Estados Unidos na década de 50. O método passou por diversas revisões desde sua implementação.

Ela é uma técnica consolidada e simples de ser utilizada. $\mathrm{O}$ valor da $\mathrm{CN}$ varia de 1 a 100 sendo este valor em função das seguintes variáveis: padrão hidrológico do solo; uso e manejo da terra; condições da superfície do solo; e umidade antecedente. Sendo que quando o CN é igual a 100 o "runoff" seria igual à chuva total e quando o $\mathrm{CN}$ for igual a 1 não há "runoff".

O modelo Curva Número foi desenvolvido pelo USDA na década de 1950, o modelo passou por mais de 20 anos de estudo e pesquisa. O uso do $\mathrm{CN}$ é bastante simplificado, sendo uma função que relaciona precipitação, permeabilidade do solo, uso e ocupação do solo e capacidade de campo inicial do solo.

A classificação original de grupos hidrológicos de solos grupamento hidrologico do SCS ("Soil Conservation Service") foca principalmente na textura do solo. A profundidade e as características das camadas mais profundas são brevemente discutidas. Algumas destas características, que não são contempladas nesta classificação original, são importantes para avaliar a gênese do escoamento superficial. O que se observa na prática é uma dificuldade de enquadrar os solos tropicais brasileiros dentro desta classificação de grupos hidrológicos de solos original proposta pelo SCS. Uma generalização que pode ser adotada como tentativa de se obter alguma compatibilidade para aplicar o método é o de considerar apenas as camadas superiores do solo, ignorando as camadas mais profundas. 
Sartori (2004), três classificações foram propostas para grupamento hidrológico de solos para o estado de São Paulo Setzer \& Porto $^{2}$, (1979 apud Sartori, 2004a), Lombardi Neto et $a l^{3}$, (1989 apud Sartori, 2004a) e Kutner et al ${ }^{4}$ (2001 apud Sartori, 2004a). No entanto em meios práticos a proposta de Lombardi Neto et al (1989) se mostra a mais parecida com a classificação original e mais fácil de ser aplicada, as outra metodologias apresentam complicações que limitam sua aplicação e uma compatibilidade total.

Sartori, op cit, afirma ainda que a classificação de Lombardi Neto op cit é mais minuciosa que a classificação original abrangendo profundidade, textura, gradiente, razão textural dentro dos horizontes subsuperficiais e superficiais, porosidade do solo e atividade de argila expansiva. No entanto, esta classificação adota alguns critérios controversos considerando alguns solos argilosos nos grupos A e B (baixo escoamento superficial) e classificando alguns solos arenosos nos grupos C e D (alto escoamento superficial). Na Tabela 18, abaixo estão representados a classificação proposta por Lombardi Neto et al (1989)

${ }^{2}$ Setzer, J; Porto, R.L.L. 1979. Tentativa de avaliação do escoamento superficail de acordo com o solo e sue recebimento vegetal nas condições do Estado de São Paulo. Boletim Técnico DAEE. 2(2):.81-104. São Paulo.

${ }^{3}$ Lombardi Neto,F.; Bellinazzi Júnior, R.; Galeti, P. A.; Bertolini,D.; Lepsch, I.F.; Oliveira, J.B. 1989.Nova abordagem para cálculo de espaçamento entre terraços. In Simpósio sobre terraceamento agrícola. Campinas. Fundação Cargill. P.99-124

${ }^{4}$ Kutner, A.S.; Conte, A.E.; Nitta, T. 2001. Análise geológica e caracterização dos solos para avaliação do coeficiente de escoamento superficial na bacia do Alto Tietê. In: XIV Simpósio Brasileiro de Recursos Hídricos, Aracajú-SE. 
Tabela 18 - Grupamento de Solos segundo sua qualidades, características e resistência à erosão (Lombardi Neto et al $^{5}$. 1989 apud Sartori, 2005a ).

\begin{tabular}{|c|c|c|c|c|c|c|c|}
\hline \multirow[b]{2}{*}{ Grupo } & \multirow{2}{*}{$\begin{array}{l}\text { Grupo de } \\
\text { resistência à } \\
\text { erosão }\end{array}$} & \multicolumn{5}{|c|}{ Principais Características } & \multirow[b]{2}{*}{$\begin{array}{c}\text { Índice } \\
\text { K }\end{array}$} \\
\hline & & Profundidade & Permeabilidade & Textura & $\begin{array}{c}\text { Razão } \\
\text { Textural } \\
\text { (1) }\end{array}$ & $\begin{array}{l}\text { Grandes } \\
\text { Grupos de } \\
\text { Solo (4) }\end{array}$ & \\
\hline A & Alto & $\begin{array}{l}\text { Muito profundo } \\
\qquad(>2 \mathrm{~m}) \text { ou } \\
\text { profundo( } 1 \text { to } \\
2 \mathrm{~m})\end{array}$ & $\begin{array}{l}\text { Rápida/Rápida } \\
\text { Moderada/Rápida }\end{array}$ & $\begin{array}{c}\text { Média/media } \\
\text { Muito argilosa/Muito } \\
\text { argilosa }\end{array}$ & $<1,2$ & $\begin{array}{l}\text { LR,LE, LV, } \\
\text { LVr, LVt, LH } \\
\text { LEa and LVa }\end{array}$ & 1,25 \\
\hline B & Moderado & $\begin{array}{l}\text { Profundo (1 to } \\
\qquad 2 \mathrm{~m})\end{array}$ & $\begin{array}{c}\text { Rápida/Rápida } \\
\text { Moderada/Rápida } \\
\text { Moderada/Moderada }\end{array}$ & $\begin{array}{l}\text { Arenosa/Arenosa } \\
\text { Arenosa/Média } \\
\text { Arenosa/Argilosa } \\
\text { Média/ Argilosa } \\
\text { Argilosa/Muito } \\
\text { Argilosa }\end{array}$ & $1,2-1,5$ & $\begin{array}{l}\text { LJ, LVP, PV, } \\
\text { PVL, Pln, TE, } \\
\text { PVls, R, RPV, } \\
\text { RLV, LEa(3) } \\
\text { and LVa(3) }\end{array}$ & 1,1 \\
\hline $\mathrm{C}$ & Baixo & $\begin{array}{l}\text { Profunod (1 to } \\
\qquad 2 \mathrm{~m}) \text { ou } \\
\text { moderadamento } \\
\text { profundo }(0,5 \\
\text { to } 0,1 \mathrm{~m})\end{array}$ & $\begin{array}{l}\text { Lenta/Rápida } \\
\text { Lenta/Moderada } \\
\text { Rápida/Moderada }\end{array}$ & $\begin{array}{l}\text { Arenosa/Média } \\
\text { Média/Argilos } \\
\text { Arenosa/Argilosa } \\
\text { Arenosa/Muito } \\
\text { Argilosa }\end{array}$ & $>1,5$ & $\begin{array}{c}\text { Pml, PVp, } \\
\text { PVIs, Pc and } \\
\text { M }\end{array}$ & 0,9 \\
\hline $\mathrm{D}$ & Muito Baixo & $\begin{array}{l}\text { Moderadamente } \\
\text { profundo }(0,5 \\
\text { to } 0,1 \mathrm{~m}) \text { ou } \\
\text { raso }(0,25 \text { to } \\
0,50 \mathrm{~m})\end{array}$ & $\begin{array}{l}\text { Rápida, Moderada } \\
\text { ou Lenta sobre } \\
\text { Lenta }\end{array}$ & Muito vairável & $\begin{array}{c}\text { Muito } \\
\text { Vairável }\end{array}$ & $\begin{array}{l}\text { Li-b, Li-ag, gr, } \\
\text { Li-fi, Li-ac } \\
\text { and PVp } \\
\text { (shallow) }\end{array}$ & 0,75 \\
\hline
\end{tabular}

${ }^{(1)}$ : Média da porcentagem de argila do horizonte B sobre media da porcentagem de argila de todo horizonte A..

(2): Somente com mudança textural abrupta entre os horizonte A e B.

(3): Somente aqueles com horizonte A arenoso.

(4): Legendsa Segundo Brasil (1960).

${ }^{5}$ Lombardi Neto,F.; Bellinazzi Júnior, R.; Galeti, P. A.; Bertolini,D.; Lepsch, I.F.; Oliveira, J.B. 1989.Nova abordagem para cálculo de espaçamento entre terraços. In Simpósio sobre terraceamento agrícola. Campinas. Fundação Cargill. P.99-124 
Sartori (2004) e Sartori et al (2005b) compararam o escoamento superfical obtido utilizando a classificação acima em uma bacia hidrográfica dentro do estado de São Paulo e observando uma tendência geral de subestimar os valores observados. Em geral a adaptação para as condições brasileiras se mostrou mais consistente, porém é enfatizado que tal classificação não é otimizada e pode ser melhorada.

Em um estudo usando o SWAT em Benin, país africano de clima temperado, o modelo apresentou uma superestimação da descarga líquida total utilizando o método original SCS (Hiepe, 2008). Isto é atribuído a picos, para o qual o modelo respondeu de maneira insatisfatória. Este estudo encontrou através da análise de sensibilidade que as medidas médias diárias da descarga líquida e de produção de sedimentos utilizando o a metodologia SCS foi de longe o parâmetro mais sensível, assim confirmando a alta sensibilidade do modelo a mudanças nos parâmetros de Curva Número.

\section{Método de Infiltração Green \& Ampt}

Esta abordagem alternativa do modelo para estimar o escoamento superficial parte da hipótese de um perfil de solo homogêneo e de uma umidade uniformemente homogênea nas camadas de solo. Conforme a água infiltra no perfil de solo o modelo considera que a porção do solo acima da frente de molhamento está completamente saturada e que há uma ruptura acentuada da umidade nesta frente.

Este método, no entanto, permite simular eventos de intensa precipitação, que são característicos das regiões tropicais, porém há um comprometimento de informação devido às 
equações de regressão que são necessárias para parametrizar o modelo (Wilcox et $a 1^{6}, 1990$ apud King et al, 1999).

Esta abordagem, no entanto requer dados horários de chuva. King et al (1999) constatou que a utilização da equação Green \& Ampt no lugar da metodologia padrão Curva Número, não acarretou em uma melhoria significativa dos resuldos do SWAT. Ao se modelar grandes bacias hidrográficas, deve-se levar em consideração a meta geral para escolha do procedimento para excedente de precipitações. Conforme a área de drenagem aumenta, os picos de vazão tendem a ser atenuados e os benefícios do uso do Green \& Ampt se tornam ineficazes.

\subsection{BALANÇO HÍDRICO}

O balanço hídrico,que é uma consideração primária do modelo para cada HRU “Hidrologic Response Units”, está representada conforme em (Arnold et al., 1998).

$$
S W_{t}=S W+\sum_{i=1}^{t}\left(R_{t}-Q_{i}-E T_{i}-P_{i}-Q R_{i}\right)
$$

Onde SW (mm) é o conteúdo de água no solo, i é o tempo em dias para o período de simulação t (dias), e R (mm) a precipitação diária, Q (mm) escoamento superficial ou “runoff', ET é a evapotranspiração, P a percolação (mm) e QR (mm) o fluxo de retorno. Os processos descritos na equação estão ilustrados na Figura 14 abaixo.

${ }^{6}$ Wilcox, B.P.;RAWL,W.J.; BRAKENSIEK, D.L.; WRIGHT, J.R.. 1990. Predicting runoff from rangeland catchments: A comparison of two models. Water resources research, 26 (10): 2401-2410. 


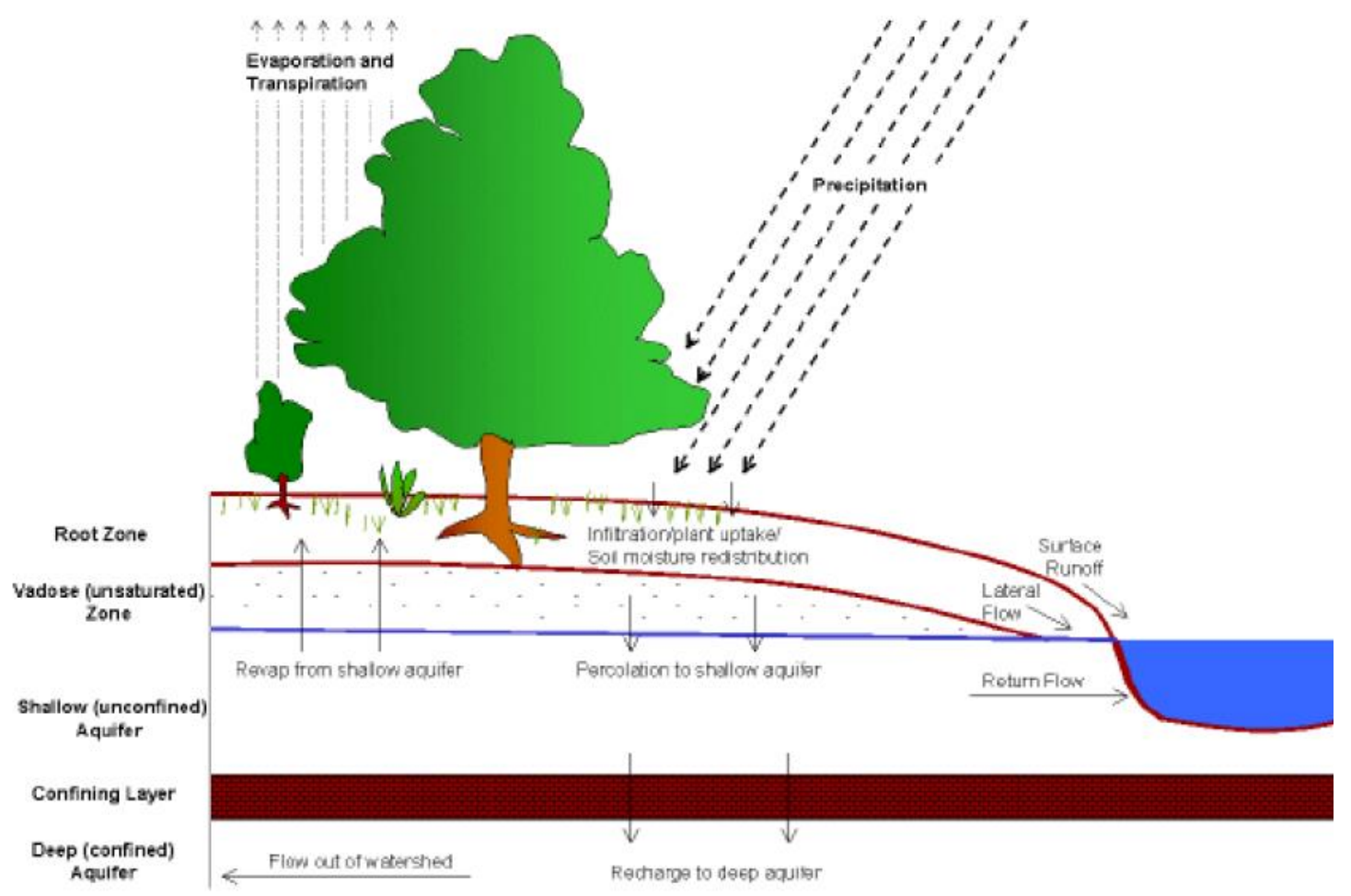

Figura 14 - Ciclo Hidrológico considerado pelo modelo SWAT (NEITSCH et al., 2001).

Os dados de água entram nos limites do sistema do modelo de bacia hidrográfica do SWAT, predominantemente na forma de precipitação. Os dados de entrada de precipitação para os cálculos hidrológicos podem ser dados medidos, ou dados simulados pelo gerador de clima disponível dentro do modelo SWAT. A precipitação é particionada em diferentes cursos de água, dependendo das características do sistema. O balanço hídrico de cada HRU na bacia contém quatro volumes de armazenamento: neve, perfil do solo (0-2 m), o aqüífero raso (2-20 m) e do aqüífero profundo (> $20 \mathrm{~m}$ ). O perfil de solo pode estar sub-dividido em várias camadas. Os processos de água no solo incluem infiltração, percolação, evaporação, absorção pelas plantas, e fluxo lateral. O escoamento superficial "runoff" é estimado utilizando o número da curva SCS ou a equação de infiltração Green-Ampt. (ARNOLD et al., 1998). 
As cargas do fluxo de sedimentos, nutrientes, pesticidas e bactérias dos planaltos para o canal principal são feitas pelas redes de fluxo da bacia. A corrente de processos modelados pelo SWAT é mostrada na Figura 15.

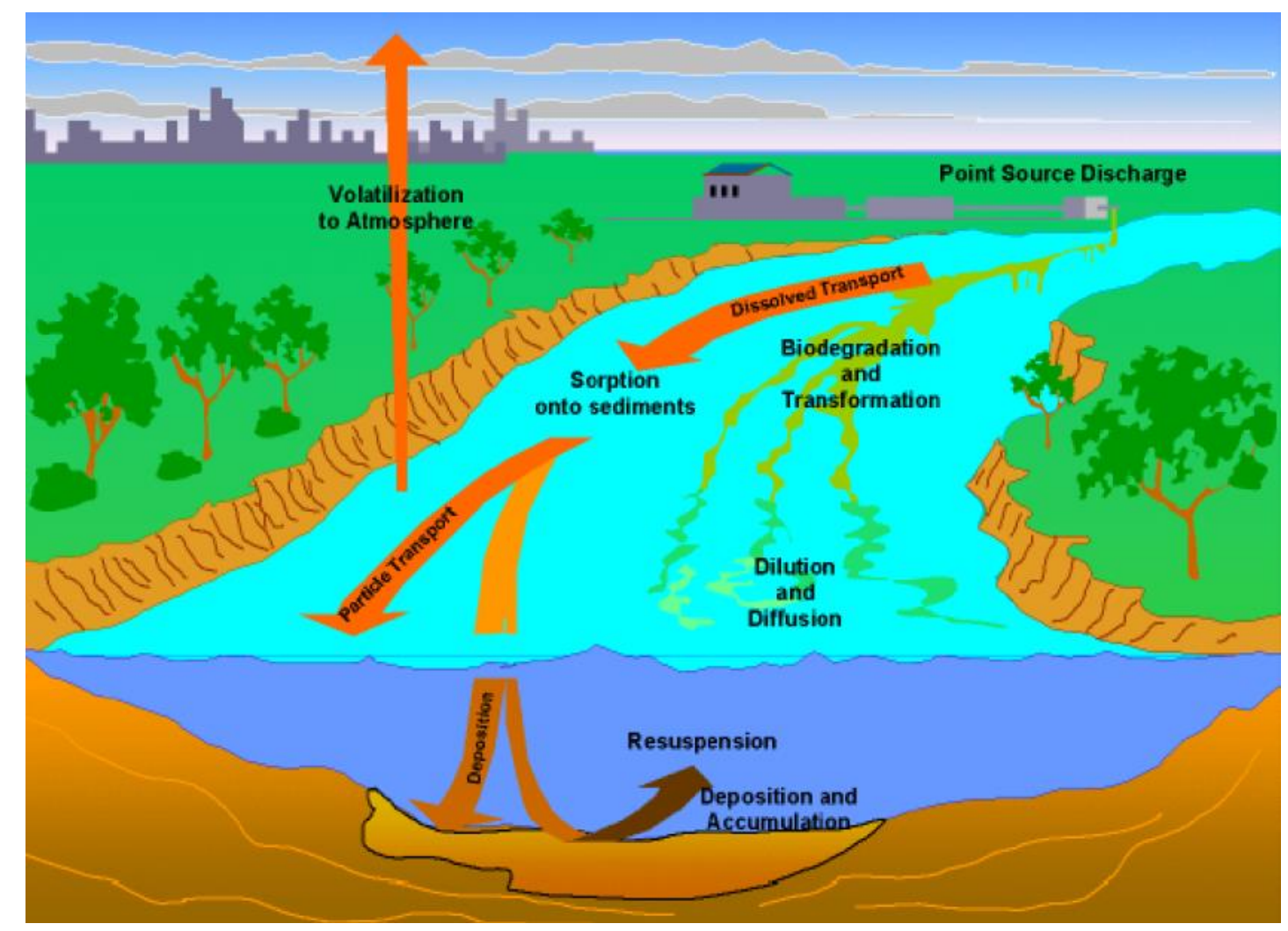

Figura 15 - Processos ecológico considerado pelo modelo SWAT (NEITSCH et al., 2001).

\subsection{BALANÇO DE SEDIMENTOS}

A rotina utilizada pelo modelo para simular a erosão de uma bacia utiliza a Equação Universal de Perda de Solos Modificada (EUPSM) ou "Modified Universal Soil Loss Equation" (MUSLE). Esta equação estima a produção de sedimentos Sed (ton) a partir do volume do escoamento superficial $(\mathrm{mm})$, do pico da taxa de escoamento superficial $\left(\mathrm{m}^{3} / \mathrm{s}\right)$, da área da HRU (ha), utiliza também parâmetros da Equação Universal de Perda de Solos (EUPS) ou "Universal Soil Loss Equation" (USLE) desenvolvida por WISCHMEIER \& 
SMITH (1978): K erodibilidade do solo, C de cobertura e manejo do solo, $\mathrm{P}$ de práticas conservacionistas e LS parâmetro referente à topografia. A fórmula do MUSLE é dada abaixo:

$$
\text { Sed }=11,8 \times\left(Q_{\text {surf }} \times q_{\text {peak }} \times \text { area }_{H R U}\right)^{0,56} \times K_{U S L E} \times C_{U S L E} \times P_{U S L E} \times L S_{U S L E}
$$

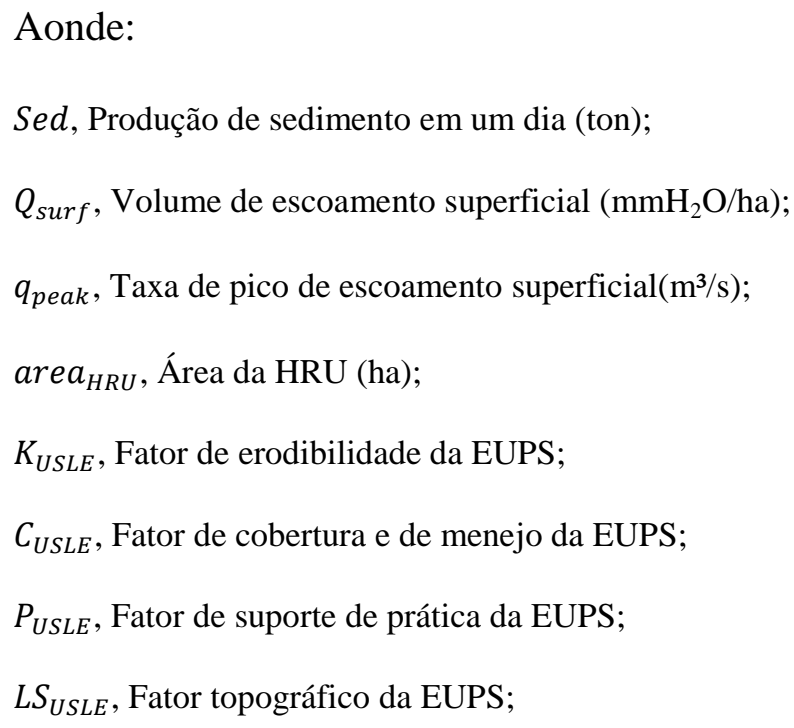

Segundo o manual do modelo (NEITSCH et al.,2001), após a produção de sedimento ser avaliada através da equação MUSLE, o SWAT corrige esse valor posteriormente considerando efeitos relacionados a neve e retardamentos e atrasos dos sedimentos devido ao escoamento superficial. O modelo calcula também a contribuição de sedimento para canais de fluxo a partir de fontes subterrâneas e laterais. Os sedimentos erodidos, que entram nestes canais, são simulados como sendo transportados a jusante pela deposição e degradação 


\subsection{CALIBRAÇÃO}

Para melhor eficiência do modelo SWAT, que é semi-empírico, é necessário comparar os dados gerados por ele com os observados. Através da análise de sensibilidade é possível determinar quais variáveis são mais importantes para o modelo local, ou seja, quais variáveis influenciam mais os resultados. Esta etapa tem como objetivo minimizar as diferenças entre o observado e resultados do modelo através do ajuste dos parâmetros do modelo.

Esta etapa de calibração do modelo possui três etapas principais, a de calibração, a de validação e de verificação. A calibração como já dito seria o ajuste dos valores estimados através do teste dos dados de entrada e saída, a validação seria a etapa onde os resultados do modelo seriam comparados sem que houvesse o ajuste e a verificação seria o estudo da técnica numérica para assegurar que esta representa realmente o modelo conceitual.

A calibração e validação do modelo é o processo de avaliação e teste de diferentes parâmetros do modelo, a fim de refinar, melhorar e aumentar a confiabilidade das estimativas do modelo de forma que permitam um melhor julgamento para as tomadas de decisões.

O processo de validação a ser utilizado, para que haja uma precisão satisfatória, é o “Split Sample Test Method" (XU, 1999). Neste método, a série temporal é dividida em três: aquecimento do modelo, calibração e validação. O aquecimento do modelo, geralmente no começo da série temporal dos dados, é usado para iniciar condições para subseqüentes simulações. O procedimento de calibração, é a etapa aonde os parâmetros mais sensíveis são ajustados para otimizar os resultados das simulações. Já a validação envolve a aplicação do modelo calibrado sem qualquer alteração por outro período temporal. Nesta etapa, espera-se que o modelo responda com a mesma precisão do período de calibração. Caso isto ocorra o desempenho do modelo estará validado e apto ser utilizada para simulações daí por diante. 
A fidelidade das simulações com a realidade é aferida através da comparação dos dados hidrográficos simulados com os observados. Esta comparação é possível tanto por funções objetivas (WILLMOTT, 1981, NASH e SUTCLIFFE 1970) ou obtida graficamente, por exemplo comparando os gráficos de picos de vazões simuladas com os gráficos de vazão observados.

Os testes mais utilizados para a calibração são por tentativa e erro, o método automático para estimativa de parâmetros ou uma combinação dos dois.

\subsection{SWAT-CUP}

O SWAT CUP é um sotware que serve para calibração e avaliação de incertezas das simulações do SWAT, este programa gratuito utiliza procedimentos GLUE (Generalized Likelihood Uncertainty Estimation), ParaSol (Parameter Solution), SUFI2 (Sequential Uncetainty Fitting) e MCMC (Markov Chain Monte Carlo) para realizar análise de sensibilidade, calibração, validação e análise de incertezas.

\section{GLUE}

O método GLUE (Beven e Binley,1992) é um procedimento simples que assume que não existe um conjunto único de parâmetros que otimiza o critério de adequação. Baseada em estimação de pesos ou probabilidades associadas para diferentes conjuntos de parâmetros baseados no uso de uma medida subjetiva de versossimilhança para derivar a saída de dados. Utilizando uma abordagem bayesiana de estimativa estatística, necessita de suposições acerca da estrutura estatística dos erros. 


\section{PARASOL}

Outra abordagem para calibração de van Griensven e Meixner (2006) é o método Parasol que agrega funções objetivas dentro de um critério de otimização global, sendo estas funções objetivas e estes critérios minimizados através do Shuffle-Complex (SCE-UA). O SCE é um algoritmo de busca global para minimização para uma função, combinando o procedimento de busca do Simplex com um de busca aleatória controlada.

\section{MCMC}

Este é outro método de calibração, validação e análise de incertezas que utiliza estatística bayesiana e densidade de probabilidade para eleger, testar, rejeitar conjuntos de parâmetros para adequação da função objetiva.

\section{SUFI2}

Neste método de Abbaspour et al (2007) a incerteza dos parâmetros é levada em consideração para todas possíveis origens: modelo conceitual, parâmetros e valores observados. Neste modelo, a calibração ocorre através de uma sistemática seleção de intervalos de valores de parâmetros que são testados a cada interação a fim de estreitar este intervalo até um intervalo de dados para um intervalo de confiança.

A distribuição dos processos que afetam os dados de entrada se manifesta com de saída contendo erros, os quais não se podem medir diretamente por estarem embutidos nos dados de entrada, portanto seria uma medida incerteza. Então estas incertezas geradas pelos erros são 
estimadas através da porção de dados entre a faixa defina pelo $P$-factor, porcentagem de valores obtidos entre uma faixa de 95\% de incertezas (95PPU), previstos pelo modelo podem servem para avaliar nossa análise de incertezas.

O 95PPU é calculado através dos níveis de 2,5\% e 97,5\% de distribuição cumulativa de uma variável de saída, que são obtidas através de amostragem por hipercubo latino, rejeitando 5\% das simulações insatisfatórias.

Outra maneira para medir o grau de eficiência da calibração é o Rfactor,definido como espessura média da faixa 95PPU dividida pelo desvio médio dos dados observados. Desta forma o algoritmo tenta enquadrar os dados medidos para uma faixa mais estreita possível. Esta largura do 95PPU é estreitada por etapas. A cada etapa o intervalo de parâmetros é atualizado, após serem calculados por uma matriz de sensibilidade, seguidos por uma matriz de covariância, intervalos de confiança dos parâmetros de $95 \%$ e matriz de correlação. Então estes valores são atualizados de forma que o intervalo de dados fique sempre menor que o anterior.

$\mathrm{O}$ valor do Pfactor varia entre 0 e $100 \%$ e o do $R$-factor entre 0 e $\infty$. Assim um Pfactor com valor 1 e um $R$-factor de valor 0 corresponde a uma simulação que corresponde exatamente ao valor medido. O modelo não busca a melhor simulação, mas um intervalo final de parâmetros. No caso de não haver uma solução, em outras palavras, quando os valores simulados não coincidem com um 95PPU, então a origem do problema pode ser que não seja originada dos parâmetros e sim do modelo conceitual. A Tabela 19 abaixo descreve as etapas do SUFI-2. 
Tabela 19 - Sumário de estatísticas comparando diferenetes procedimentos de calibração de incertezas (Abbaspour, 2008 - modificado).

\begin{tabular}{|c|c|c|c|c|c|}
\hline \multicolumn{2}{|c|}{ Critério } & GLUE & ParaSol & SUFI-2 & МСMC \\
\hline \multicolumn{2}{|c|}{ Função Objetiva } & Nash-Sutcliffe & Nash-Sutcliffe & Nash-Sutcliffe & $\begin{array}{c}\text { Probabilidade de } \\
\text { densidade }\end{array}$ \\
\hline \multicolumn{2}{|c|}{ 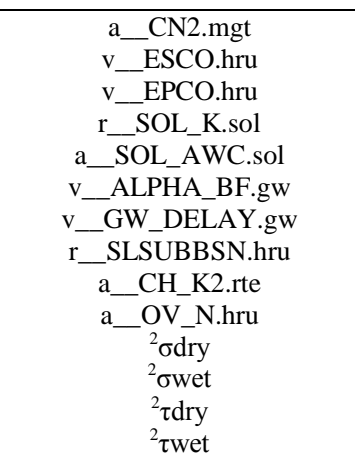 } & $\begin{array}{c}-16.8(-29.6,-9.8)^{1} \\
0.76(0.02,0.97) \\
0.22(0.04,0.90) \\
-0.16(-0.36,0.78) \\
0.11(0.01,0.15) \\
0.12(0.06,0.97) \\
159.58(9.7,289.3) \\
-0.45(-0.56,0.46) \\
78.19(6.0,144.8) \\
0.05(0.00,0.20) \\
- \\
- \\
- \\
-\end{array}$ & $\begin{array}{c}-21.0(-21.9,-20.1) \\
0.67(0.65,0.69) \\
0.16(0.13,0.20) \\
-0.37(-0.41,-0.34) \\
0.07(0.08,0.08) \\
0.12(0.08,0.13) \\
107.7(91.2,115.2) \\
-0.59(-0.60,-0.58) \\
35.70(27.72,37.67) \\
0.11(0.07,0.10) \\
- \\
- \\
- \\
-\end{array}$ & $\begin{array}{c}-26.9(-30.0,-7.2) \\
0.82(0.43,1.0) \\
1(0.34,1.0) \\
-0.1(-0.58,0.34) \\
0.07(0.05,0.15) \\
0.51(0.23,0.74) \\
190.07(100.2,300) \\
-0.52(-0.60,0.03) \\
83.95(69.4,150.0) \\
0.06(0.00,0.11) \\
- \\
- \\
- \\
-\end{array}$ & $\begin{array}{c}-14.2(-16.8,-11.6) \\
0.74(0.63,0.75) \\
0.94(0.39,0.98) \\
-0.29(-0.31,0.78) \\
0.12(0.1,0.13) \\
0.14(0.11,0.15) \\
25.5(17.8,33.3) \\
-0.55(-0.56,0.15) \\
78.3(68.0,86.2) \\
0.12(0.00,0.19) \\
0.93(0.81,1.10) \\
2.81(2.4,3.9) \\
38.13(29.5,53.8) \\
3.42(2.4,8.0)\end{array}$ \\
\hline Calibração & $\begin{array}{c}\mathrm{NS} \\
\mathrm{R}^{2} \\
\operatorname{LogPDF}\end{array}$ & $\begin{array}{c}79 \\
0,65 \%\end{array}$ & $\begin{array}{l}18 \% \\
0,08\end{array}$ & $84 \%$ & $\begin{array}{l}85 \% \\
1,47\end{array}$ \\
\hline Validação & $\begin{array}{c}\mathrm{NS} \\
\mathrm{R}^{2} \\
\text { LogPDF }\end{array}$ & $\begin{array}{l}69 \% \\
0,51\end{array}$ & $\begin{array}{l}20 \% \\
0,07\end{array}$ & 1,03 & $\begin{array}{l}84 \% \\
1,19\end{array}$ \\
\hline Calibração & $\begin{array}{l}{ }^{3} P \text {-factor } \\
{ }^{4} d \text {-factor }\end{array}$ & $\begin{array}{l}79 \% \\
0,65\end{array}$ & $\begin{array}{l}18 \% \\
0,08\end{array}$ & $\begin{array}{l}84 \% \\
1,03\end{array}$ & $\begin{array}{l}85 \% \\
1,47\end{array}$ \\
\hline Validação & $\begin{array}{l}{ }^{3} P \text {-factor } \\
{ }^{4} d \text {-factor }\end{array}$ & $\begin{array}{l}69 \% \\
0,51\end{array}$ & $\begin{array}{l}20 \% \\
0,07\end{array}$ & $\begin{array}{l}82 \% \\
0,82\end{array}$ & $\begin{array}{l}84 \% \\
1,19\end{array}$ \\
\hline $\begin{array}{l}\text { Incertezas } \\
\text { Incertezas c }\end{array}$ & $\begin{array}{l}\text { scritas por } \\
\text { parãmetros }\end{array}$ & $\begin{array}{l}\text { Todos Tipos de } \\
\text { incertezas }\end{array}$ & $\begin{array}{l}\text { Incertezas de } \\
\text { parâmetros } \\
\text { Somente }\end{array}$ & $\begin{array}{l}\text { Todos Tipos de } \\
\text { incertezas }\end{array}$ & $\begin{array}{c}\text { Incertezas de } \\
\text { parâmetros } \\
\text { Somente }\end{array}$ \\
\hline Dificuldad & le apliação & Muito Fácil & Fácil & Fácil & Mais complicado \\
\hline $\mathrm{N}^{\circ}$ de $\mathrm{l}$ & rações & 10000 & 7500 & $1500+1500$ & $5000+20000+20000$ \\
\hline
\end{tabular}

${ }^{1}$ c(a,b) para cara do parâmetro significa: c é o melhor parâmetro estimado (a,b) é o parâmetro de $95 \%$ de probabilidade de variação, exceto para SUFI-2 (No SUFI-2, este intervalo denota a distribuição final do parâmetro).

${ }^{2} \sigma d r y, \sigma w e t, \tau d r y$, $\tau$ wet são utilizados para calcular o logarítimo para o posterior função de probabilidade de densidade (PDF).

${ }^{3} P$-factor porcentagem de observações dentro do 95PPU

${ }^{4} d$-factor largura relativa da faixa de $95 \%$ de probabilidade 


\subsection{SUFI-2}

Para a calibração do modelo foi optado a abordagem SUFI-2. O primeiro passo do algoritmo é a escolha de uma função objetiva, após esta etapa um intervalo representativo (valores máximos e mínimos) dos parâmetros selecionados para calibração.

$b_{j}: b_{j \_ \text {min }} \leq b_{j} \leq b_{j, a b s \_\max } \quad \mathrm{j}=1 \ldots . \mathrm{m}$

Aonde:

$b_{j} ; j$-nésimo parâmetro;

$M ; N^{o}$ de parâmetros;

O intervalo de parâmetros são então designados para uma amostragem por meio de um hipercubo latino. Resultando em n combinações de parâmetros, para o qual n é o número de iterações estipuladas. O programa então roda $n$ vez e as variáveis simuladas de saída são salvas e avaliadas para função objetiva elegida.

A seguir várias medições são feitas de forma avaliar cada rodada de amostragem. Primeiro a matriz de sensibilidade, $\mathrm{J}$ da função objetiva $\mathrm{g}(\mathrm{b})$ é calculada através de:

$$
J_{i j}=\frac{\Delta g_{i}}{\Delta b_{j}} \quad \mathrm{i}=1, \ldots, C_{2}^{n}, \mathrm{j}=1, \ldots, \mathrm{m},
$$

Aonde:

$\mathrm{C}_{2}^{\mathrm{n}} ; \mathrm{N}^{\mathrm{o}}$ de linhas na matriz de sensibilidade (igual a todas possíveis combinações de simulações pareadas);

j; $\mathrm{N}^{\circ}$ de colunas ( $\mathrm{N}^{\circ}$ de parâmetros); 
O próximo passo é a matriz $\mathrm{H}$ calculada utilizando o método de Gauss-Newton.

$$
H=J^{T} J
$$

Em seguida a estimativa do limite inferior para a matriz de parâmetro de covariância é calculado através de:

$$
C=S_{g}^{2}\left(J^{T} J\right)^{-1}
$$

\section{Aonde:}

$S_{g}^{2}$; variância da função objetiva em função dos valores resultantes das n iterações;

O desvio padrão estimado e o intervalo de $95 \%$ de confiança do parâmetro $b_{j}$ é obtido dos elementos da diagonal de $\mathrm{C}$ de:

$$
\begin{aligned}
& S_{j=\sqrt{C_{j j}}} \\
& b_{j, \text { inf }}=b_{j}^{*}-t_{v, 0,025} S^{j} \\
& b_{j, \text { sup }}=b_{j}^{*}+t_{v ; 0,025} S_{j}
\end{aligned}
$$

\section{Aonde:}

$b_{\mathrm{j}}^{*}$; parâmetro b para uma das melhores soluções;

v; graus de liberdade (n-m); 
As correlações dos parâmetros podem ser avaliadas utilizando os temos da matriz de covariância:

$$
r_{i j=} \frac{c_{i j}}{\sqrt{C_{i i} \sqrt{C_{j j}}}}
$$

As sensibilidades dos parâmetros são calculados através do sistema de regressão linear múltipla, a qual faz a regressão dos valores gerados pelo hipercubo latino em relação aos da função objetiva.

$$
g=\propto+\sum_{i-1}^{m} \beta_{i} b_{i}
$$

Um teste t então é utilizado para ranquear a significância relativa para cada parâmetro $b_{i}$. Estas medidas de sensibilidade são estimativas das alterações na função objetiva resultantes das variações para cada parâmetro.

A próxima é o cálculo do 95PPU para todas variáveis na função objetiva através de:

$$
\bar{d}_{x}=\frac{1}{k} \sum_{l=1}^{k}\left(X_{\text {sup }}-X_{\text {inf }}\right)_{l}
$$

Aonde:

$\bar{d}$; Distância média entre os limites superior e inferior de 95PPU;

$k ; N^{o}$ de pontos de dados observados;

$X_{\text {inf }}$; percentil correspondente a 2,5o da distribuição cumulativa de cada ponto simulado;

$X_{\text {sup }}$; percentil correspondente a 97,5o da distribuição cumulativa de cada ponto simulado; 
A fim de obter um estimativa otimizada para $\bar{d}$, é calculado através do $R$-factor calculado através de:

$$
R-\text { factor }=\frac{\bar{d}_{x}}{\sigma_{x}}
$$

\section{Aonde:}

$\sigma_{\mathrm{x}}$; Desvio-padrão da variável medida X;

Devido alto grau de incertezas inicial, oas valores acima calculados tendem a ser bastante grandes durante as primeiras iterações. Então estes valores são atualizados por:

$$
\begin{aligned}
& b_{j, \text { min }}^{\prime}=b_{j, \text { inf }}-\operatorname{MAX}\left(\frac{\left(b_{j, \text { inf }}-b_{j, \text { min }}\right)}{2}, \frac{\left(b_{j, \text { max }}-b_{j, \text { sup }}\right)}{2}\right) \\
& b_{j, \text { max }}^{\prime}=b_{j, \text { sup }}+\operatorname{MAX}\left(\frac{\left(b_{j, \text { inf }}-b_{j, \text { min }}\right)}{2}, \frac{\left(b_{j, \text { max }}-b_{j, \text { sup }}\right)}{2}\right)
\end{aligned}
$$

Aonde:

b'; valores atualizados; 
A Figura 16 abaixo descreve as etapas do SUFI-2 e as interações do SWAT CUP, com a interface SWAT.

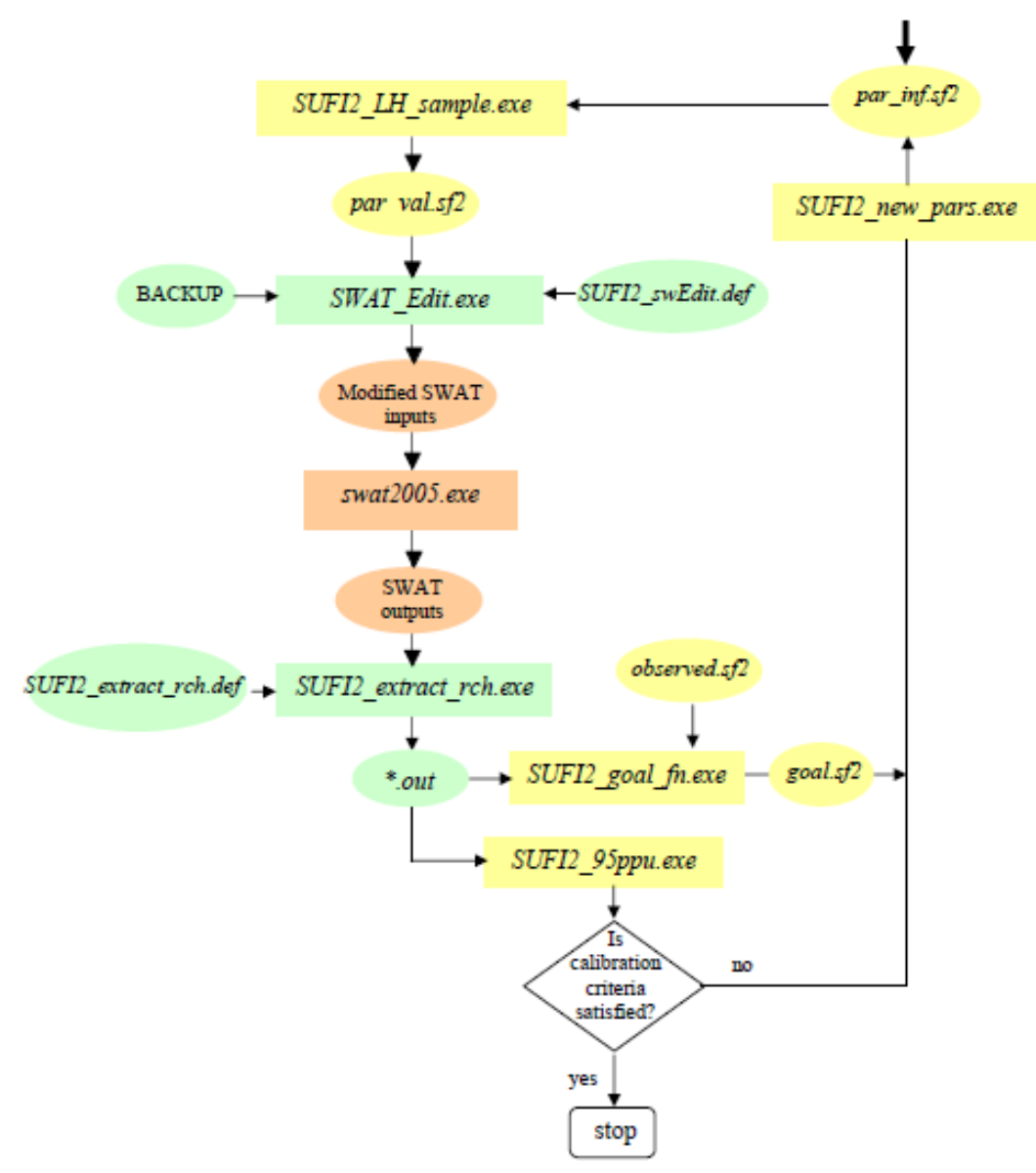

Figura 16 - Etapas do algoritmo SUFI-2 (Abbaspour, 2008).

\subsubsection{COEFICIENTES DE CORRELAÇÃO DE PEARSON}

Os coeficientes de correlação de Pearson são utilizados como testes globais de eficácia de ajuste. Um $r$ pequeno é desejado, uma vez que um valor grande é geralmente interpretado como sendo indicador de má eficácia de ajuste do modelo. O coeficiente de correlação do produto-momento tipicamente denotado pelo $r$ mede a correlação entre duas variáveis $\mathrm{X}$ e $\mathrm{Y}$, 
linearmente dependentes entre si, seu valor varia entre +1 e -1 . A partir de dados pareados (Xi, Yi), a correlação de Pearson da amostra é calculada como:

$$
r=\frac{\sum_{t=1}^{n}\left(X_{t}-\bar{X}\right)\left(Y_{t}-\bar{Y}\right)}{\sqrt{\sum_{t=1}^{n}\left(X_{t}-\bar{X}\right)^{2}} \sqrt{\left(Y_{t}-\bar{Y}\right)^{2}}}
$$

Onde $\bar{X}$ e $\bar{Y}$ representam a amostra de médias de $\mathrm{X}$ e $\mathrm{Y}$, respectivamente

$\mathrm{O}$ índice de ajuste $\mathrm{R}^{2}$ mede a fração da variabilidade total em resposta ao que é estimado pelo modelo. Seu valor varia de 1 (ajuste perfeito) até 0 .

\subsubsection{COEFICIENTE DE EFICIÊNCIA DE NASH-SUTCLIFFE}

O coeficiente de eficiência de Nash-Sutcliffe (NS) é uma estatística confiável usada amplamente na avaliação de eficácia de ajuste em modelos hidrológicos. Os valores de NS variam de 1 até $-\infty$, onde NS=1 indica uma combinação perfeita entre os dados medidos e os observados; NS $=0$ corresponde aos valores simulados pelo modelo como sendo iguais as médias dos valores medido; já um valor negativo para NS demonstra que os valores simulados são inadequados em relação aos observados,

O Comitê tarefa sobre definições de critérios para avaliação de modelos de bacia hidrográfica ASCE (ASCE, 1993) recomendam os coeficientes de Nash-Sutcliffe para avaliação de modelos contínuos de cálculo umidade. NS é calculado como:

$$
\mathrm{NS}=1-\frac{\sum_{t=1}^{n}\left(Q_{0}^{t}-Q_{m}^{t}\right)^{2}}{\sum_{t=1}^{n}\left(Q_{o}^{t}-\overline{Q_{o}}\right)^{2}}
$$


Onde $Q_{\mathrm{o}}$ é a descarga observada e Om é a descarga modelada, ou simulada em um tempo t.

\subsection{3. ÍNDICE DE CONCORDÂNCIA (D)}

O índice de concordância é a medida de conformidade entre o "runoff" estimado e o medido (LEAGATES \& McCABE, 1999; WILMOTT, 1984; e WIMOTT, 1981). HIEPE \& DIEKKRÜGER (2007), CHEKOL (2006) utilizaram tal índice com sucesso nos últimos anos. O modelo foi desenvolvido para superar a falta de sensibilidade de correlação baseado nas diferenças de médias de amostras e variâncias dos valores observados e medidos.(WILMOTT, 1981 e 1984).

$$
d=1,0-\frac{\sum_{t=1}^{n}\left(O_{t}-P_{t}\right)^{2}}{\sum_{t=1}^{n}\left(\left|P_{t}-\bar{O}\right|+\left|O_{t}-\bar{O}\right| t\right)^{2}}
$$

Onde $O i$ é o valor observado; $P i$ é o valor simulado pelo modelo para os valores $O i$. 


\section{RESULTADOS E DISCUSSÃO}

\section{Características Físicas da Bacia:}

A bacia de estudo apresenta uma área de 220, $62812 \mathrm{Km}^{2}$ apresentando cota máxima de 976 m e cota mínima de 664 a cota média para a bacia toda é de 781,334 m e desvio-padão de 49,1206 m. As classes de declividade (Figura 17) definidas foram as que estão comprendidas no três intervalos de (0-5\%), de (5-10\%) e ( >10\%).

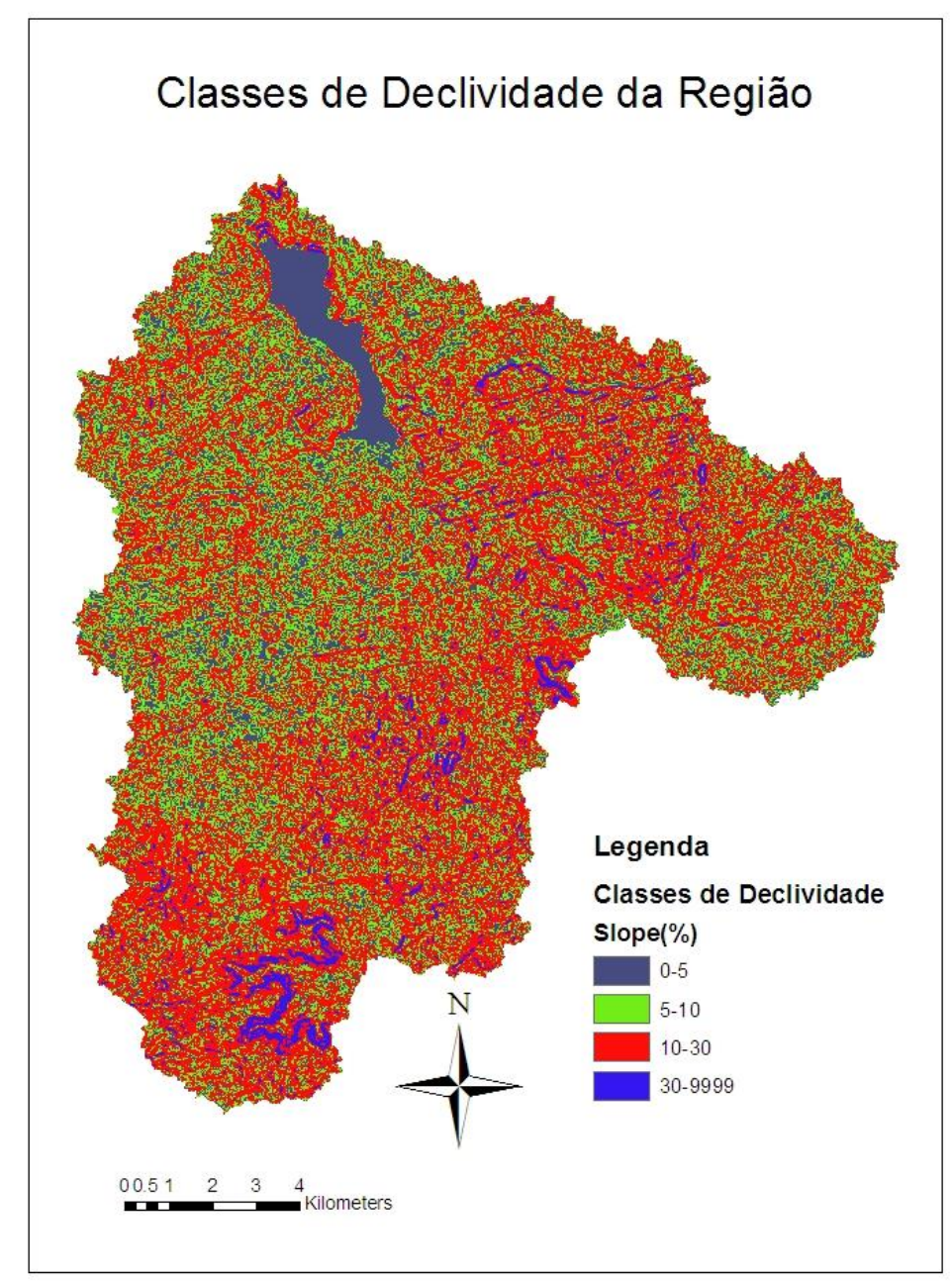

Figura 17 - Classes de Declividade da Região de Estudo. 
A Tabela 20 sumariza os intervalos de declividade e a área ocupada na bacia, observando que a maior parte da declividade da região encontra-se no intervalo entre 10 e 30 $\%$, uma área de $133,36 \mathrm{~km}^{2}$, representando $60,45 \%$ da bacia.

Tabela 20 - Classes de Declividade da Bacia.

\begin{tabular}{|l|l|r|}
\hline Declividade (\%) & $\begin{array}{l}\text { Area } \\
\left(\mathbf{K m}^{2}\right)\end{array}$ & Área (\%) \\
\hline $0-5$ & 12.10513 & 5.49 \\
\hline $5-10$ & 75.16421 & 34.07 \\
\hline $10-30$ & 133.3588 & 60.45 \\
\hline
\end{tabular}

Por ser um modelo semi-distribuído, as classes de solo identificadas anteriormente sofreram alterações para serem processadas no modelo, sendo as novas classes para o SWAT apresentadas na Figura 18. 


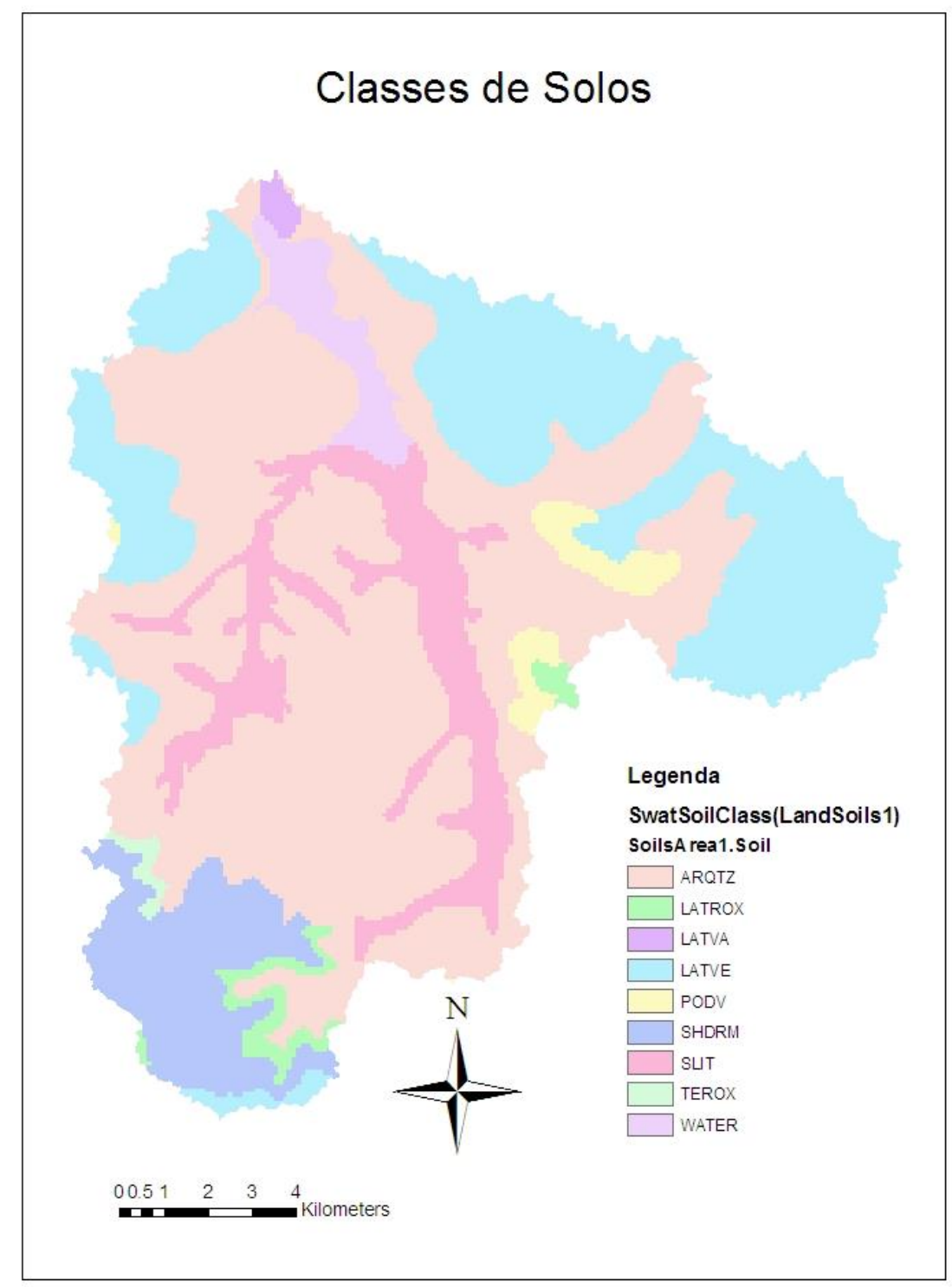

Figura 18 - Classificação Pedológica da Região de Estudo.

$\mathrm{Na}$ Tabela 21, estão identificadas as classes, área em km2 e área em (\%) das classes utilizadas pelo modelo para o processamento de dados. Podemos notar a ausência da classe Terra Roxa Estruturada, que deve ter sido assimilada por outras classes devido a uma área muito pequena e/ou muito fragmentada. 
Tabela 21 - Classes de Solo para o modelo SWAT.

\begin{tabular}{|c|c|c|}
\hline Classe & Área $\mathbf{( k m}^{2} \mathbf{)}$ & $\begin{array}{c}\text { Área } \\
(\mathbf{\%})\end{array}$ \\
\hline Areias Quartzosas & 108.862837 & 49.34 \\
\hline $\begin{array}{c}\text { Latossolo Vermelho } \\
\text { Amarelo }\end{array}$ & 0.603833 & 0.27 \\
\hline Latossolo Vermelho Escuro & 49.586278 & 22.48 \\
\hline Água & 3.93951 & 1.79 \\
\hline Solos Litólicos & 15.319984 & 6.94 \\
\hline $\begin{array}{c}\text { Podzólico Vermelho } \\
\text { Amarelo }\end{array}$ & 3.073106 & 1.39 \\
\hline Solos Hidromórficos & 30.480045 & 13.82 \\
\hline Latossolo Roxo & 8.762526 & 3.97 \\
\hline \multicolumn{2}{|c|}{} & \\
\hline
\end{tabular}

\subsection{Cenário de 1977-1985}

Novamente as classes de uso e ocupação obtidas foram convertidas para classes utilizadas pelo modelo SWAT (Figura 19), sendo observado que algumas classes que ocupavam parcelas muito pequenas e/ou muito fragmentadas foram assimiladas por outras como o exemplo de regiões predominantemente ocupadas pelas classes cana-de açúcar, loteamento e cultura (Tabela 22). 


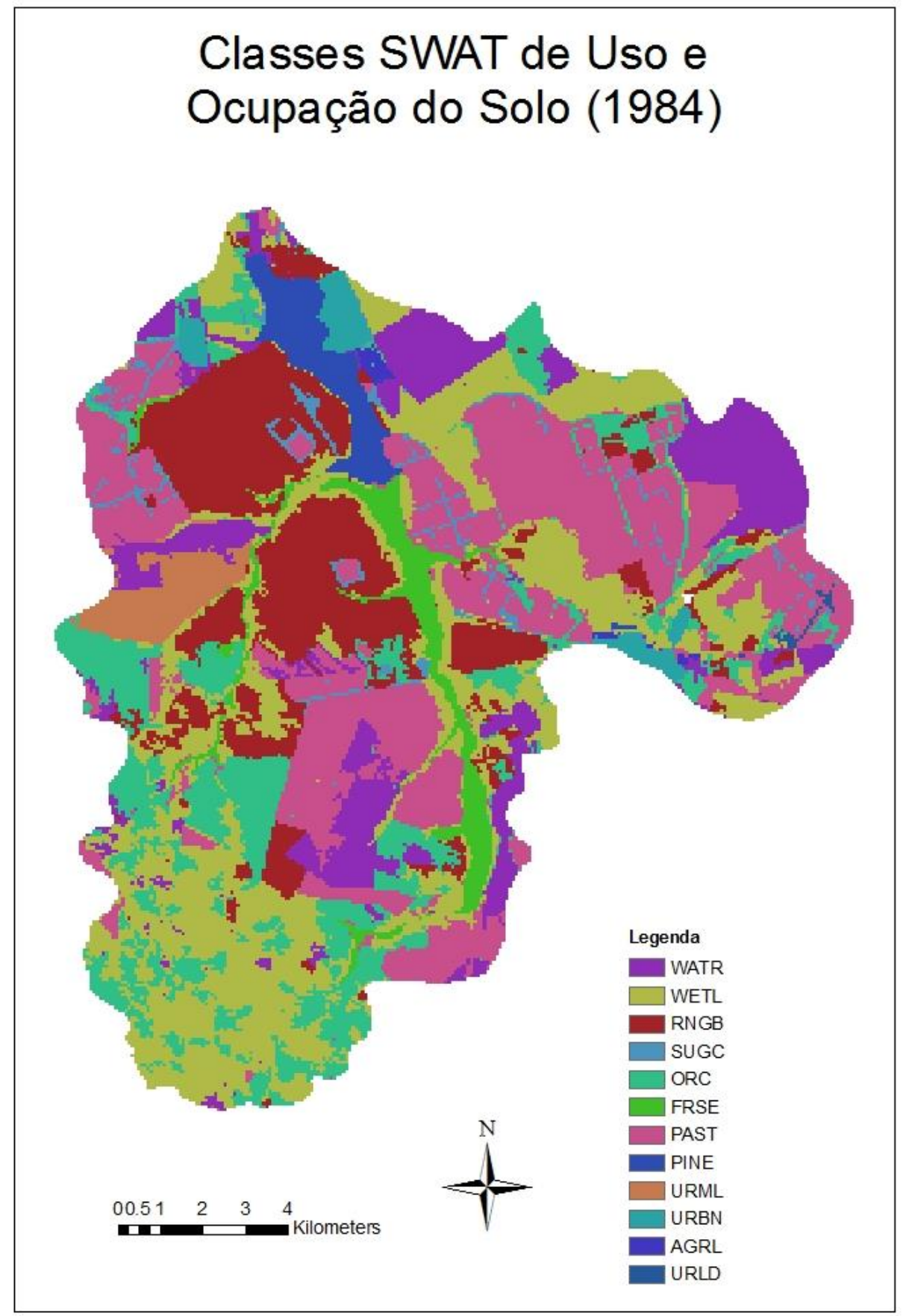

Figura 19 - Classes de Uso e Ocupação de Solo utilizadas pelo SWAT (1984). 
Tabela 22 - Classes de Uso e Ocupação do Solo (1984).

\begin{tabular}{|c|c|c|c|}
\hline Uso e Ocupação do Solo & $\begin{array}{c}\text { SIGLA } \\
\text { SWAT }\end{array}$ & Área km $^{\mathbf{2}}$ & $\begin{array}{c}\text { Área } \\
(\boldsymbol{\%})\end{array}$ \\
\hline Corpos de Água & WATR & 6.074119 & 2.75 \\
\hline Áreas Alagadiças Mistas & WETL & 87.049214 & 39.46 \\
\hline Campo de Arbustos (Cerrado) & RNGB & 45.395318 & 20.58 \\
\hline Pinus & PINE & 3.961672 & 1.8 \\
\hline Pastagem & PAST & 58.270595 & 26.41 \\
\hline Área Residencial (média- Baixa Densidade) & ORCD & 14.582089 & 6.61 \\
\hline
\end{tabular}

Para o cenário de 1977 e 1985 foram identificadas 22 Sub-Bacias (Figura 20) e 141 Unidades de Resposta Hidrológicas (Figura 21). 


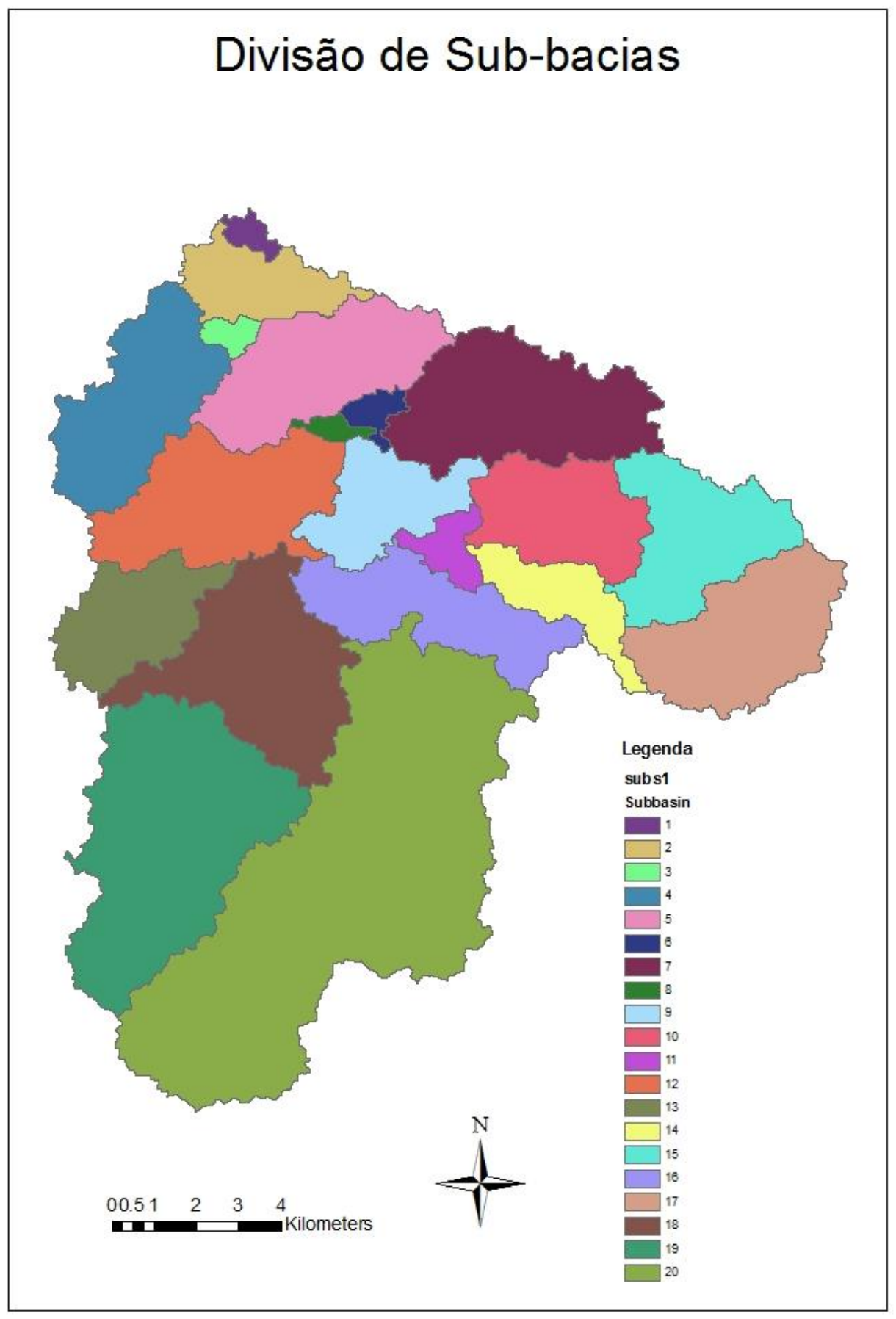

Figura 20 - Sub-bacias para o período de 1977-1985. 


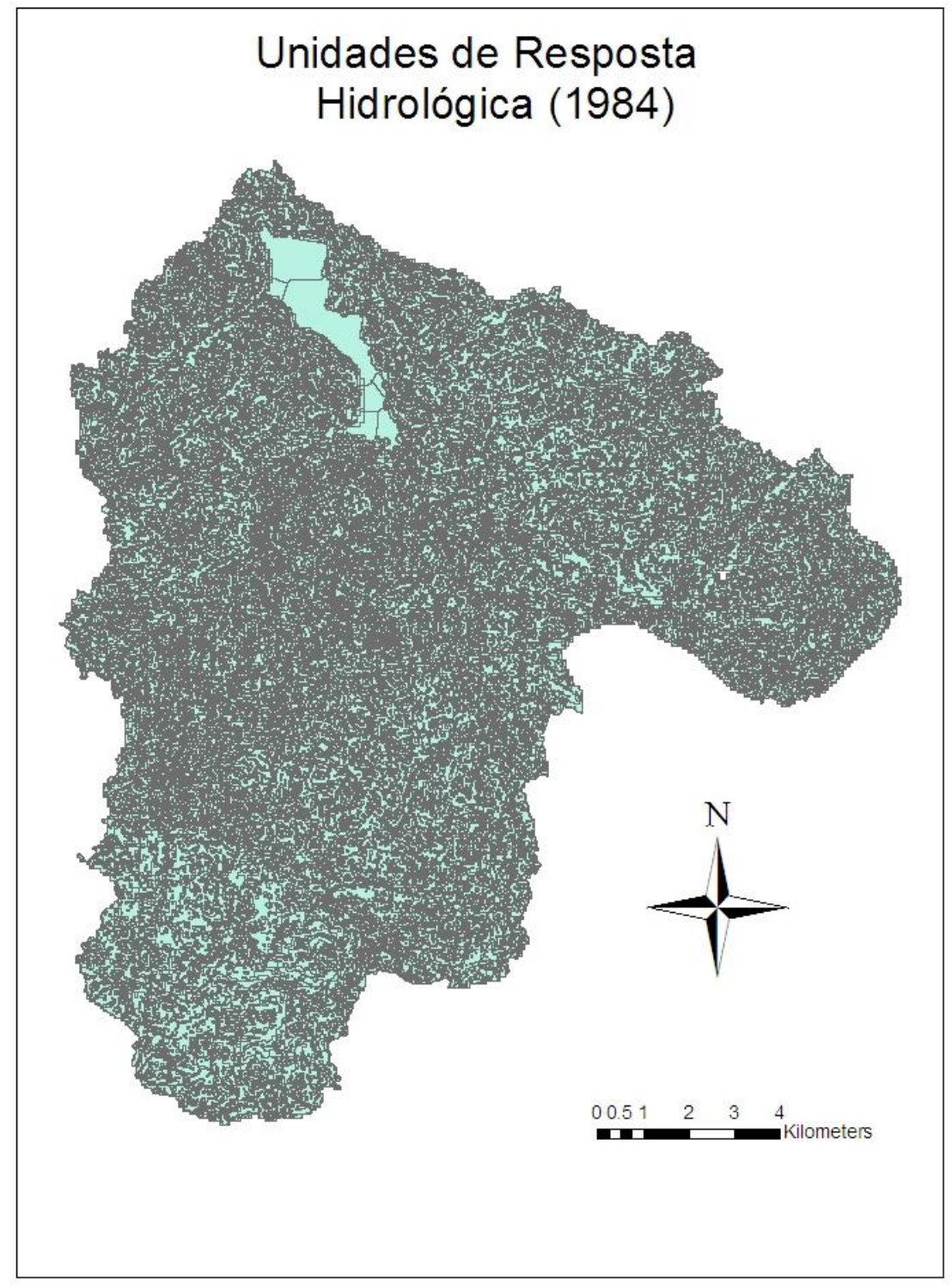

Figura 21 - Unidades de Resposta Hidrológica (1984).

\section{Calibração}


Para este cenário de simulação de 12 anos foram utilizados um período de 4 anos de "warm-up" para preparar as condições iniciais de umidade do solo, este período foi obtido através da replicação das precipitações e condições climáticas dos primeiros 4 anos.

Os parâmetros selecionados para a calibração, bem como os valores finais da calibração estão enumerados na Tabela 23 abaixo

Tabela 23 - Valores dos parâmetros finais da calibração (1977-1985).

\begin{tabular}{|c|c|c|c|c|}
\hline Parâmetros & Descrição & Melhores parâmetros & Valor Mínimo & Valor Máxmo \\
\hline $\mathrm{r} \_\mathrm{CN} 2 . \mathrm{mgt}$ & $\begin{array}{c}\text { Condição inicial do CN } \\
\text { para condição de } \\
\text { humidade II } \\
\end{array}$ & -0.607603 & -0.638464 & -0.506296 \\
\hline v__ALPHA_BF.gw & $\begin{array}{c}\text { Fator Alpha do } \\
\text { escoamento de base }\end{array}$ & 1.137512 & 1.0942 & 1.274292 \\
\hline v__GW_DELAY.gw & $\begin{array}{c}\text { Tempo de Retardamento } \\
\text { da água subterrânea } \\
\text { (dias) }\end{array}$ & 492.508118 & 390.381256 & 512.323792 \\
\hline v__GWQMN.gw & $\begin{array}{l}\text { Profundidade limiar da } \\
\text { água no aquífero } \\
\text { superficial para que } \\
\text { ocorra abastecimento } \\
\text { pelo aquífero. }\end{array}$ & 2.650803 & 2.444162 & 3.440024 \\
\hline v__GW_REVAP.gw & $\begin{array}{l}\text { Coeficiente de "revap" } \\
\text { ou fluxo ascendente de } \\
\text { água subterrâneas para } \\
\text { zona insaturada por } \\
\text { evapotranspiração.. }\end{array}$ & 0.252587 & 0.195124 & 0.263492 \\
\hline v__ESCO.hru & $\begin{array}{l}\text { Fator de compensação do } \\
\text { evaporação do solo. }\end{array}$ & 0.903672 & 0.903191 & 0.914003 \\
\hline $\mathrm{v} \_$CH_N2.rte & $\begin{array}{c}\text { Valor de Manning para o } \\
\text { principal canal }\end{array}$ & 0.093144 & 0.083479 & 0.097395 \\
\hline $\mathrm{v} \_$CH_K2.rte & $\begin{array}{c}\text { Condutividade hidráulica } \\
\text { no aluviaõ do canal } \\
\text { principal } \\
\end{array}$ & 86.287712 & 73.642265 & 90.011772 \\
\hline v__ALPHA_BNK.rte & $\begin{array}{c}\text { Fator alfa do escoamento } \\
\text { de base (dias) }\end{array}$ & 0.116949 & 0.113437 & 0.232489 \\
\hline r__SOL_AWC(1).sol & $\begin{array}{c}\text { Capacidade de campo na } \\
\text { camada superficial de } \\
\text { solo }\left(\mathrm{mmH}_{2} \mathrm{O} / \mathrm{mm} \text { de }\right. \\
\text { solo })\end{array}$ & 0.126897 & 0.034954 & 0.243206 \\
\hline r__SOL_K(1).sol & $\begin{array}{c}\text { Condutividade hidráulica } \\
\text { do camada superficial de } \\
\text { solo (mm/hora) }\end{array}$ & -0.973462 & -1.011305 & -0.925003 \\
\hline r__SOL_BD(1).sol & $\begin{array}{c}\text { Densidade aparente da } \\
\text { umidade do solo } \\
\left(\mathrm{Mg} / \mathrm{m}^{3}\right) \\
\end{array}$ & -0.429724 & -0.439676 & -0.31605 \\
\hline
\end{tabular}


A análise de sensibilidade (Tabela 24) mostrou que os parâmetros que mais influenciaram a calibração foram r_SOLK(1), ou o índice $\mathrm{K}$ para a $1^{\mathrm{a}}$ camada de todos os solos e o r_CN2.mgt, que representa o valor Curva Número.

Tabela 24 - Análise de Sensibilidade para os parâmetros (1977-1985).

\begin{tabular}{|l|r|r|}
\hline Parâmetros & \multicolumn{1}{l|}{ Teste-t } & \multicolumn{1}{l|}{ Valor P } \\
\hline r_CN2.mgt & 2,417730736 & 0,015798084 \\
\hline v_ALPHA_BF.gw & 0,319340891 & 0,749535672 \\
\hline v_GW_DELAY.gw & 0,784648378 & 0,432848230 \\
\hline v_GWQMN.gw & 0,457675962 & 0,647286094 \\
\hline v_GW_REVAP.gw & $-0,374831438$ & 0,0707866437 \\
\hline v_ESCO.hru & 1,00335 & 0,315934682 \\
\hline v_CH_N2.rte & 0,967238 & 0,333662107 \\
\hline v_CH_K2.rte & 0,498626647 & 0,618153642 \\
\hline v_ALPHA_BNK.rte & 0,224783090 & 0,822194596 \\
\hline r_SOL_AWC(1).sol & $-1,770947953$ & 0,076878251 \\
\hline r_SOL_K(1).sol & 26,5547 & 0,0000 \\
\hline r_SOL_BD(1).sol & 1,7947 & 0,0730069 \\
\hline
\end{tabular}

No entanto a calibração não foi satisfatória apresentando coeficientes de NashSutcliffe e de Pearson $\left(\mathrm{R}^{2}\right)$ baixos. A Tabela 25 apresenta os índices para cada ponto de monitoramento.

Tabela 25 - Sumário da performance da calibração (1977-1985).

\begin{tabular}{|l|r|r|r|r|r|r|c|}
\hline $\begin{array}{l}\text { Ponto de } \\
\text { Monitoramento }\end{array}$ & p-factor & \multicolumn{1}{l|}{ r-factor } & \multicolumn{1}{l|}{ R2 } & \multicolumn{1}{l|}{ NS } & \multicolumn{1}{l|}{ br2 } & \multicolumn{1}{l|}{ MSE } & \multicolumn{1}{l|}{ SSQR } \\
\hline Jacaré-Açú-2 & 0.36 & 1.09 & 0.04 & -0.18 & 0.0054 & 11.2583 & 2.2239 \\
\hline Jacré-Açú-1 & 0.39 & 1.24 & 0.06 & -0.2 & 0.0119 & 8.761 & 1.1744 \\
\hline $\begin{array}{l}\text { Córrego da } \\
\text { Perdizes }\end{array}$ & 0.76 & 3.01 & 0.17 & -0.63 & 0.0799 & 0.0222 & 0.0063 \\
\hline $\begin{array}{l}\text { Córrego do } \\
\text { Geraldo }\end{array}$ & 0.33 & 0.26 & 0.01 & -0.22 & 0 & 3.2902 & 3.0006 \\
\hline Siriema & 0.3 & 0.15 & 0.01 & -0.19 & 0.0001 & 4.1361 & 3.7582 \\
\hline Rio Itaqueri & 0.32 & 0.94 & 0.01 & -0.62 & 0.0003 & 0.7269 & 0.3789 \\
\hline
\end{tabular}


Ao analisarmos os gráficos resultantes comparando a vazão observada com a simulada para a melhor simulação e da faixa 95PPU, podemos visualizar que o modelo para o cenário 1 (1977-1985) apresentou uma tendêndia geral de subestimar muito a vazão simulada em relação aos dados observados. A causa deste comportamento pode ser explicado pelos dados inconsistentes utilizados nas estações de monitoramento de vazão do Córrego das perdizes e do Rio Itaqueri, estes contribuiram negativamente para a performance das simulações.

No Gráfico 11 estão os resultados gráficos para a estação Jacaré-Açú 2 no Ribeirão do Lobo. Neste gráfico estão representados da zona de confiança de 95 PPU sendo o L995PPU o limite inferior da zona de confiança e o U995 PPU o limite superior. Observa-se que devido aos dados mais consistentes este apresentou resultados aceitáveis.

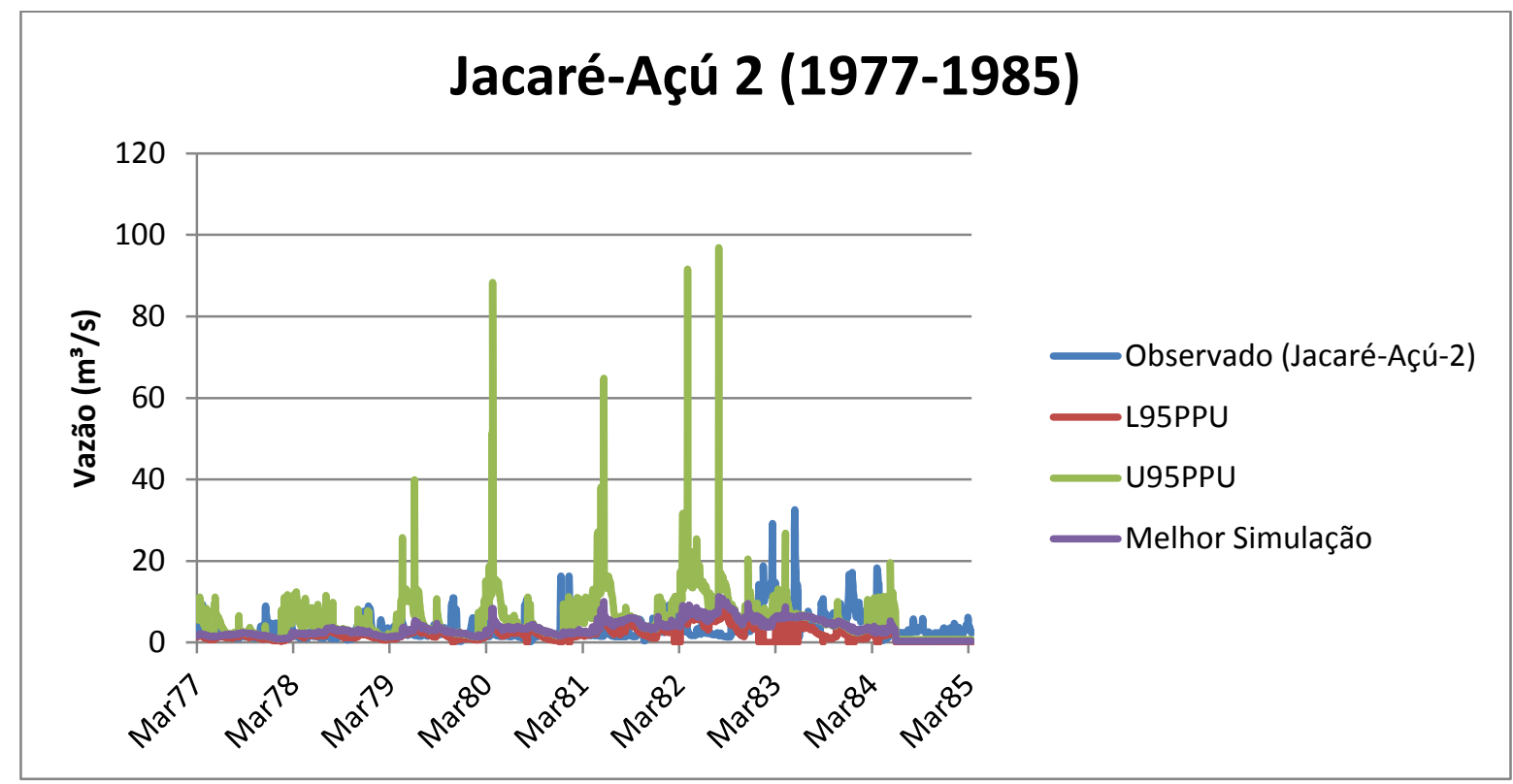

Gráfico 11 - Calibração da vazão para Jacaré-Açú 2(1977-1985).

No Gráfico 12 estão os resultados gráficos para a estação Jacaré-Açú 1 no Ribeirão do Lobo. Neste gráfico estão representados da zona de confiança de 95 PPU sendo o L995PPU o limite inferior da zona de confiança e o U995 PPU o limite superior. Observa-se assim como 
os resultados do Gráfico 11, devido aos dados mais consistentes este apresentou resultados aceitáveis.

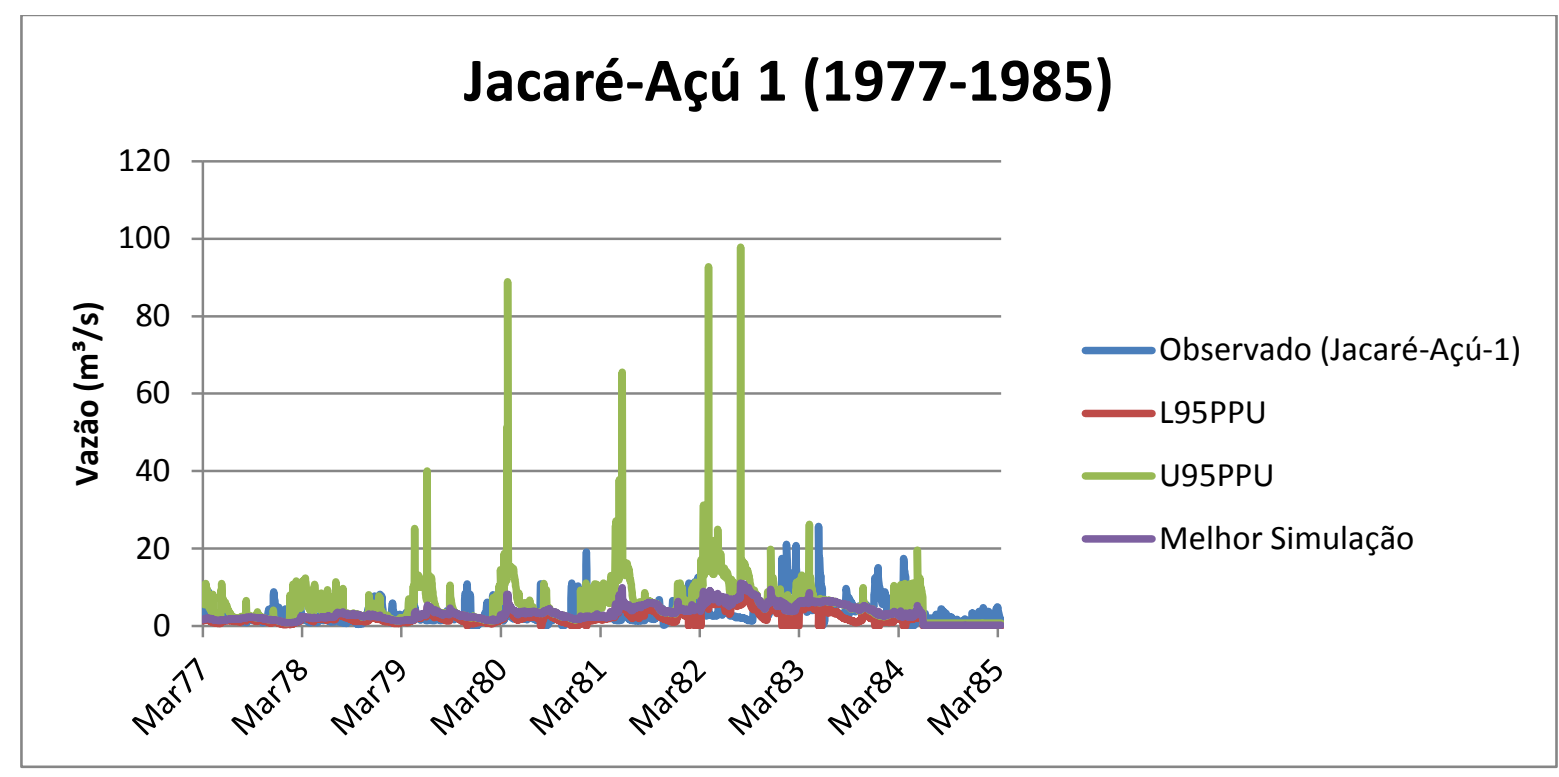

Gráfico 12 - Calibração da vazão para Jacaré-Açú 1(1977-1985).

No Gráfico 13 estão os resultados gráficos para a estação de monitoramento no córrego das perdizes. Neste gráfico estão representados da zona de confiança de 95 PPU sendo o L995PPU o limite inferior da zona de confiança e o U995 PPU o limite superior. Observa-se uma grande amplitude da zona de confiança, este gráfico, apesar de possuir dados bastante inconsistentes não apresentou resultados tão ruins devido as baixas vazões do mesmo, que pode ser um fator que tenha atenuado a amplitude dos erros. 


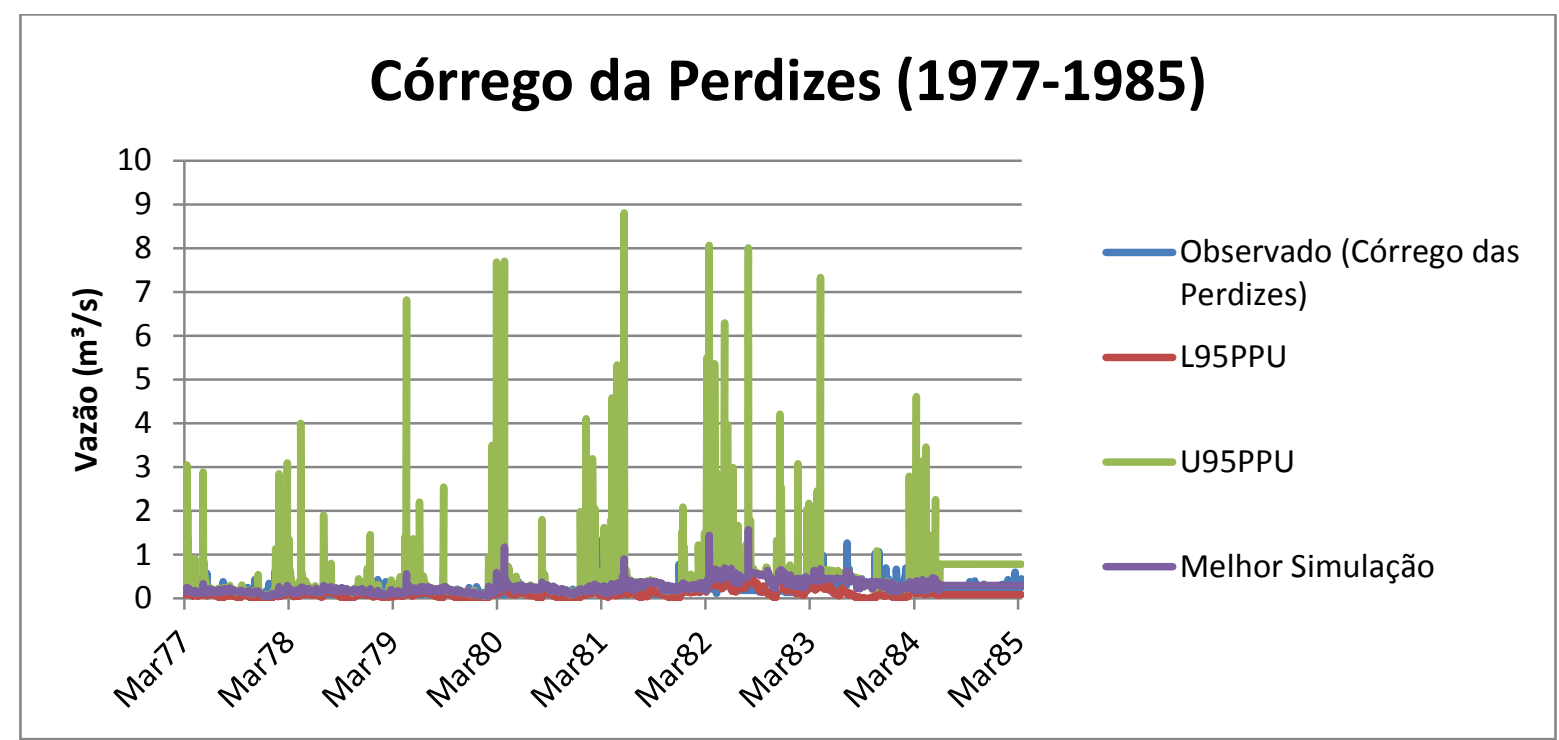

Gráfico 13 - Calibração da vazão para Córrego das Perdizes(1977-1985).

No Gráfico 14 estão os resultados gráficos para a estação de monitoramento no córrego das perdizes. Neste gráfico estão representados da zona de confiança de 95 PPU sendo o L995PPU o limite inferior da zona de confiança e o U995 PPU o limite superior. Observa-se uma grande amplitude da zona de confiança, este gráfico, apesar de possuir dados bastante consistentes isto pode ser explicado pelo efeito das incertezas introduzidas no modelo pelos dados inconsistentes pelas estações no Córrego das Perdizes e Rio Itaqueri. 


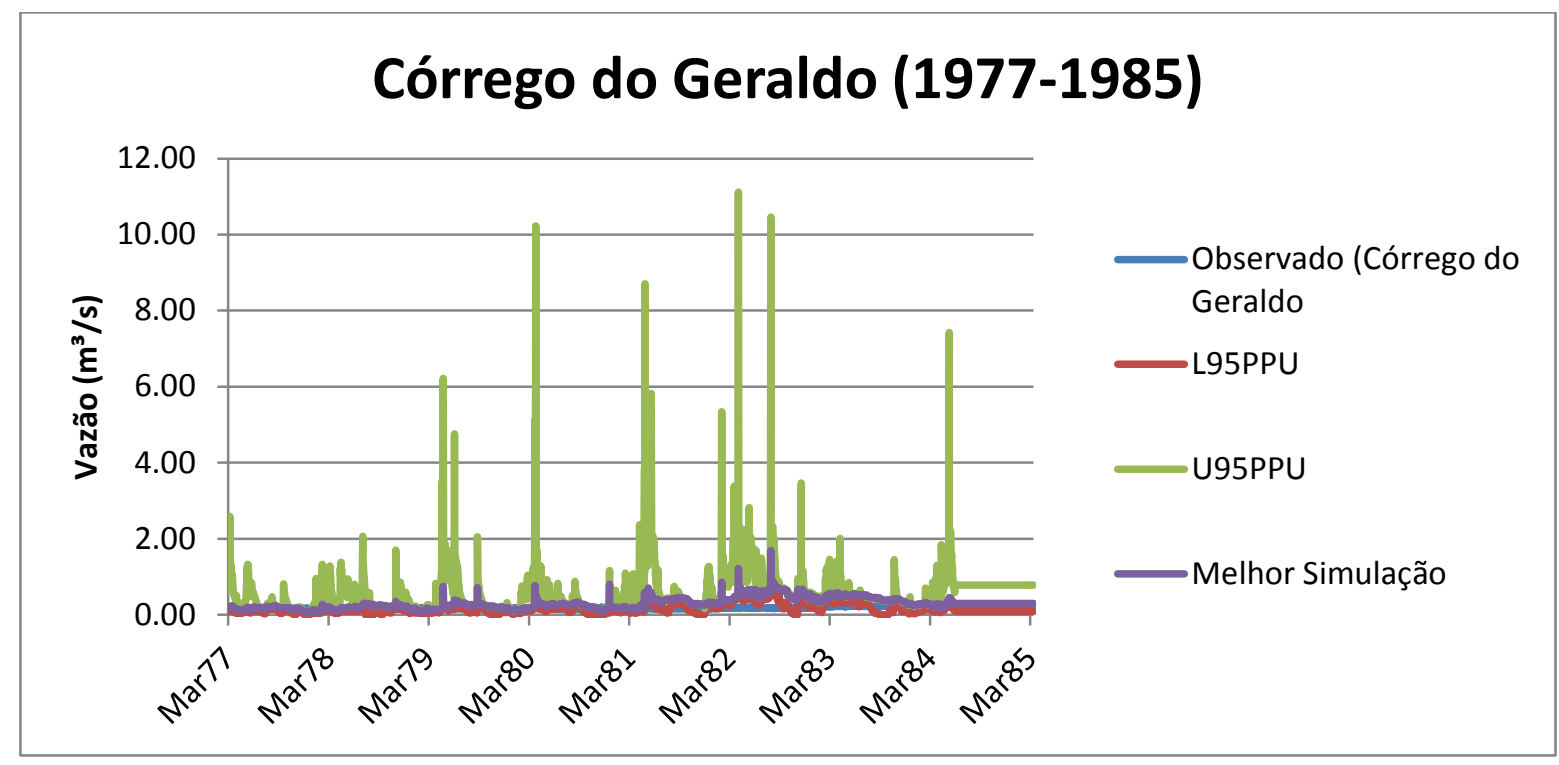

Gráfico 14 - Calibração da vazão para Córrego do Geraldo (1977-1985).

No Gráfico 15 estão os resultados gráficos para a estação Siriema no Ribeirão do Lobo. Neste gráfico estão representados da zona de confiança de 95 PPU sendo o L995PPU o limite inferior da zona de confiança e o U995 PPU o limite superior. Observa-se que esta estação apresentou uma tendência de sobrestimar os dados de vazão observados. 


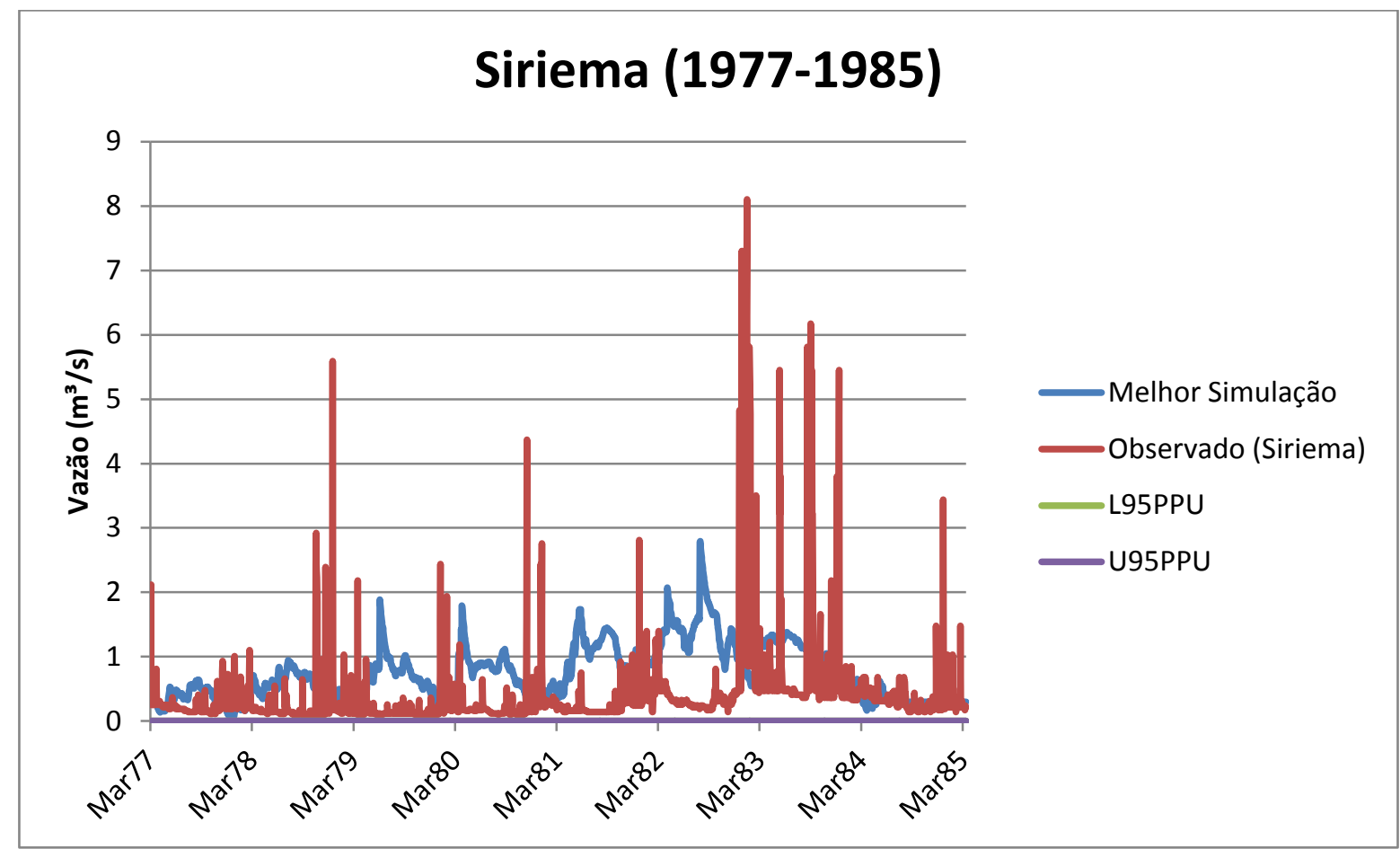

Gráfico 15 - Calibração da vazão para Siriema (1977-1985).

No Gráfico 16 estão os resultados gráficos para a estação Siriema no Ribeirão do Lobo. Neste gráfico estão representados da zona de confiança de 95 PPU sendo o L995PPU o limite inferior da zona de confiança e o U995 PPU o limite superior. Observa-se que esta estação apresentou uma grande tendência em subrestimar os dados de vazão observados, isto pode ser explicado devido aos dados de vazão observados com muita inconsistência. Acredita que este ponto seja a maior fonte de incertezas da simulação e possívelmente o principal agente para contribuir negativamente com a performance da simulação. 


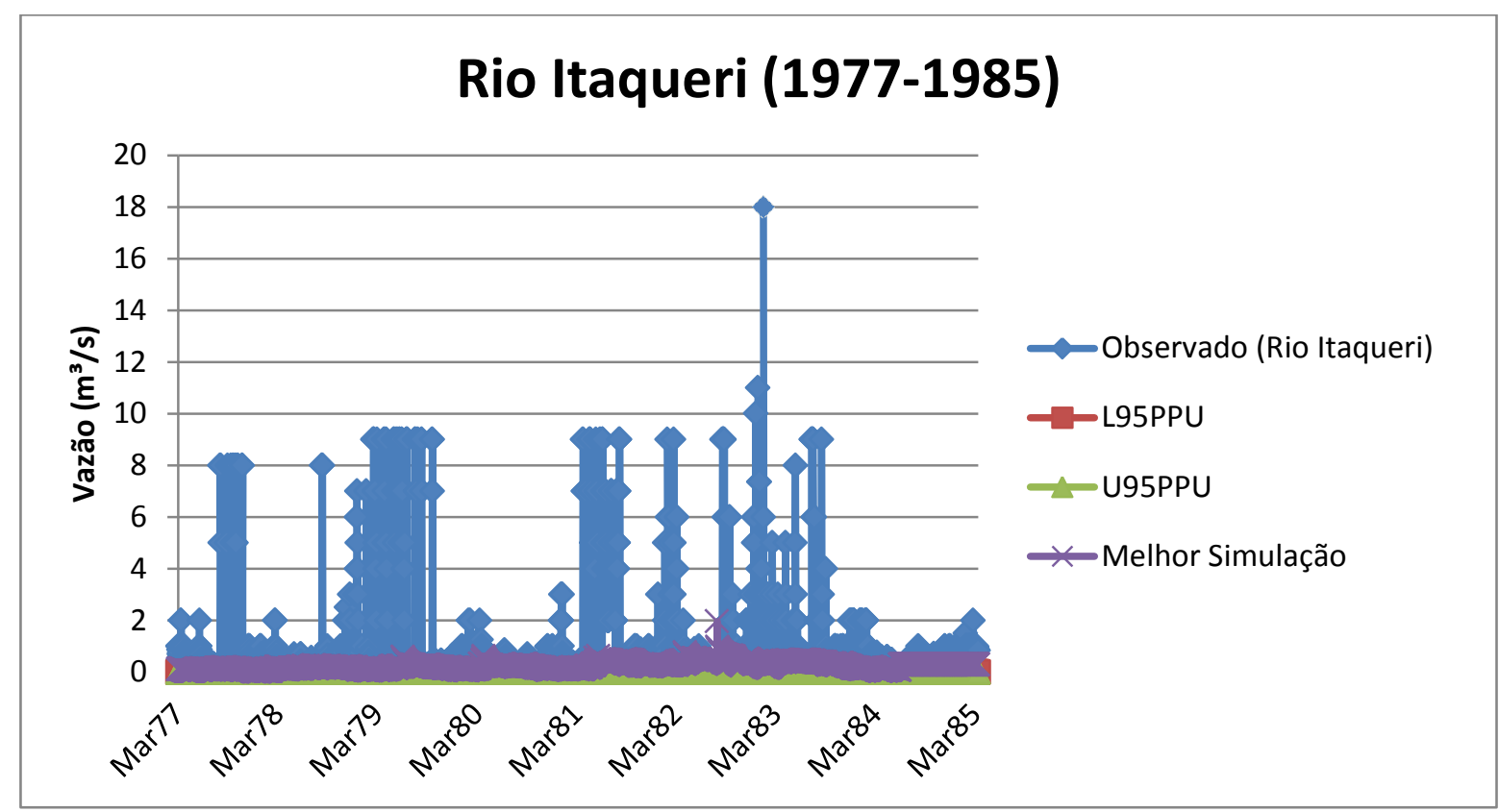

Gráfico 16 - Calibração da vazão para Rio Itaqueri (1977-1985).

\section{Aporte de Sedimentos}

A estimativa de aporte de sedimentos, não foi calibrada, uma vez que não existem dados para realizá-los, portanto estes resultados são muito questionáveis. O aporte de sedimentos estimado para a bacia foi de 7,8 toneladas $/ \mathrm{km}^{2}$, para o reservatório o aporte de sedimentos foi de 5,9 toneladas $/ \mathrm{km}^{2}$.

Os resultados da simulação mesmo após 4530 iterações não se mostrou satisfatório, as razões para isso podem ser tanto os dados de vazão utilizados, que se mostraram muito inconsistentes, como uma representação do uso e ocupação comprometidos pela dificuldade do modelo em representar bacias hidrográficas muito fragmentadas. Na classificação das imagens de satélite a área ocupada por cana de açúcar representava uma área de $26,08 \mathrm{~km}^{2}$ aproximadamente $11,50 \%$ da área total da bacia, as parcelas por serem muito pequenas e fragmentadas foram completamente descartadas pelo modelo. Outro fator que pode ter 
comprometido o rendimento do modelo foram os dados climatológicos, apesar de haver dados medidos, principalmente nos primeiros anos de simulação havia muitas séries sem dados, estas foram completadas pelo gerador de clima, que recomendo utilizar só como último recurso.

No entanto, este resultado negativo não significa que o modelo falhou completamente em simular os processos da bacia, sendo recomendada uma parametrização melhor dos parâmetros escolhidos para calibração e um melhor tratamento dos dados de vazão. A regressão linear utilizada para completar os dados de vazão aparentemente introduziu mais incertezas ao modelo.

\subsection{Cenário de 1996 -2006}

Conforme procedimento anteriormente descrito as classes de uso e ocupação obtidas foram convertidas para classes utilizadas pelo modelo SWAT (Figura 22), sendo observado que algumas classes que ocupavam parcelas muito pequenas e/ou muito fragmentadas foram assimiladas por outras (Tabela 26). 


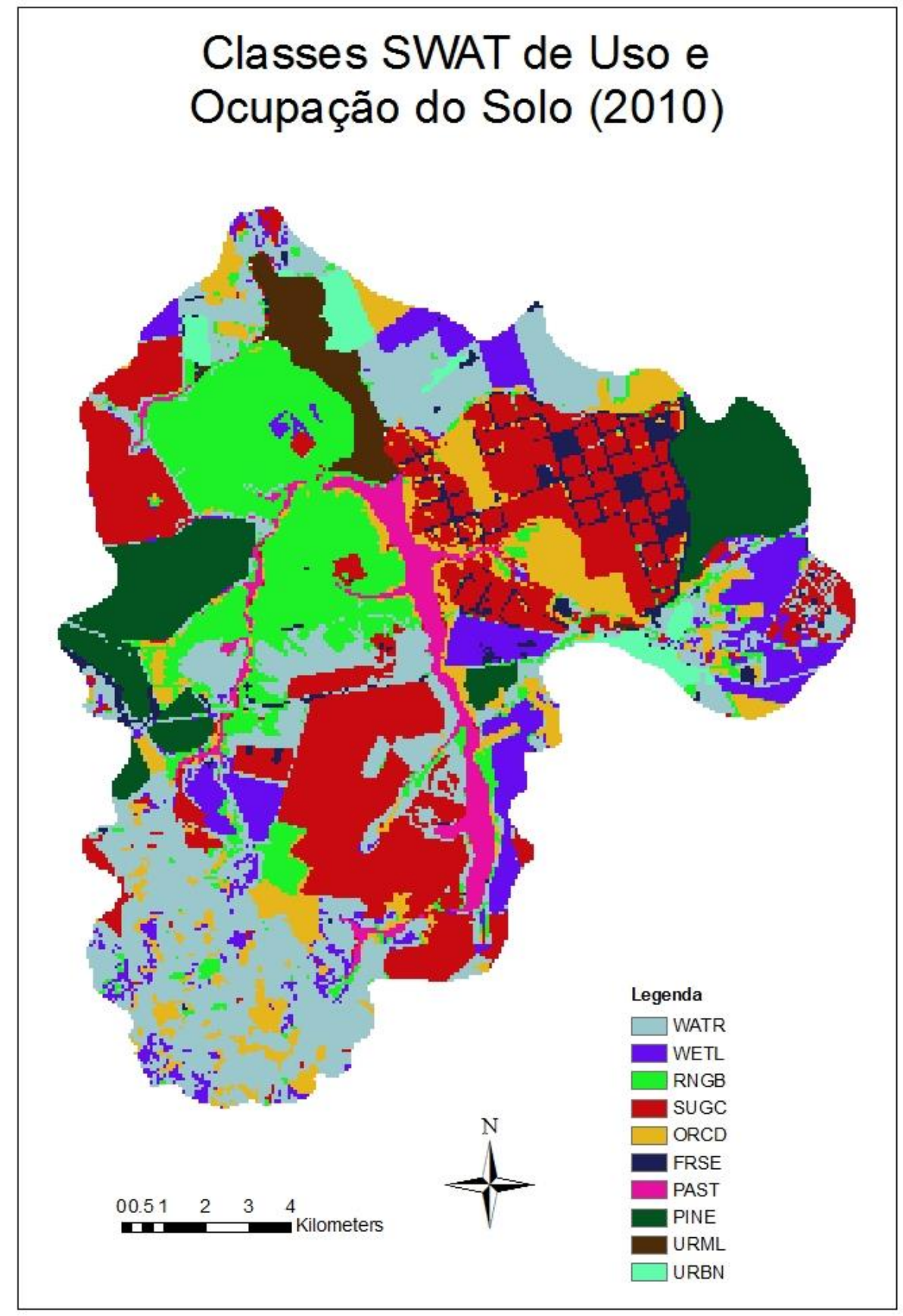

Figura 22 - Classes de Uso e Ocupação de Solo utilizada pelo SWAT (2010). 
Tabela 26 - Classes de Uso e Ocupação do Solo (1984).

\begin{tabular}{|l|l|r|r|r|}
\hline Uso e Ocupação do Solo & $\begin{array}{l}\text { SIGLA } \\
\text { SWAT }\end{array}$ & Área (Ha) & Área km² & \multicolumn{1}{|c|}{$\begin{array}{l}\text { Área } \\
(\%)\end{array}$} \\
\hline Corpos de água & WATR & 9070.3494 & 90.703494 & 41.11 \\
\hline Cana-de açúcar & SUGC & 6170.9986 & 61.709986 & 27.97 \\
\hline Residential-Med/Low Density & URML & 332.7383 & 3.327383 & 1.51 \\
\hline Campo de arbustros (Cerrado) & RNGB & 3166.4821 & 31.664821 & 14.35 \\
\hline Plantação de Árvores (citrus) & ORCD & 380.6456 & 3.806456 & 1.73 \\
\hline Pinus & PINE & 2286.9622 & 22.869622 & 10.37 \\
\hline Áreas alagadiças & WETL & 654.6357 & 6.546357 & 2.97 \\
\hline
\end{tabular}

Para o cenário de 1996 e 2006 foram identificadas 16 Sub-Bacias (Figura 23) e 98 Unidades de Resposta Hidrológicas (Figura 24). 


\section{Divisão de Sub-Bacias}

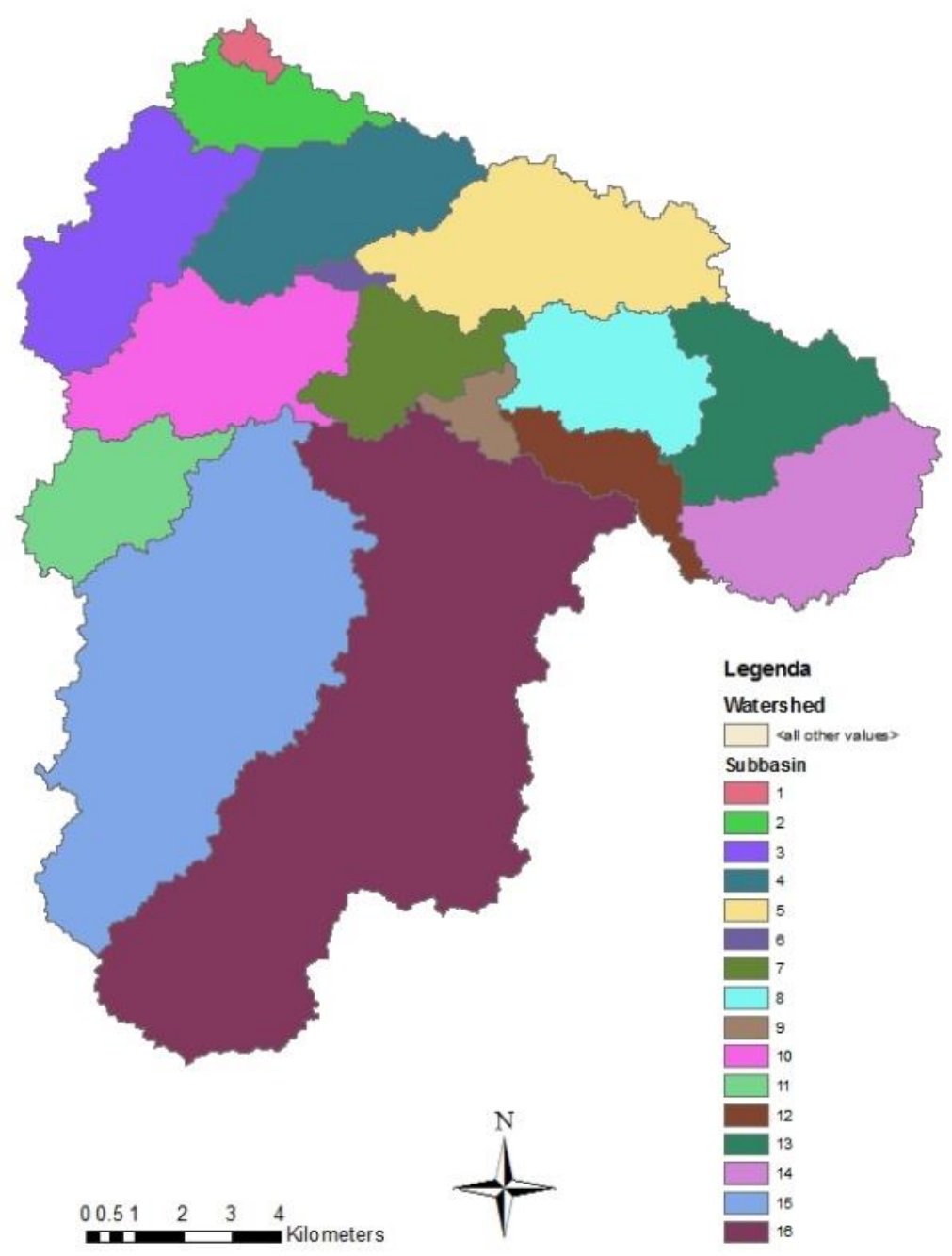

Figura 23 - Sub-bacias para o período de 1996-2006. 


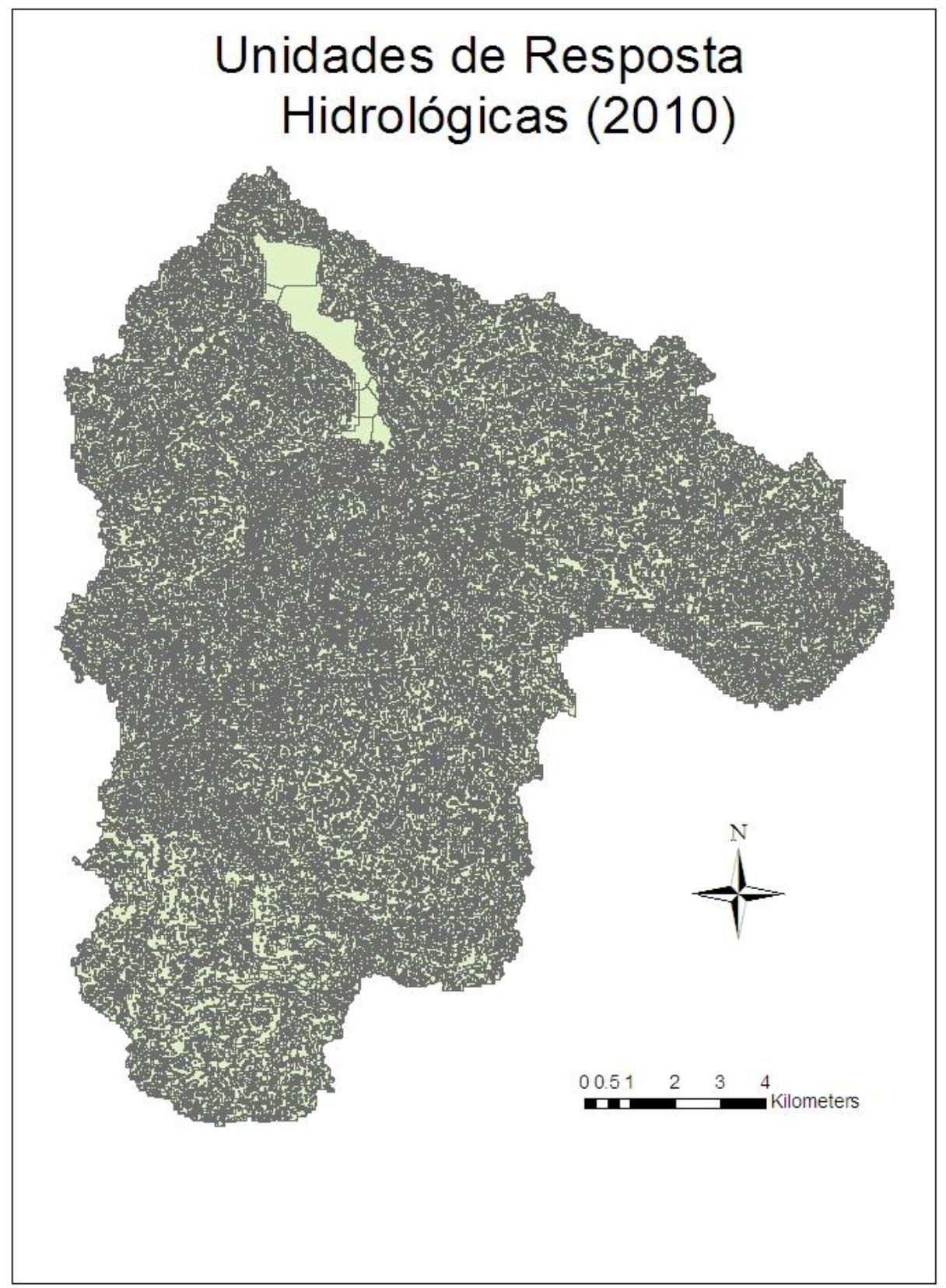

Figura 24 - Unidades de Resposta hidrológica (2010). 


\section{Calibração}

Para este cenário de simulação de 14 anos foi utilizado um período de 3 anos de "warm-up" para preparar as condições iniciais de umidade do solo, este período foi obtido através da replicação das precipitações e condições climáticas dos primeiros 3 anos. Sendo realizadas 4550 iterações nesta calibração, que obteve um comportamento muito mais satisfatório do que a calibração anterior. Os parâmetros selecionados para a calibração, bem como os valores finais da calibração estão enumerados na Tabela 1 abaixo

Tabela 27 - Valores dos parâmetros finais da calibração (1996-2006).

\begin{tabular}{|c|c|c|c|c|}
\hline Parâmetro & Descrição & Melhores Valores & Valor Mínimo & Valor Máxim \\
\hline r__CN2.mgt & $\begin{array}{l}\text { Condição inicial do CN para } \\
\text { condição de humidade II }\end{array}$ & -0.082552 & -0.096916 & -0.069556 \\
\hline v_ALPHA_BF.gw & $\begin{array}{l}\text { Fator Alpha do escoamento de } \\
\text { base }\end{array}$ & 0.732711 & 0.695032 & 0.810966 \\
\hline v_GW_DELAY.gw & $\begin{array}{l}\text { Tempo de Retardamento da água } \\
\text { subterrânea (dias) }\end{array}$ & 429.244324 & 266.145569 & 491.109375 \\
\hline v__GWQMN.gw & $\begin{array}{c}\text { Profundidade limiar da água no } \\
\text { aquífero superficial para que } \\
\text { ocorra abastecimento pelo } \\
\text { aqüífero. }\end{array}$ & 0.867059 & 0.767941 & 1.001161 \\
\hline v__GW_REVAP.gw & $\begin{array}{l}\text { Coeficiente de "revap" ou fluxo } \\
\text { ascendente de água subterrâneas } \\
\text { para zona insaturada por } \\
\text { evapotranspiração.. }\end{array}$ & 0.235509 & 0.229105 & 0.257569 \\
\hline v__ESCO.hru & $\begin{array}{l}\text { Fator de compensação do } \\
\text { evaporação do solo. }\end{array}$ & 1.109344 & 1.086831 & 1.111169 \\
\hline _CH_N2.rte & $\begin{array}{c}\text { Valor de Manning para o } \\
\text { principal canal }\end{array}$ & 0.03833 & 0.02161 & 0.066198 \\
\hline v__CH_K2.rte & $\begin{array}{c}\text { Condutividade hidráulica no } \\
\text { aluviaõ do canal principal }\end{array}$ & 92.16275 & 76.20591 & 98.21534 \\
\hline v_ALPHA_BNK.rte & $\begin{array}{l}\text { Fator alfa do escoamento de base } \\
\text { (dias) }\end{array}$ & 0.132126 & 0.079862 & 0.133466 \\
\hline r_SOL_AWC(1).sol & $\begin{array}{c}\text { Capacidade de campo na camada } \\
\text { superficial de solo }\left(\mathrm{mmH}_{2} \mathrm{o} / \mathrm{mm}\right. \\
\text { de solo) }\end{array}$ & -0.019752 & -0.029271 & -0.009231 \\
\hline r__SOL_K(1).sol & $\begin{array}{c}\text { Condutividade hidráulica do } \\
\text { camada superficial de solo } \\
\text { (mm/hora) }\end{array}$ & -1.05005 & -1.076536 & -0.980224 \\
\hline r_SOL_BD(1).sol & $\begin{array}{l}\text { Densidade aparente da umidade } \\
\text { do solo }\left(\mathrm{Mg} / \mathrm{m}^{3}\right)\end{array}$ & -0.320329 & -0.336421 & -0.244469 \\
\hline
\end{tabular}


A análise de sensibilidade para este cenário (Tabela 28) apresentou maior equilíbrio em comparação ao do cenário anterior de 1977 até 1985 onde claramente dois parâmetros eram influenciavam muito mais a calibração da vazão que os outros. Para este período os parâmetros mais sensíveis foram r__SOL_BD(1).sol (densidade aparente da camada 1 do solo), __CH_N2.rte (curva número), v__ESCO.hru (conservação da evapotranspiração do solo), v__GW_REVAP.gw (evapotranspiração) e r__SOL_K(1).sol (Índice K da camada 1 do solo).

Tabela 28 - Análise de Sensibilidade para os parâmetros (1996-2006).

\begin{tabular}{|c|c|c|}
\hline Parameter_Name & Teste t & Valor p \\
\hline r__CN2.mgt & $-0,049096671$ & 0,962435795 \\
\hline v__ALPHA_BF.gw & $-0,079178942$ & 0,939465028 \\
\hline v_GW_DELAY.gw & 0,011324822 & 0,9913311455 \\
\hline v__GWQMN.gw & $-0,364771222$ & 0,7277494118 \\
\hline v_GW_REVAP.gw & $-1,662254535$ & 0,147523969 \\
\hline v_ESCO.hru & 0,606597200 & 0,566346989 \\
\hline _CH_N2.rte & 0,710234632 & 0,504214305 \\
\hline v__CH_K2.rte & $-0,250428740$ & 0,810610507 \\
\hline v_ALPHA_BNK.rte & 0,362359559 & 0,729504604 \\
\hline r_SOL_AWC(1).sol & 0,101600177 & 0,922384304 \\
\hline r_SOL_K(1).sol & -1.6622544535 & 0,147523969 \\
\hline r_SOL_BD(1).sol & $-0,989644956$ & 0,360562930 \\
\hline
\end{tabular}

O desempenho da calibração se mostrou bastante eficiente, principalmente se levarmos em consideração a escala de tempo de 14 anos de simulação, na Tabela 29 podemos verificar que para as duas estações de monitoramento os índices de Pearson $\left(\mathrm{R}^{2}\right)$ e de NashSutcliffe apresentaram valores satisfatórios. 
Tabela 29 - Sumário da performance da calibração (1996-2006).

\begin{tabular}{|c|c|c|c|c|c|c|c|}
\hline $\begin{array}{c}\text { Estação de } \\
\text { Monitoramento }\end{array}$ & p-factor & r-factor & R2 & NS & br2 & MSE & SSQR \\
\hline Jacaré-Açú-2 & 0.6 & 1.02 & 0.37 & -1.46 & 0.3223 & 18.1109 & 7.9175 \\
\hline Jacaré-Açú-1 & 0.35 & 0.98 & 0.29 & -2.17 & 0.2811 & 25.198 & 13.3191 \\
\hline
\end{tabular}

Os gráficos de vazão para as duas estações confirmam a eficácia da calibração, sendo observados picos estimados de ordem parecida com os observados. Ao analisarmos os gráficos resultantes comparando a vazão observada com a simulada para a melhor simulação e da faixa 95PPU, podemos visualizar que o sinal de vazão observada, da faixa 95PPU e de melhor estimação costuma ter o mesmo comportamento.

No Gráfico 17 estão os resultados gráficos para a estação Jacaré-Açú 2 no Ribeirão do Lobo. Neste gráfico estão representados da zona de confiança de 95 PPU sendo o L995PPU o limite inferior da zona de confiança e o U995 PPU o limite superior.

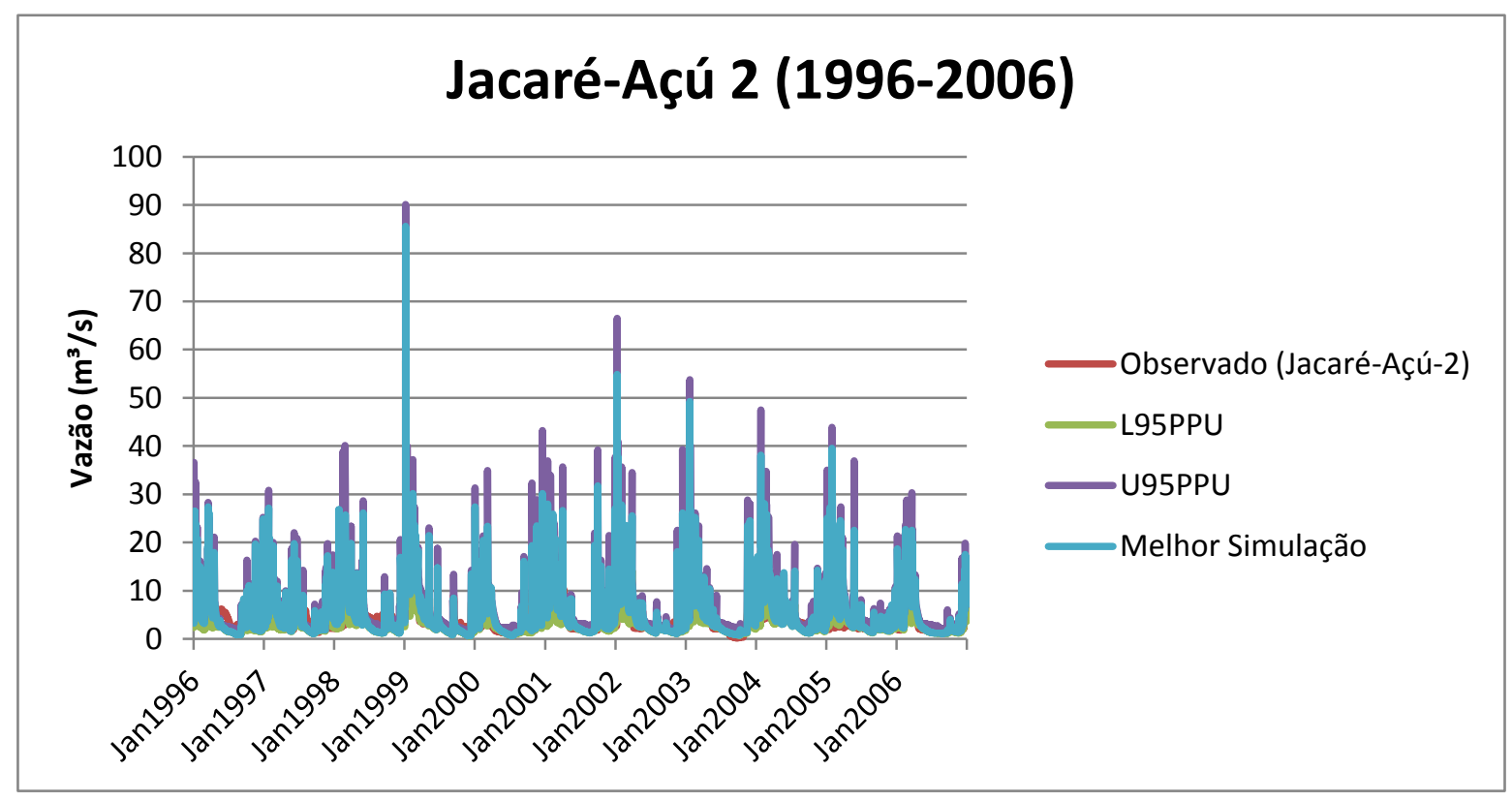

Gráfico 17 - Calibração da vazão para Jacaré-Açú 2(1996-2006). 
No Gráfico 18 estão os resultados gráficos para a estação Jacaré-Açú 2 no Ribeirão do Lobo. Neste gráfico estão representados da zona de confiança de 95 PPU sendo o L995PPU o limite inferior da zona de confiança e o U995 PPU o limite superior.

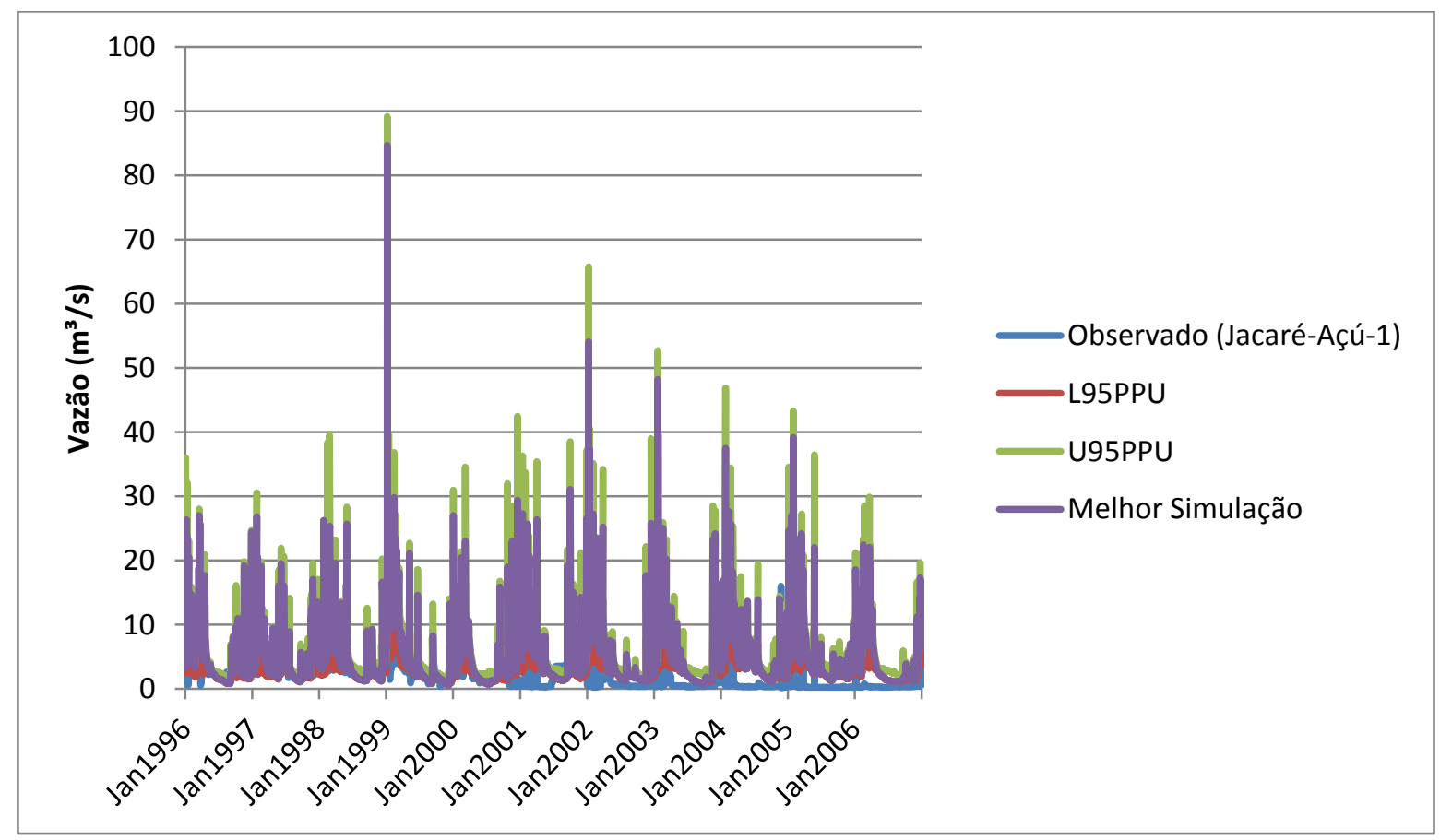

Gráfico 18 - Calibração da vazão para Jacaré-Açú 1(1996-2006).

\section{Aporte de sedimentos}

Assim como no cenário anterior, não foi possível calibrar a curva de estimativa de aporte de sedimentos. O aporte de sedimentos estimado para a bacia foi de 38,6 toneladas $/ \mathrm{km}^{2}$, para o reservatório o aporte de sedimentos foi de 21,1 toneladas $/ \mathrm{km}^{2}$.

Muito embora faltem dados para comprovar e validar estes valores, os mesmo se mostram plausíveis, uma vez que é observado um aumento na urbanização da região para o 
período em comparação como o cenário de 1977 até 1985 e o modelo hidrológico melhor calibrado para este cenário deve resultar em estimativas mais adequadas para a produção de sedimentos. 


\section{CONCLUSÕES E RECOMENDAÇÕES}

Conforme já exposto no trabalho o modelo utilizado foi projetado para as condições de solo e clima dos EUA, para aplicação do mesmo em condições tropicais há necessidade de modificações de parâmetros, alteração e criação de bancos de dados para solos, manejos e comportamento de culturas e uso ocupação, além de considerar a utilização de abordagens alternativas para as equações embutidas dentro do modelo. A maior dificuldade para aplicar o SWAT seria a dificuldade de encontrar parâmetros regionais para realizar tais modificações.

Os banco de dados de solos (SOL.DAT), de culturas (CROP.DAT), de manejo (INPUT.MGT) e os de clima (WGN) devem ser alterados para possibilitar simulações mais reais e calibradas, uma vez que os dados "default" o modelo utiliza se mostram inadequados para as condições brasileiras. Outro desafio é buscar uma abordagem para modelar fenômenos que o modelo não é capaz de simular como o de queimadas o da contribuição de sedimentos através de carreadores nas plantações. Existem muitos indícios que estas estradas não pavimentadas sejam responsáveis pelo maior aporte de sedimentos na região. Outro ponto que poderia influenciar negativamente os resultados do modelo seriam bacias com classes de uso e ocupação muito fragmentadas, o modelo apresenta dificuldade em representá-las.

Ao contrário das plantações em que se situam, estas estradas de terra não apresentam práticas de conservação de solo como terraceamento em curvas de nível. Ao contrário destas, elas geralmente tem seu traçado a favor do declive e como agravante o solo compactado e descoberto devido ao tráfego de veículos pesados tornam este solo pouco permeável, favorecendo que o desprendimento e carreamento de sedimentos pelas enxurradas.

A qualidade dos dados de entrada e disponibilidade também é outro aspecto fundamental para a operação do modelo, visto que dados inconsistentes, dificultam ou mesmo 
impossibilitam a calibração do SWAT. Na área de estudo encontram-se relativamente bastante informação em comparação a outras bacias nacionais, aonde é difícil obeter quaisquer dados de vazão, ou mesmo cartas topográficas com baixa resolução. O cenário 1 (1977-1985) apresentou simulações com performance insatisfatória principalmente devido ao fato de que utilizou-se dados de vazão inconsistentes conforme exposto na seção 764.6.1. Na seção 6.1, podemos ver que o modelo apresentou a tendência geral de subestimar as vazões em relação aos dados observados, na verdade o modelo pode ter obtido dados mais confiáveis do que os dados observados visto aos fatos já expostos, portanto seria importante avaliar a consistência dos dados de vazão antes de utiliza-los para evitar aumentar as fontes de incertezas do modelo.

Há uma necessidade em âmbito nacional de expansão e modernização das estações de monitoramento, visto que as existentes se mostram insuficientes e com séries de dados insatisfatórias para obter resultados mais satisfatórios utilizando a ferramenta. Espera-se que com a resolução conjunta ANEEL/ANA este cenário seja revertido, porém é importante ressaltar novamente que ao utilizar as séries históricas do banco de dados da ANA, que o usuário avalie se os dados são inconsistentes.

Esta falta de dados limitou o modelo conceitual adotado, não havendo dados de aporte de sedimento disponíveis para a região de estudo, a saída encontrada foi de adotar um modelo simplificado aonde a erosão dos tributários, deposição e refluidificação de sedimentos dentro dos mesmos foi considerada como nula, utilizando apenas o reservatório para deposição deles, o que pode gerar resultados de assoreamento exagerados. Pode se considerar que os algoritmos utilizados para estimação destes processos do SWAT são bastante satisfatórios, no entanto a falta de dados para trabalha-los se mostrou uma grande barreira. 
Mesmo com as dificuldades encontradas o SWAT mostrou-se uma ferramenta bastante eficaz para avaliar a produção de sedimentos e aporte de sedimentos em bacias com barragens. Foi possível quantificar o aporte para ambas os cenários, a única barreira para melhores resultados são os fatores expostos nos parágrafos acima.

Embora estudos feitos para condições temperadas não indiquem grande melhoria e benefícios do emprego desta abordagem, mais estudos sobre a potencialidade para resultados utilizando o método de Green-Ampt devem ser realizados para as condições tropicais, visto que os eventos de chuva intensa são mais acentuadas nestas condições, podendo gerar resultados mais realistas do que os obtido utilizando o método de Curva Número. O vasto número de aplicações do SWAT em todo mundo evidenciam a robustez e flexibilidade do modelo para simular diversas condições e fenômenos em bacias hidrográficas. Portanto o SWAT apresentou potencial para ser aplicado como uma ferramenta muito poderosa para avaliação e estudos de recursos hídricos, incluindo o monitoramento do assoreamento em barragens.

É importante frisar também que mais estudos devem ser feitos no intuito de criação de um banco de dados nacionais para aplicação no Brasil. A falta de dados para construir este banco de dados é outro desafio, sendo necessário a instalação de mais pontos de monitoramento hidrossedimentológico e de qualidade, uma vez que a estrutura existente encontra-se em um estado precário, com muitas estações desativadas, produzindo dados inconsistentes e/ou muito fragmentados o que dificulta o processamento de dados. Outra simulação para o cenário 1 retirando os dados de vazões do Rio Itaqueri e do Córrego das Perdizes é recomentdado para poder avaliar o efeito que dados inconsistentes podem ter na performance do modelo. Seria também interessante realizar simulações comparando os dois 
métodos CN e Green-Ampt para a região de forma avaliar qual terá desempenho melhor para as condições tropicais 


\section{REFERÊNCIAS BIBLIOGRÁFICAS ${ }^{7}$}

ABBASPOUR,K.C. 2008. SWAT-CUP2: SWAT Calibration and Uncertainty Programs - A User Manual. Department of Systems Analysis, Integrated Assessment and Modelling (SIAM), Eawag, Swiss FederalInstitute of Aquatic Science and Technology, Duebendorf, Switzerland, 2008, 95pp.

ADRIOLO, M.V. SANTOS, I.;GILBERTONI, R.C.; CAMARGO, A.S.G. 2008. Calibração do modelo SWAT para a produção e transporte de sedimentos In: Simpósio Brasileiro sobre pequenas e médias centrais hidrelétricas, 6.,2008, Belo Horizonte. Anais...Rio de Janiero;CBDB, 2008.

ANEEL - ANA, Resolução Conjunta $\mathbf{n}^{0}$ 003. 2010.: Estabelecer as condições e os procedimentos a serem observados pelos concessionários e autorizados de geração de energia hidrelétrica para a instalação, operação e manutenção de estações hidrométricas visando ao monitoramento pluviométrico, linimétrico, fluviométrico, sedimentométrico e de qualidade da água associado a aproveitamentos hidrelétricos, e dar outras providências. Brasília, 10 de Agosto de 2010.

ANEEL. 2011a. Banco de Informação de Geração, Disponível em http://www.aneel.gov.br/aplicacoes/capacidadebrasil/capacidadebrasil.asp Acessado em 06/05/2011. 2011.

ANEEL. 2011b., Boletim da Energia, Número 447, Ano 9, Brasília - DF. Brasil. 2011.

ARNOLD, J. G.; SRINIVASAN, R.; MUTTIAH, R. S.; e WILLIAMS, J. R. 1998. Large Area Hydrologic Modeling and Assessment Part I: Model Development. Journal of the American Water Resources Association 34: 73-89. 1998

ASCE. 1993. ASCE - TASK COMMITTEE ON DEFINITION OF CRITERIA FOR EVALUATION OF WATERSHED MODELS OF THE WATERSHED MANAGEMENT, IRRIGATION, AND DRAINAGE DIVISION (ASCE), Criteria for evaluation of watershed models. J. Irrig. Drain. Eng., 1193, 1993

BALTOKOSKI, V. 2008. Modelo SWAT2005 aplicado às sub-bacias dos rios Conrado e Pinheiro - Pato Branco/PR. Dissertação de Mestrado. Cascavel: Universidade Estadual do Oeste do Paraná. 2008.

BALTOKOSKI, V.; T., FERREIRA, M. H.; MACHADO, RONALTON, E. DE OLIVEIRA, M. P.2010. Calibração de modelo para a simulação de vazão e de fósforo total nas sub-bacias dos Rios Conrado e Pinheiro - Pato Branco (PR). Rev. Bras. Ciênc. Solo.34, (1): 253-262. 2010

${ }^{7}$ De acordo com a International Organization for Standardization (ISO). 
BATES, B.C.; KUNDZEWICZ, Z.W; WU, S. e PALUTIKOF, J.P. 2008. Climate Change and Water. Technical Paper of the Intergovernmental Panel on Climate Change, IPCC Secretariat, Geneva, 210 pp. 2008

BEVEN, K. e BINLEY, A. 1992. The Future of Distributed Models - Model Calibration and Uncertainty Prediction. Hydrological Porcesses, 6(3):279-298. 1992

BLAINSKI, E.; SILVEIRA, F.A.; CONCEIÇÃO, G. 2008. Utilização do modelo hidrológico SWAT para estudos na microbacia hidorgráfica do rio Araranguá/SC. In: Taller International Red Riegos Cyted, 2008, Florianópolis. Anais... Florianópolis:CEER, 2008.

BRANCO, S.M.; ROCHA, A. A. 1977. Poluição, Proteção e Usos Múltiplos de Represas, Editora Edgard Blucher/CETESB, São Paulo, 1977.

CARVALHO, N. O. 1994. "Hidrossedimentologia Prática", CPRM - Companhia de Pesquisa em Recursos Minerais. Rio de Janeiro-RJ. 1994.

CARVALHO, N.O. et al. 2000. Guia de Avaliação de Assoreamento em Reservatórios. Brasilia:ANEEL - Agência Nacional de Energia Elétrica - Superintendência de Estudos e Informações Hidrológicas , 2000. 132p. 2000.

CHAO B. F.; WU Y. H. e LI, Y. S. 2008. Impact of Artificial Reservoir Water Impoundment on Global Sea Level. Science 320 (5873): 212-14. 2008.

CHEKOL, D.A. 2006. Modelling of Hydrology and Soil Erosion of Upper Awash River Basin. PhD Thesis, University of Bonn: 233pp. 2006.

CHEN, D; SHAMS, S.; CARMONA-MORENO, C; LEONE, A. 2010. Assessment of open source GIS software for water resources management in developing countries, Journal of Hydro-environment Research. 2010.

WALLING, D. E. e PROBST, J.-L. Wallingford, UK: International Association of Hydrological Sciences.

DENDY, F.E. 1968. Sedimentation in the nation's reservoirs. Journal of Soil and Water Conservation, v.23, Jul./Ago, p. 135-13, 1968.

DI LUZIO, SRINIVASAN, M.; R ARNOLD, J.G. e. NEITSCH, S.L. 2002. Soil and Water Assessment Tool. ArcView GIS Interface Manual: Version 2000. GSWRL Report 0203, BRC Report 02-07, Published by Texas Water Resources Institute TR-193, College Station, TX. 346p. 2002.

EMMERICH, W. \& MARCONDES, M.A.P. 1975. . Algumas Características do Manejo de Bacias Hidrográficas. São Paulo. (Boletim técnico IF), 1975.

ESTIGONI, M. V. \& MATOS, A. J. 2009. "Comparação de Diferentes Batimetrias do Reservatório da Usina Hidroelétrica do Lobo”, XVIII Simpósio Brasileiro de Recursos Hídricos, Campo Grande, MS. 2009. 
ESTIGONI, M.V.; KUWAJIMA,J.I; MIRANDA, R.B.; MAUAD, F.F. 2011. Análise Técnica da Legislação e Normas sobre Estudos Hidrossedimentológicos em Empreendimentos Hidrelétricos, XIV World Water Congress, Porto de Galinhas,PE. 2011.

FLANAGAN, D. C., e NEARING, M. A. 1995. USDA-Water Erosion Prediction Project hillslope and watershed model documentation. NSERL Report No. 10. West Lafayette, Ind. 1995.

GARBOSSA, L.H.P.; et al. 2011. The use and results of the Soil and Water Assessment Tool in Brazil: A review from 1999 until 2010. 2011 Internationla SWAT Conference. Toledo, Espanha .2011

GASSMAN, P.W. 2011. The Worldwide Use of the SWAT Model: Technological Drivers, Networking Impacts, Simulation Trends, and Potential Future Constraints.2011 International SWAt Conference, Toledo, Espanha 2011

GASSMAN, P.W.; REYES, M.; GREEN, C.H. e ARNOLD, J.G. 2007.The Soil and Water Assessment Tool: Historical development, applications, and future directions. Transactions of the American Society of Agricultural and Biological Engineers (Invited Paper Series) 50(4): 1211-1250. 2007.

GRAYSON, R.B.; MOORE, I.D.; E MCMAHON, T.A. 1992. "Physically-based hydrologic modeling: Is the concept realistic?”, Water Resoureces. Res, 26,2659-2666. 1992.

HIEPE, C. e DIEKKRÜGER, B. 2007. Modelling soil erosion in a sub- humid tropicalenvironment at the regional scale considering land use and climate change. Book of abstracts, 4th International SWAT conference, UNESCO-IHE Institute for Water Education, Delft, The Netherlands. July 4-6, 2007

HIEPE,C. 2008. Soil degradation by water erosion in a sub-humid West-African catchment: a modeling approach considering land use and climate change in Benin. PhD diss. Bonn, Germany.: Universität Bonn, Mathematisch-Naturwissenschaftliche Fakultät. 2008.

HU C.; LIU C.; ZHOU Z.; e JAYAKUMAR, R. 2008. Changes in Water and Sediment Loads of Rivers in China. Working Paper prepared as a contribution to UNESCO's World Water Development Report 3. International Research and Training Center on Erosion and Sedimentation, Beijing. 2008.

ICOLD (International Commission of Large Dams). 2003. World Register of Dams 2003. Paris: International Commission of Large Dams. 2003.

ICOLD (International Commission on Large Dams). 1989. Sedimentation control of reservoirs/Maîtrise de l'alluvionnement des retenues. Committee on Sedimentation of Reservoirs. Paris. 1989.

IPCC (Intergovernmental Panel on Climate Change). 2007. Climate Change 2007: Impacts, Adaptation and Vulnerability. Contribution of Working Group II to the Fourth Assessment Report of the Intergovernmental Panel on Climate Change, ed. 2007. 
JAKUBAUSKAS \& de NOYELLES. 2007. Methods for Assessment of Sedimentation in Reservoirs, palestra apresentada na University of Kansas, Lawrence, 2007.

JIONGXIN, X. 2003. Sediment flux to the sea as influenced by changing human activities and precipitation: example of the Yellow River, Environ. Manage, China. 31, 328-341.2003.

KATO, M. S. A; LATO, O. R.; DENICH, M. E VVLEK, P. L. G. 1999. Fire-free alternatives to slash-and-burn for shifting cultivation in the eastern Amazon Region: the role of fertilizers. Field Crops Research, (62); 225-237. Amsterdan, EIsevier Science. 1999.

KING, K. W.; ARNOLD, J. G. e BINGER, R. L. 1999. "Comparison of Green-Ampt and curve number methods on Goodwin Creek Watershed using SWAT." Transactions of the American Society of Agricultural Engineers (ASAE) 42(4): 919-925. 1999.

KUWAJIMA, J.I.; CRESTANA, S.; ZUQUETTE, L.V.; MAUAD, F.F. 2011b. Challenges and Difficulties in Sediment Modeling Applied to Sedimentation Study of the Lobo Reservoir in Brazil. 2011International SWAT Conference, Toledo, Espanha. 2011

KUWAJIMA, J.I; ARANTES, D.M.;ESTIGONI, M.V.;MAUAD, F.F. 2011a. Proposta da aplicação do modelo SWAT como ferramenta complementar de gerenciamento de recursos hídricos e estimativa de assoreamento em reservatórios. XIV World Water Congress, Porto de galinhas, PE. 2011

LEEMANS, R. \&. KLEIDON, A. 2002. Regional and global assessment of the dimensions of desertification. Global Desertification: Do Humans Cause Deserts? J.F. Reynold and D.S. Smith, Eds., Dahlem University Press, Berlin, 215-232. 2002

LEGATES, D. R. e MCCABE, G. J. 1999. Evaluating the use of goodness-of-fit measures in hydrologic and hydroclimatic model validation. Water Resources Research, 35, 233-241. 1999.

LELIS, T.A. e CALIJURI, M.L. 2010. Modelagem hidrossedimentológica de bacia hidrográfica na região sudeste doBrasil, utilizando SWAT. Ambi-água, 5 (2): 158-174. 2010.

LEMPÉRIÈRE, F. 2006. The Role of Dams in the XXI Century: Achieving a Sustainable Development Target. International Journal on Hydropower \& Dams 13 (3): 99-108. 64. 2006.

LIMA, J. E. F. W.; SANTOS, P. M. C.; CARVALHO, N. O.; SILVA, E. M. 2003. Fluxo De Sedimentos Em Suspensão Na Bacia Araguaia-Tocantins, XV Simpósio Brasileiro de Recursos Hídricos, Curitiba - PR., 2003

LINIGER, H. \& WEINGARTNER, R. 1998. Mountains and freshwater supply. Unasylva, 195(49), 39-46. 1998

LINO, J .F .L. 2009. Análise da dinâmica hidrossediemntológica da bacia hidorgráfica do Rio Preto (SC) com o modelo SWAT. Dissertação de mestrado. Florianópolis: Universidade Federal de Santa Catarina. 2009 
LOPES, N. H. Y. 2008. Análise da produção de água e sedimentos em microbacias experimentais com o modelo SWAT. MS thesis. Florianópolis: Universidade Federal de Santa Catarina - Departamento de Engenharia Sanitária e Ambiental. 2008

MacCAULEY, D.S. \& HUFSCHMIDT, M.M. 1995. Gerenciamento de Recursos Hídricos: Planejamento e Implantação. HASHIMOTO, M. (ed.). Diretrizes para o gerenciamento de lagos. Japão. v.2, 39 p. 1995

MACHADO, R.E. 2002. Simulação de escoamento e de procução de sedimento em uma microbacia hidrográfica utilizando técnicas de modelagem e geoprocessamento Tese (doutorado) - Escola Superior de Agricultura Luiz de quieroz, Piracicaba. 2002.

MME \& EPE. 2010. Plano Decenal de Expansão de Energia 2019 / Ministério de Minas e Energia. Empresa de Pesquisa Energética. Brasília: MME/EPE, Brasília. 2010

MORO, M. 2005. A utilização da interface SWAT-GIS no estudo da produção de sedimentos e do volume de escoamento superficial com simulação de cenáriso alternativos. Dissertação de Mestrado. Piracicaba: Universidade de São Paulo - Escola Superior de Agricultura Luiz de Queiroz. 2005

MORRIS \& FAN. 1997. Reservoir Sedimentation Handbook: Design and Management of Dams, Reservoirs, and Watersheds for Sustainable Use. Editora McGraw-Hill, New York. 1997.

NASH, J. E. \& SUTCLIFFE, J. V. 1970. River flow forecasting through conceptual models. Journal of Hydrology, 10, 282-290. 1970

NEITSCH, S.L.; ARNOLD, J.G.; KINIRY, J.R. e WILLIAMS, J.R. 2005. Soil and Water Assessment Tool Theoretical Documentation Version 2005. Grassland, Soil and Water Research Laboratory; Agricultural Research Service; USA. 2005.

NEVES, F. F. 2005. Análise prospectiva das áreas de risco à erosão na microbacia hidrográfica do Rio Bonito (Descalvado-SP), potencialmente poluidoras por dejetos de granjas. Dissertação de mestrado. São Carlos: Universidade de São Paulo- Escola de Engenharia de São Paulo. 2005.

OLIVEIRA, M.Q.C. 1999. Impacto de mudanças no uso do solo nas características hidrossedimentológicas da bacia hidrográfica do rio Joanes e sua repercussão na zona costeira. Dissertação de Mestrado- Salvador: Universidade Federal da Bahia. 1999.

OLIVEIRA,J. B. \& PRADO, H. 1984. Levantamento pedológico semi-detalhado do Estado de São Paulo: quadrícula de São Paulo.1984

PATERNIANI, E. 2001. Agricultura sustentável nos trópicos. Estud. Av., 15 (43), pp. 303 326. 2001.

PATERNIANI, E. 1990. Maize breeding in the tropics. Critical Reviews in Plant Sciences. 9: 125-154. 1990. 
Plano Estadual de Recursos Hídricos - Estado de São Paulo 2004/2007. 2004: São Paulo: Consórcio JMR-ENGECORPS, 2004.

RANIERI, S.B.L.; Van LIER, J., Q.; SPAROVEK, G.; FLANAGAN, D.C. 2002. Erosion database interface (EDI): a computer program for georeferenced application of erosion prediction models. Computers \& Geosciences 28 (1), 661-668. 2002.

RENARD, K. G.; FOSTER, G. R.; WEESIES, G. A.; MCCOOL, D. K e YODER, D. C. 1997. Predicting Soil Erosion by Water: A Guide to Conservation Planning with the Revised Universal Soil Loss Equation (RUSLE). Agriculture Handbook No. 703.Washington D.C.: USDA. 1997.

SANTOS, I. et al. 2001. Hidrometria Aplicada. Curitiba: LATEC,. 372 p. 2001

SARTORI, A. 2004. Avaliação da classificação hidrológica do solo para determinação do excesso de chuva do método do serviçp de conservação dos solo dos Estados Unidos. MS thesis. Campinas: Universidade Estadual de Campinas - Faculdade de Engenharia Civil, Arquitetura e Urbanismo. 2004.

SARTORI,A.; GENOVEZ, A.M.; LOMBARDI NETO, F. 2005b Classificação Hidrológica de solos Brasileiros Para a Estimetiva da Chuva Excedente com o Método Serviço de Conservação de Solos dos Estados Unidos. Parte2: Aplicação. Revista Brasileira de Recursos Hídricos, v.10 n4, p. 19-29, Out/Dez, 2005

SARTORI, A.; .LOMBARDI NETO, F.; GENOVEZ, A.M.F. 2005a. Classificação Hidrológica de solos Brasileiros Para a Estimetiva da Chuva Excedente com o Método Serviço de Conservação de Solos dos Estados Unidos. Parte1: Classificação. Revista Brasileira de Recursos Hídricos, v.10 nº4, p. 5-18, Out/Dez, 2005.

SIGRH. 2000. SIRGH - Relatório de Situação dos Recursos Hídricos do Estado de São Paulo, 06/2000 - Disponível em: http://www.sigrh.sp.gov.br Consultado em 09/2009. 2000.

SIMONS, D.B. \& SENTURK, F. 1992. Sediment transport technology: Water and sediment dynamics, Water Resources Publications, 897p., Denver, Colorado 1992.

SMITH, D. D. 1941. Interpretation of soil conservation data for field use. Agric. Eng. 22(5): 173-175. 1941.

SWIERZOWSKI \& GODLEWSKA. 2001. Efects of Hydropower Plant Activities on Fish Population, Abundande and Distribuction, Archives of Polish Fisheries, Vol. 9, Fasc. 2, 2001.

SYVISTKI, J.P.M.; VOROSMARTY, C.J; KETTNER, A.J. e GREEN, P. 2005. Impact of humans on the flux of terrestrial sediment to the global coastal ocean. Science, 308, 376380. 2005

TUNDISI, J. G. 2003. Água no Século XXI: Enfrentando a Escassez, São Carlos: RiMa. IIE, 2003.

TUNDISI, J.G. et al. 1986. The Lobo (Broa) ecosystem. Ciência Interamericana, Washington, v.25, n.114, p.18-31. 1986. 
URI, N. D., \& LEWIS, J. A. 1999. Agriculture and the Dynamics of Soil Erosion in the United States. Journal of Sustainable Agriculture 14 (2-3): 63-82. 1999.

Van GRIENSVEN, A., MEIXNER,T. 2006. Methods to Quantify and Indentify the Sources of Uncertainty for river Basins Water Quality Models. Water resources. 39(12): Art. No 1348 DEC 16. 2006.

VÖGTLE, T. \& BÄHR, H.P. 1999. Gis for Environmental Monitoring. Stuttgart: Scheizerbart,. 360p. 1999.

VÖRÖSMARTY, C. J., MEYBECK, M.; FEKETE, B. e SHARMA, K. 1997. The Potential Impact of Neo-Cartorization on Sediment Transport by the Global Network of Rivers. In Proceedings of the Fifth IAHS Scientific Assembly at Rabat, Morocco, April-May 1997, eds. 1997.

WCD (World Commission of Dams). 2000. Dams and Development: A New Framework for Decision-Making. London: Earthscan. 2000.

WILLMOTT, C.J. 1981. On the validation of models. Physical Geography 2, 184-194. 1981

WILLMOTT, C.J. 1984. On the evaluation of model performance in physical geography. In Spatial Statistics and Models, G.L. Gaile, and C.J. Willmott (Editors). D. Reidel, Dordrecht, 443-460. 1984.

WISCHMEIER, W. H. \& SMITH, D. D. 1961. A universal equation for predicting rainfall-erosion losses: An aid to conservation planning in humid regions. Special Report No. 22-66. Washington D.C.: USDA-ARS. 1961.

WISCHMEIER, W. H. \& SMITH, D. D. 1965. Predicting Rainfall Erosion Losses from Cropland East of the Rocky Mountains: Guide for Selection of Practices for Soil and Water Conservation. Agriculture Handbook No. 282. Washington D.C.: USDA. 1965.

WISCHMEIER,W.H. \& SMITH, D.D. 1978. Predicting rainfall erosion losses - a guide to conservation planning. USDA: Agricultural Handbook No. 537, Wasington, 537. 1978.

WORLD WATER ASSESSMENT PROGRAMME. 2009. The United Nations World Water Development Report 3: Water in a Changing World. Paris: UNESCO Publishing, and London:Earthscan. 2009.

XU, C. 1999. Operational testing of a water balance model for predicting climate change impacts, Jou Agricultural and Forest Meteorology, 98-99, 295-304. 1999.

YANG, C. T. et al 2006. Reclamation. Managing Water in the West: Erosion and Sedimentation Manual, U. S. Department of the Interior, Bureau of Reclamation, Denver Colorado, 2006.

ZINGG, A. W. 1940. Degree and length of land slope as it affects soil loss in runoff. Agric. Eng. 21(2): 59-64. 1940. 